\title{
WHAT A DIFFERENCE A DEFINITION MAKES: MISMATCHES IN PARTNER MARKETS ACROSS THREE DECADES IN DENMARK
}

\author{
Emil A. L. Simonsen, ROCKWOOL Foundation \\ Peter Fallesen*, Stockholm University, ROCKWOOL Foundation, European University Institute
}

\begin{abstract}
In this study, we apply a framework that allows a flexible approach to understanding and evaluating mismatch in partner markets and studies three decades of data on the complete Danish population aged 25-45. We evaluate the importance of including people in cohabiting unions as being "off the market" as well as allowing people searching for a partner to obtain one from existing relationships. In doing so, we document the key role of considering both cohabitation and market reentry, as well as document an increasingly mismatched partner market for women driven primarily by changes in demand, whereas men experience declining supply due to an increasingly geographically polarized market, while their demand also changes. In addition, we show that the probability of obtaining a partner from an existing relationship increases the more mismatched a partner market people face. Our findings are relevant for understanding current processes of fertility decline and rise in single living.
\end{abstract}

Keywords: administrative data; cohabitation; family formation; marriage market; partner market

*Corresponding author: peter.fallesen@sofi.su.se. The authors thank Torben Tranæs, Adam Altmejd, Anni Erlandsson, Jan van Bavel, Anne Sofie Tegner Anker, and colleagues at the Swedish Institute for Social Research and the ROCKWOOL Foundation for helpful comments. Peter Fallesen carried out part of the work while being a visiting fellow at Department of Political and Social Science, European University Institute. This work was funded by the ROCKWOOL Foundation (grant no. 1226) (EALS) and Riksbankens Jubileumsfond (grant no. $\mathrm{P} 20-0270)$ (PF). The research was carried out independently of the funders. 


\section{INTRODUCTION}

Across the Americas, Europe, and parts of Asia, marriage rates are declining and singlehood increasing (e.g., Eurostat 2018; Manning 2020; Raymo, Uchikoshi, and Yoda 2020). At the same time, cohabitation has become increasingly important as either a middle-stage or an alternative to marriage (Farmer and Horowitz 2015; Grow and Van Bavel 2015; Heuveline and Timberlake 2004; Manning 2020). Taken together, these developments raise important and interrelated questions about the changing nature of union formation, and the what underlies the increase in singlehood—especially given that more than 4 in 5 among singles (in Denmark at least) want a partner (Frisch et al. 2019).

In this study, we use administrative data for the entire Danish population covering close to three decades to outline, identify, and expand the definition of a partner market and mismatches on these. We refer to partner markets analogously to labor markets and as consisting of an assignment problem in which a person offers the bundle of traits that make up themselves to another person, whose bundle of traits matches the initial offeror's own wants, and any agreement hinges on an all-or-nothing acceptance of the full bundles (Mortensen 1998). A successful match leads to the two people forming a partnership. We define a partner market's degree of mismatch as the difference in the distribution of the bundle of traits being offered (supply) measured against the distribution of bundles being sought (demand).

Our article develops a formal framework that allows us a flexible approach to understanding and evaluating mismatch in partner markets. We extend previous work on US data by Lichter et al. $(2020 ; 2021)$ to study mismatch on partner markets in a country considered further along in the process of deinstitutionalization of marriage (Cherlin 2020) across three decades. We evaluate the importance of including people in cohabiting unions as being "off the market" as well as allowing people searching for a partner to obtain one from existing relationships. Last, 
we document the degree of mismatch in the partner market across different market definitions, locate the specific characteristics of people who experience the most mismatched relationship market, decompose the underlying market dynamics driving the development in mismatch, and consider the individual consequences of facing a market with poor possibilities of finding a match among local singles.

As reported in Figure 1(a), Denmark has seen increases in both singlehood and cohabitation among the 25-45-year-old in recent decades, driven initially by increased relationship turnover but in the later part of the study period by declining rates of new marriages and cohabitations [Figure 1(b)]. We find that jointly approaching cohabitation and marriage as similar statuses in terms of being "off the market" provides a better description of people's actual opportunities and behavior on the partner market across our study period and that models of union formation should account for people findings partners in already existing relationships, to better capture observed processes. We show that the degree of mismatch in the relationship market in Denmark has increased for women over the period studied, and is most pronounced in terms of employment status, educational level, and income. Failing to include cohabitating individuals as being off the market leads to an overestimation of how mismatched the relationship market is. Last, we decompose the development in mismatch across changes to supply, demand, and characteristics of those seeking a partner, and show that changes to demand-in particular, changes in tastes among women seeking a partner-drive most of the developments in mismatch.

[Figure 1 about here].

Our study offers four contributions to family sociology and family demography. First, we document a geographically uniform increase in mismatch for women in Denmark, and a geographic polarization for men and show that cohabitation and not marriage best captures 
partner market. Second, we demonstrate that those who experience the most mismatched markets also have the highest probability of finding a partner from an existing relationship. Third, we show that changes to women's mismatch are primarily driven by changes in taste, and changes in men's mismatch is driven by both changes in changes in taste and the characteristics of women on the market. Fourth, we relate our findings on relationship market mismatches to relevant current processes including the ongoing fertility decline and the rise in single living.

\section{BACKGROUND}

Rise in singlehood among the younger may have two distinct driving forces. Increased individual affluence and change in preferences for lifestyle may lead more people to actively choose to go completely "off the market (Lahad 2017 p. 124)" or remain single for a longer part of early adulthood to pursue other goals (Klinenberg 2012; Lahad 2017). Contrastingly, individuals' wants for partners may have remained unchanged, but the characteristics of available partners may have changed in ways that make it harder to locate an acceptable partner match. Job polarization has lowered earnings capacity among low-skilled men with direct implication for their value as partners (e.g., Autor, Dorn, and Hanson 2019) and the gender-gap reversal in education has implications for assortative mating (e.g., Van Bavel, Schwartz, and Esteve 2018). The relationship market may therefore have increasingly become mismatched (Lichter et al. 2020), with an increasing share of people looking for a partner having difficulty finding someone who match what they are looking for.

Classical theoretical models and seminal empirical studies of union formation in economics and sociology have often considered marriage as the central market institution governing union formation (e.g., Becker 1973; Kalmijn 1994; Mare 1991; Mortensen 1988; Oppenheimer 1988; Smith 2006), while describing cohabitation as a category distinct from the union type defined by marriage (Bumpass, Sweet, and Cherlin 1991; Lundberg, Pollak, and Stearns 2016; Schwartz 
2013). At the same time, cohabitation is becoming increasingly common as a modal social phenomenon (Farmer and Horowitz 2015; Gassen and Perelli-Harris 2015; Manning 2020), and the Nordic countries that often are considered the vanguard of family demographic development have increasingly equalized informal and formal rights between marriage and cohabitation (Cherlin 2004, 2020; Perelli-Harris and Gassen 2012). Thus, from the vantage point of a single person searching for a partner, people in cohabiting unions may be equally unavailable as a potential partner as someone in a marriage, in so far that marriage and cohabitation are becoming complementary states. This does not mean that people necessarily are completely unavailable if in an existing relationship. People may move from one union directly into a new one without being available on the market first. In total, these developments raise the question of how to theoretically outline, and empirically identify, the most relevant arena for the formation of union — that is, what defines the partner market?

\section{THEORETICAL OUTLINE}

\subsection{Finding a Partner, Finding a Market}

Partner markets present a coordination problem. A person (A) with a specific set of characteristics searchers for a partner that: i) has a set of specific characteristics $V$; and ii) themselves searches for a partner with the specific characteristics present in person A. People may search for someone who has substitutional (Becker 1973) or similar (Oppenheimer 1988) traits, depending on preferences. The distribution of available partners relative to what type of partner a person looks for (i.e., part of their search friction) affects how long people search and what they settle for on the relationship market. We assume that with the ideal-typical perfect match a person will at least be as happy in a relationship as being single, which is the same as assuming that the following inequality always holds when people find their perfect match:

$$
\mathrm{U}(\text { Single })_{\mathrm{it}} \leq \mathrm{U}(\text { Relationship })_{\mathrm{it}}
$$


but that, depending on difference in utility of being single vis-a-vis being in a relationship, people are willing to enter a relationship with a less-than-perfect match insofar the match between what they want and what they can get are not too large:

$$
\mathrm{U}(\text { Single })_{\text {it }} \leq \mathrm{U}(\text { Relationship })_{\mathrm{it}} * \mathrm{q}_{\mathrm{i}, \mathrm{jt}}
$$

where $q_{i, j t}$ is the match quality expressed as degree of overlap between what people want and what a potential match $j$ offers and bounded between 0 and $1 .{ }^{1}$

\subsection{Defining mismatch}

The subsection above laid out the search dynamic from a person's point of view, but this can be extended to cover the situation where a group of singles are searching for specific distribution of partners (i.e., a demand, $Q_{t}$ ) and compared against the distribution of available partners (i.e., the supply, $\left.\widetilde{Q_{t}}\right)$. The sets $Q_{t}, \widetilde{Q_{t}}$ encompass all relevant observable and unobservable partner characteristics. We make the mild assumption that people form demands based on a realistic translation of their preferences to actual opportunities. That is, while someone may prefer to marry a billionaire, their choice set is likely to be limited, so they are willing to set the lower bar for demand at someone having a steady income (acceptability threshold), although they will prefer finding someone located higher in the income distribution. Miller and Todd (1998) have referred to this mate search strategy as satisficing.

$Q_{t}$ and $\widetilde{Q_{t}}$ are empirical, but unobservable, distributions, and their degree of overlap depends solely on difference between what people demand in a partner and what is available. $Q_{t}$ and $\widetilde{Q_{t}}$ originates from the same probability density function of, respectively, preferred $\left(V_{t}\right)$ and

\footnotetext{
${ }^{1}$ This allows us to include people who at any giving time point $t$ is single but also off the market, because they can within the model be recast as having $U(\text { Single })_{i t}=U(\text { Relationship })_{i t}$ with no perfect match available on the market, so $q_{i, j t}<1$ for all $j$.
} 
available $\left(\widetilde{V_{t}}\right)$ characteristics, so $Q_{t}=\widetilde{Q_{t}}=\phi\left[g\left(V_{t}\right)\right] \mid V_{t}=\widetilde{V_{t}}$ if the partner market is in equilibrium. We can express the match quality at a given point in time as the degree of overlap between the two distributions across the union of $V_{t}$ and $\widetilde{V}_{t}$ :

$$
q_{t}=\int \sqrt{Q_{t}(v) \widetilde{Q_{t}}(v)} d v
$$

and the degree of mismatch as $1-q_{t}$.

$Q_{t}$ and $\widetilde{Q_{t}}$ are unobserved because they rely on the complete set of relevant characteristics of what people want in a partner $\left(V_{t}\right)$ and what is available $\left(\widetilde{V}_{t}\right)$, which in their complete form are unobservable. Nevertheless, at least a subset of the dimensions of $\widetilde{V}_{t}$ consists of characteristics for single individuals that is observable through traditional data sources. This includes characteristics often used in the study of assortative mating, intermarriage, and marriage market mismatches, such as race/ethnicity, age, education, employment status, income, relationship history, parent status, and more (e.g., Lichter et al. 2020; Schwartz 2013). Thus, we can ascertain mismatch across the individual and joint distributions of observable characteristics in so far as we can adequately define who are available on the partner market.

Allowing the degree of mismatch to change over time captures two simultaneous processessupply might change either through cohort replacement or through exogenous shocks to characteristics (e.g., the impact of a recession on earnings capacity) or because of changes in tastes either through evolution of cultural values surrounding partnership preferences (cf. EspingAndersen and Billari 2015) and people updating their preferences based on experiences from previous unsuccessful partner search (Raymo et al. 2015). Further, it follows from Eq. 2 that people may settle for less than a perfect match. Comparing how the overall mismatch develops relative to how mismatched the market is on individual characteristics can add a second dimension to assessing whether a market is getting tighter or looser. 


\subsection{Delimiting the partner market}

As cohabiting unions become more common and closer aligned to married unions (Gassen and Perelli-Harris 2015; Heuveline and Timberlake 2004; Manning 2020; Perelli-Harris and Gassen 2012), this will increasingly mean that equalizing cohabiting and single people misidentifies the group of actual unattached individuals (see also Van Bavel 2021). Further, people searching for a partner may look beyond the relationship market of available singles. Building upon additional insight from the job search literature, this can be conceptualized similar to what has been termed raiding behavior in hiring (Tranæs 2001). Analogous, evolutionary psychology has used the term mate poaching (e.g., Davies and Shackelford 2017). Under some conditions, people searching for a partner may prefer to find an already partnered individual from another relationship instead of partnering with a single person. An already partnered individual is assumed to be positively selected, because they have already demonstrated that they are partner material (cf. Tranæs 2001). Thus, finding a partner among already partnered people may occur when the market of unpartnered people is mismatched ( $q_{t}$ is small) or because searching for a partner is time consuming, with the classic empirical example being finding an already partnered partner in the workplace (e.g., Kalmijn and Flap 2001; Uggla and Andersson 2018). If a substantial number of new relationships are formed based on 'raiding' and the tendency increases with increases in mismatch, then failing to account for this will lead to misrepresenting both the scope and behavior in the partner market (Van Bavel 2021). Further, this insight also allows us to validate our empirical approach - if we capture a meaningful measure of mismatch, then the lower the level of match, the higher the probability of an individual instead partnering with someone already in a relationship.

In the analysis, we use three definitions of partner markets (married/unmarried, in relationship/not in relationship, and in relationship/not in relationship allowing for raiding 
behavior by singles). The nature of our data forces us to only study opposite-sex couples in the analyses, but the above framework can be extended to beyond studying opposite-sex coupling. The above section has established a set of parameters for delimiting who are available on the market, yet that still leaves us with only half of the necessary information to establish the degree of mismatch - we also need to establish what people want.

\subsection{Identifying demand}

Single peoples' demand for a partner $\left(V_{t}\right)$ are fundamentally unobservable from our perspective, given the data we possess. Instead, we follow the approach by Lichter et al. (2020), who rightly identifies this conceptually as a missing data problem, and suggests using imputations to solve it based of the attributes of partners among recently coupled individuals with similar characteristics to those who are presently searching for a partner. Essentially, this is an extension of the assumptions underlying theories on homophily and assortative mating: single and recently coupled likes like alike. That is, we can proxy single people's demand for a partner at a given point in time $V_{t}$, with the revealed preferences for a partner among individuals with same characteristics who recently have found partners with characteristics $V_{t-\epsilon}^{*}$, where $\epsilon$ is small. This also allows us to account for supply-driven and taste-based structural changes to partner opportunities over time, as suggested by, for example, Oppenheimer (1988) and EspingAndersen and Billari (2015). Thereby, we can compare observable aspects of $\phi\left(V_{t-\epsilon}^{*}\right)$ to $\phi\left(\widetilde{V_{t}}\right)$ to examine mismatch on the relationship markets across the joint and marginal distributions of the observable aspects of $V_{t-\epsilon}^{*}$ and $\widetilde{V}_{t}$, thereby obtaining an empirical measure for $q_{t}$.

\section{DATA}

The data used for this study consists of Danish administrative data provided by Statistics Denmark. The data allows researchers to link detailed information for every individual in 
Denmark, using national identification numbers assigned at time of birth or immigration. ${ }^{2} \mathrm{We}$ construct four separate samples that all covers 1986-2018: two used to generate $V_{t-\epsilon}^{*}$ assuming first a market where the deciding dichotomy is married vs. unmarried, and second a market where it is cohabiting/married vs. single. The first sample consists of all women aged $25-45$ who married a male spouse within the previous five years (our set value for $\epsilon$ ), including information on their spouses. The second sample consists of both marriages and cohabitations, but only include those who cohabit for at least a year to avoid high volatility in cohabitation turnover and misconstruing flat mates as being in a relationship. We follow Statistics Denmark's definition of a cohabiting couple as two individuals, who share a dwelling, and either a) are unmarried but has a joint child; or b) are of opposite sex, within 15 years of age of each other, and not directly related. ${ }^{3}$ Our third sample consists for each year 1986-2018 of all unmarried women and men aged 25-45. The final sample consists for each year 1986-2018 of all unmarried women and men aged 25-45 who also are not cohabiting. ${ }^{4}$

For each sample, we use demographic information from the population registries for both women and men. This includes age, address at the apartment level, immigrant status (nonmigrant, first generation migrant from EU+-countries ${ }^{5}$, or first-generation migrant from other countries), whether they previously divorced, whether they had at least one child with a different partner prior to entering the relationship (in the case of singles whether they had at least one

${ }^{2}$ All code necessary to construct the samples and carry out the analysis is available in Online Appendix X.

${ }^{3}$ Note that this definition allows some to be married to one person but cohabiting with another. This situation may arise if, for example, a married couple is separated awaiting divorce (Fallesen 2021; Rosenbeck 2017). In case of a new cohabitation that lasts for at least twelve months, we consider those who begin a cohabitation while married to someone else as being divorced.

${ }^{4}$ We remove all individuals we can identify as legally married and for whom the spousal information is missing, since these are likely to be married individuals living in Denmark with a spouse living abroad.

${ }^{5}$ EU+ countries include the EU27, Norway, Switzerland, Iceland, the UK, Andorra, Monaco, San Marino, and the Vatican State. 
child). We linked each sample to information about the highest completed level of education. We classified the highest completed level of education into three categories based on the International Standard Classification of Education (ISCED) classification: low education for those without education above lower secondary (ISCED 0-2), medium education for those with education up to post-secondary non-tertiary education (ISCED 3-4), and high education including all short- and long-cycle tertiary degrees (ISCED 5-8). Individuals with unknown highest completed level of education were grouped as the low education category.

Further, we obtained annual information about labor market status as of end of year 19812018. We classified everyone as either being employed, unemployed, or outside the labor force. Students were classified as employed. Finally, we obtained information about gross income for 1981-2018. ${ }^{6}$ That is, our income measure captures total income before taxes and thus reflects an individual's complete income capacity. This was deflated to 2019 prices, using the consumer price index (CPI), and rescaled to thousand Euros. Missing or negative incomes were set to zero, and a separate indicator was created for if this was the case. Finally, we top-coded yearly incomes at 100.000 Euros. We present descriptive statistics for all samples in the "Results" section below.

\section{ANALYTICAL STRATEGY}

To obtain a measure of single people's assumed partner demand, we employ a similar approach as Lichter et al. (2020) illustrated in Figure 2. Essentially, we treat the problem of unobserved demand as a missing data problem, where information on people's preferred partner is absent

\footnotetext{
${ }^{6}$ Our income measure contains a break in the years 1986/1987. From 1987 onwards, interest payments from one's own firm and refunded permanent unemployed insurance are deducted, and green checks and repaid payments from early retirement pension schemes are added. Given the age-bracket of our sample, this is only of very marginal concern.
} 
from the dataset, and we instead impute using the partners of people with similar characteristics (synthetic partners). For each year in the period 1986-2018, we construct synthetic spouses (partners) for unmarried (single) people, by matching the unmarried (single) people based on observable characteristics, to same sex individuals that have married (formed a union) within the previous 5 years. Due to our definition of cohabitation as discussed above, we are at presently limited to only consider opposite-sex relationships. The observable characteristics we use are age, education, income, immigrant status, labor market status, an indicator for whether they had at least one child with a different partner prior to entering the relationship (in the case of singles whether they had at least one child), and an indicator for being divorced. We use these variables to capture socioeconomic status, ethnicity, life-cycle developments, preferences for assortative mating and low-search friction partner choice, and whether partnership also comes with a stepparent role.

[Figure 2 about here]

We use coarsened exact matching (CEM) as matching method. For each successfully matched unmarried (single) person this yields a set of matched people that have married (formed a union) in the previous 5 years. Based on these matches, the synthetic spouses (partners) are imputed with the characteristics from the spouse (partner) of an identical-on-observables married (cohabiting or married) person. The imputation is carried out using a hot-deck approach, which involves randomly drawing spouses (partners) with equal probabilities from the set of matches. As a robustness check, and analogously to Lichter et al. (2020), we repeat the exercise where instead of the hot-deck method, we use the mean-imputation method. However, the hot deck approach has several advantages as we discuss below, which is why it is our primary method used. Further, mean-imputation may lead to biased estimates (Van Buuren 2018). 
Having constructed the synthetic spouses (partners), we proceed to a second round of matching, where we match the synthetic spouses (partners) one-to-one to unmarried (single) individuals, with CEM using the same set of observable characteristics, but restricting peoples search radius to only be within their own geographical region (defined at the nomenclature of geographical units for statistics [NUTS] level, 2 which also describes Danish administrative regions/commuting zones), because partner search generally is found to be geographically delimited (e.g., Nielsen and Svarer 2009). Because women on average partner with men that are older than themselves (and vice versa), we limit women's age range for a prospective partner to 25-45 years of age, and men's to 20-40 years of age, informed by the observed age distributions of our synthetic spouses and partners (Figure A1 in appendix). From this second matching, we obtain a set of successful matches, as well as two sets of respectively unsuccessfully matched synthetic spouses (partners) and unmarried (single) people. From these, we can estimate the share with a successful match $\left(\widehat{q_{t}}\right)$. Further, we can also compare distributions of individuals characteristics for the synthetic spouses (partners) and the available unmarried (single) people. This allows us to describe the demand and supply on the marriage (partner) market, as well as identify which characteristics on the market that have certain demand or supply shortages, and how this differs across time and market definitions (section 6.2). Finally, to assess which men and women that are more or less likely to have a match, we can regress the indicator for whether they are successfully matched or not on their own characteristics (section 6.5).

We further estimate an approach where we allow single people to find partners from existing relationships to capture those who find partners who are already in a relationship. We incorporate this feature into the model by first constructing an indicator for whether each married and cohabiting person in the previous 5 years was single and subsequently found their partner 
from another relationship. We then use this to predict the probability of doing so for all those that have found a partner in the previous 5 years. This yields a set of predicted probabilities of raiding. We assign the predicted probability of raiding from a marriage or cohabiting relationship to each single person. After matching synthetic partners to actual available singles on the market, we then allow every observation to have carried out a raid with their individual predicted probability, which means that they obtain a match even if a match is not present among available singles on the partner market.

\subsection{Assumptions}

The approach rests on three assumptions: i) synthetic spouses (partners) reflect actual demand; ii) no search frictions or barriers beyond those imposed by forcing search within same region; iii) no uncertainty about observable characteristics of matches. Assumptions ii) and iii) most likely do not hold — people do not have complete information about everyone on the market, and individuals may lie about, for example, their income (whereas educational level, age, ethnicity, and similar likely are harder to lie about). Further, previous work has demonstrated the likely existence of search frictions (e.g., Kirkebøen, Leuven, and Mogstad 2021). We therefore cannot precisely estimate the true value of $q_{t}$. However, we can relax the assumptions by assuming that uncertainties are constant over time and market definition, and that changes to search frictions by, for example, the arrival of online dating, is captured in the changes in demand. Under these milder assumptions, we can interpret changes in the estimated value of mismatch of $\widehat{q_{t}}$ as reflecting corresponding changes in the value of $q_{t}$.

We test our approach empirically in two ways. First, because we can follow individuals for multiple years in our data, we test the validity of assumption i) by investigating whether those that cannot be matched to an observed potential partner also have lower subsequent probabilities 
of finding a partner. We do this by first estimating the probability of being successfully matched using linear probability models (LPMs). ${ }^{7}$ Having obtained these predicted probabilities, we then plot them against the 5-year actual probability of finding a spouse (partner). A positive slope would indicate that a higher probability of a match corresponds to a higher observed actual matching success on the marriage (partner) market. The larger the slope, the stronger the predictions from the model.

Second, if people face a very mismatched market, they may either change their demand or look for partners among those already in a relationship. The more mismatched a market an individual faces, the more they will have to be willing to change their demand to find a suitable partner, and thus may increasingly opt for finding a partner who is already in a relationship instead. To test if our matching approach captures this feature of our framework, we further examine whether the probability that a person finds a partner who already is in a relationship increases when that person's probability of having a match on the partner market decreases.

\section{RESULTS}

Table 1 provides descriptive statistics on all people living in Denmark age 25-45 for the years 1986, 1996, 2006, and 2016 across gender and relationship status, and Table 2 provides descriptive evidence on spouses from the relationships. As seen from Table 1, the development in partnership status across education and time is gendered. Women with primary education become increasingly concentrated among those who are single. For women with secondary and tertiary education there is substantial variation over the three decades, with longer educated

\footnotetext{
${ }^{7}$ This is done with the characteristics of the synthetic spouses (partners). All variables except income and age are dummy variables. For age, we use a categorical variable with each category corresponding to a 3-year age bin. In the case of income, we use a categorical variable with each category corresponding to a 50.000 DKK $(\approx € 6700)$ income bin.
} 
women going from being overrepresented among the single and cohabiting to overrepresented among the married. Men with mandatory education increasingly became overrepresented among singles over the three decades, with the opposite being true for men with longer education. Thus, whereas the education-relationship dynamic has shifted over the study period for women, men have seen an increase in already existing partnering inequality. Across employment and migration background the patterns appear less gendered, with non-immigrants increasingly being more likely to cohabit and those outside the labor force increasing being more likely to be single across the study period.

[Table 1 and 2 about here.]

From Table 2 we see changes in the distribution of partner characteristics across the study period. In 1986, partners' educational statuses were close to identical across partnership type, but in 2016 the partner were more likely to have a higher education if married and more likely to have secondary or primary education if cohabiting. Similarly, as migrants from non-EU+ countries have become a larger group across the period, cohabiting unions have become more common, even though their cohabitation rates are much lower than non-immigrants. Last, partners in married unions earn more across the study period, but this should be considered jointly with the fact that they also are older on average.

\subsection{Development in the mismatch in partner markets over time}

Figure 3 reports the estimated market mismatch for three partner market definitions where (a) all unmarried are on the market; (b) only singles are on the market, and (c) only singles are on the market, but it is also possible to partner with individuals already in relationships (raiding). ${ }^{8}$

\footnotetext{
${ }^{8}$ See Figure A24 in appendix for the share of new relationships formed on the basis of raiding across the study period.
} 
Mismatch increased across the study period. For women, we see first that the relationship market with cohabitors is neither searching nor available is less mismatched than the marriage market for most of the period, and that this difference increases from the mid-2000. Allowing for finding a partner who already are in a relationship makes the market less mismatched, but less so over time, indicating a declining tendency to find a partner who already is in a relationship.

[Figure 3 about here]

For men, we also see that the relationship market that includes cohabitation as not searching and unavailable is less mismatched than the marriage market (except the first seven years of the period), and the difference increases from the mid-2000s. For the relationship market, the development over time has a shallow U-form, but the marriage market becomes increasingly mismatched until 1994, whereafter it is roughly stable. Allowing for finding a partner already in a relationship makes the market less mismatched but does not change the general shape over time. Men have barely seen an increase in mismatch across the period.

The difference across gender may partly be driven by overall differences in gender-ratio within local markets, although there overall is more single men than women in the age group we consider (see Table 1). Figure 4 report gender ratios and percentage match for each of Denmark's NUTS2-regions. The patterns are similar across regions for women, but for men the relationship market in the capital region of Denmark has grown less mismatched since the second half of the 2000s. This coincides with the capital region increasingly having the lowest ratio of males-to-females in the age-bracket of 25-45- to 20-40-year-olds (Figure A2 in appendix). Overall, it appears that local variation in markets and the overall gender ratio is not driving the mismatch for women but does play a role for men. In the rest of the paper, we will 
continue to only report mismatches on observable characteristics for the relationship market and relegate results to the marriage market to the appendix.

[Figure 4 about here.]

\subsection{Mismatch on characteristics}

Figure 5(a) reports the absolute differences on women's relationship market between shares of synthetic partners and actual characteristics of single men (the surplus). The mismatch increase across income, immigrant status, and labor market status. Education is heavily mismatched with a surplus of primary-level educated men, but the level is largely stable over time. Across age, there is a surplus of men in their late 20s and a deficit of men in the 30 s which holds constant across the period. Availability of fathers goes from a small deficit to around 0 from 1986-1996 and then remains stable. Figure 5(b) reports the companion men. We see few changes in terms of income, and labor market status (an surpluses and deficits are small). For age, there is an increasing surplus of women aged 20-24, and a decrease in the surplus of those aged 35-40, leaving this age group roughly balanced at the end of the period. There is a stable deficit of women 25-34 across the period. For education, there is an increase in the deficit of highly educated women, with the those with primary education going from a slight deficit to a surplus across the period. In terms of migration background, we also now see a move from a surplus to a deficit of women without an immigrant background across the period, and inverse and numerically smaller development in the surplus of women with immigrant background. For parental status, there is first an increase and then a decrease in the surplus, with a surplus of between 6-8 percentage points remaining across the period.

In total, substantial degrees of mismatch exist on the relationship market. Across most observable characteristics, the size of surplus/deficits of observable characteristics were 
generally higher among women (except for parenthood), which indicates that women's mismatch likely co-occurs across more dimensions simultaneously than men's does, which would indicate that $q_{t}$ is smaller for women than for men at given observed level of share with a match. Figure A3 in appendix report the findings from the marriage market definition. Generally, trends are the same.

\subsection{Assessing market definitions and model predictions}

There is little value in the above presented results on degree and distribution of mismatches in relationship markets unless they also translate into actual differences in observed union formation. Figure A4 in the appendix shows binned scatterplots, that for the top row in each subplot shows the predicted probability of having a match on the relationship market that includes cohabitation with again the actual observed probability of forming a cohabiting relationship or marriage on the y-axis. The bottom row shows predictions from the model that also incorporates raiding behavior. The partner market definition (second row) that considers cohabitation as being off the market provides a better prediction (steeper coefficient on the fitted linear curve) than the pure marriage market definition (top row). Incorporating the probability of finding a partner who already are in a relationship further improves the predictive power of the model, but only marginally (bottom row).

\subsection{Consequences of facing a mismatched market}

A second proposition following from our strategy of identifying mismatch, was that the tighter a partner market a person face, the more likely they might be to find a partner who is already off the market (i.e., raiding/poaching from an existing relationship). The underlying assumption is that if people are faced with two "identical" choices of partners, where one is single and the other is in a relationship, people will favor forming a union with the one that is single. However, the 
more mismatched the partner market is, the more people will look to already partnered individuals for finding a partner. Figure 6 plots the predicted probability of forming a relationship within the next five years with someone who the previous year was in another relationship, across the estimated probability of having a match on the partner market, where cohabiting unions are considered as being off the market. Consistently across both genders, the probability of finding an already partnered partner is higher when the partner market is more mismatched. As an example, men without a match in 2012 had 75 percent higher probability of finding an already partnered partner in the following five years than had men with a match. For women, the difference in probability was 40 percent.

[Figure 6 about here.]

\subsection{What drives changes over time?}

In this section we decompose the developments we have documented into changes in the characteristics of those looking for a partner and changes in tastes (demand) and composition of available partners (supply). The decompositions present counterfactual scenarios under the assumption of no interdependence (or, no general equilibrium effects) between, for example, changes in characteristics and changes in taste. That is a strong assumption, and thus the results in this subsection should be interpreted as ideal-typical cases. Because a large number of figures is needed to fully capture the decomposition, we relegate the figures to appendix and here provide the overview.

For the supply decomposition, we keep the supply of partners fixed at the 1986 composition (first column of figure A6 and figures A7 and A8). For women, the development in the period 1987-2018 barely appears to be explained by supply factors. For men some of the development does appears to be driven by changes in supply of potential partners. For the demand decomposition, we first keep the composition of people searching on the market fixed at the 
1986 composition (second column of figure A6 and figures A9-A10). Most of the developments in the period 1987-2018 for both men and women are due to demand factors, driven by changes to income and education. ${ }^{9}$ Contrastingly, starting in the late 2000s, the demand for nonimmigrants decreases, leading to a surplus of non-immigrants and a deficit of immigrants, implying the main results for this variable are primarily driven by supply-factors in the same period. To estimate the component of demand due to changes in the characteristics of those seeking a partner, we fix synthetic partners to their 1986 distribution before matching to single people 1986-2018, thereby holding taste conditional on characteristics fixed to their 1986 values (first column of figure A11 and figures A12-A13). Some of the development in overall mismatch can be attributed to changes among those seeking partners. Driving characteristics are age for both men and women, likewise education and income solely for women, and immigrant category for men. In the case of age, the results show that the changes due to changes in demand to nontrivial extents are explained by changes in the characteristics of those seeking a partner, and similarly for education for women. To identify the share of the developments in demand due to changes in tastes, we fix the characteristics of those searching at their 1986 values but allow synthetic partners to vary across the period (second column of figure A11 and figures A14 and A15). Changes in tastes drive most of the development in demand on the individual characteristics, as the graphs are nearly identical to those showing the developments due to changes in demand, especially for women. The decompositions suggest that most of the changes on the partner market we observe in the period 1986-2018 for women are primarily due to

\footnotetext{
${ }^{9}$ Time trends in these variables likely cause us to overestimate the degree of mismatch, and therefore the degree to which developments are driven by demand factors.
} 
changes in the tastes of those seeking a partner and for men mostly due to changes in tastes but also partially due to changes in characteristics of the women on the market.

\subsection{Who are likely to have a match?}

Next, we consider what characterizes single people who are most likely to have a match. We do this by regressing the probability of having a match on the observable characteristics using LPMs. ${ }^{10}$ Figure 7 (a) reports the results for women. The probability of a match is lower with age across the study period. Women in the lower half of the age-bracket had stable or slightly increasing probability of match until the end of the 2000s, whereafter they saw decreases in the probability of match, with the largest decrease among the youngest part of the bracket. Among older women, the parameters oscillate across the study period, with local maxima around 1990 and the start of the 2010s, and with declines in recent years. Relative to those with only mandatory education, those with secondary and tertiary education has experienced an increase in match probability across the period relative to those with only primary education, and the same holds true for those not in the labor force relative to the employed, with the reverse being true for the unemployed. Both immigrant groups have seen an increase in their probability of match across the period, and parents have seen a decrease. Last, gross income is mostly negatively associated with match probability across the study period. Figure A5(a) reports the corresponding figure for the marriage market definition, with results being close to identical.

[Figure 7 about here]

Figure 7(b) reports the results for men. The gradient for gross income has declined across substantially, with higher income decreasing the probability of match in the most recent years of

\footnotetext{
${ }^{10}$ We obtain standard errors using bootstrap replication including the full matching procedure with 250 iterations by year.
} 
the study period. Employed men also have been experiencing a decreasing probability of having a match. For both those with secondary and tertiary education, we see a decrease in the probability of match when viewed across the whole period. Immigrants from EU+ countries experience no overall change in their probability of match, but other immigrants see an increase. Additionally, parents see a small decrease in match probability. Last, like for women we observe a negative age-gradient in match probability, but with no change when viewed from the start to the end of the period. Figure A5(b) reports the corresponding figure for the marriage market.

\subsection{Robustness}

We assess the robustness of the results we obtain in three ways. First, to ensure the imputation method does not drive the results, we repeat the exercise of comparing the distributions of characteristics between synthetic partners and singles using the mean-imputation. The results from this are shown in figures A16-A17 in the appendix, and overall, these results corroborate our main findings. The one exception is for age, where mismatch appears lower, with lower surpluses at young ages and higher deficits at older ages. The second robustness check decomposes our measure of education into four instead of three categories, wherein we decompose tertiary education into two separate categories. We do this to distinguish those with university-level education (higher education) [ISCED-2011 6+] from those with short tertiary education (further education) [ISCED 5]. The results are shown in figures A18-A20. The overall results remain stable. As a third robustness check, we include descendants into the immigrant category, so that we match on being either an immigrant or descendant, instead of only being an immigrant. The results from this are shown in figures A21-A23. Again, results remain stable.

\section{DISCUSSION}

Across recent decades cohabitation has increasingly gained traction as not only a precursor to marriage, but also as a stable family type in parallel with marriage - and nowhere more than in 
Northern Europe (Cherlin 2020). This has direct implications for the conceptualization of relationship markets - the deinstitutionalization of marriage (Cherlin 2004, 2020) gives rise to stable, cohabiting unions. As shown in this study, failing to account for this in models of relationship market opportunities leads to an incomplete view of who is on the market. Further, incorporating the possibility of market re-entry (or raiding from an existing relationship) provides a more accurate description of opportunities on the relationship market, as well as highlighting the fact that raiding from cohabiting relationships has become increasingly rare, which could indicate an increasing stability of cohabitation.

Our study builds on the assumption that matching is multidimensional, which has two implications. First, focusing on single characteristics such as education or race/ethnicity will only capture a part of market mismatch. Second, focusing solely on a joint measure of mismatch may lead to failure in capturing changes in mismatch on the market driven by changes in demand or supply of one or several characteristics that affect people's acceptability thresholds. To account for mismatch in a partner market most fully, the overall estimate of mismatch and the individual characteristics should be considered jointly. In essence, we argue that not being able to satisfy all partner preferences in a potential match is different from being below one's acceptability threshold, and by jointly studying the development overall mismatch and mismatch on characteristics we are able to approximate a measure of the relative development of people's opportunities, as expressed through the likelihood of having a match above the acceptability threshold.

A striking finding is that across market definitions there is an undersupply of both medium and highly educated men and highly educated women. Whereas this appears counterintuitive at first, it follows form a situation where there is a tendency towards educational assortative mating 
and hypergamy, together with an increasingly asymmetrical supply of the more educated across gender in Denmark. In essence, this becomes a type of crowding-out. Generally, although the overall level of mismatch appears higher for men than for women, when assessing this across individual characteristics, women seem to face a tighter market. The mismatches for men are more geographically heterogenous than for women, with men in the capital region of Copenhagen experiencing an improving market across the entire study period. In contrast, women face similar markets across Denmark. In many ways, our finding resonates with previous work showing a more mismatched market for women than for men across multiple national contexts (e.g., Choo and Siow 2006; Raymo and Iwasawa 2005).

\subsection{Limitations}

Our study sheds light on the relationship market in Denmark and its developments over more than three decades. However, it faces a set of limitations. First, our methodology does not account for those who bring a partner in from outside Denmark, and likewise does not account for those who are found as partners and brought abroad. Second, our methodology does not capture technological shocks to matching through any other channel than how such technologies change observed union formation. This omission therefore likely causes us to bias the share with a match downward. Third, we do not consider living apart together (LAT) relationships and same-sex relationships. Not accounting for these three channels has an ambiguous effect on the estimated share with a match. This is a clear limitation of our approach, and ripe for future exploration using alternative data sources.

Fourth, our models do not account for unobservable factors, such as appearance, values and personality traits, or for parental background, which has been shown to play a role in union formation (Charles, Hurst, and Killewald 2013; Wagner, Boertien, and Gørtz 2020). While these 
clearly limit the validity of the matching exercise, if we assume the set of omitted factors to be roughly constant in importance over time, and correlated with the matching variables included, this does not invalidate the findings documented. Since our models predict relationship formation roughly as well in later years as earlier years, this suggests these assumptions are not unreasonable. Fifth, we model raiding behavior as one-sided, and thus assume that only single people look for a potential partner among those in existing relationships, and not vice versa. However, the negative relationship between the predicted probability of having a match and the

predicted probability of raiding does strongly suggest that our modelling of raiding captures real behavior among singles.

\subsection{Perspective}

Throughout the last decade, Europe, North America, and parts of Asia have seen rising singlehood rates (e.g., Eurostat 2018; Manning 2020; Raymo et al. 2020), which has foreshadowed and coincided with sustained fertility decline (e.g., Comolli 2017) driven largely by declines in first births (Caltabiano, Comolli, and Rosina 2017; Hellstrand et al. 2021). Further, research from the US also finds that childlessness among higher educated women is mainly driven by constraints enforced by social position derived from education and occupation (Verweij et al. 2021). Our study contributes another perspective to this growing literature. Most people still have children within a union and most unions are still heterosexual. With heterosexual partner markets becoming more mismatched, especially following the Great Recession, people's opportunities for finding someone to form a union and start a family have dwindled, indicating that decline in partner opportunities is an additional mechanism driving the great fertility decline. 


\section{CONCLUSION}

We have studied the development in partner market mismatch in Denmark across three decades and three definitions of relationship markets. We found that cohabitation, not marriage, provided the best description of relationship markets in Denmark, and that the relationship market did extend to people already in relationships, but increasingly less so. The cohabitation market was less mismatched than the marriage market. Women seemed to have experienced the largest increase in mismatch on characteristics across the period studied, whereas men had experienced the most increase in geographical mismatch. The main characteristics driving mismatch were employment, education, and income. The changes in mismatch we observed over the three decades studied were for women predominantly driven by changes in taste-based demand, whereas for men the changes were driven both by changes to own demand and to the supply of women, the latter likely mirrored increased the geographical divide in the market. Last, we hypothesized that increased partner market mismatch may be one of the drivers of the ongoing fertility decline across Europe, North America, and Asia. 


\section{REFERENCES}

Autor, David, David Dorn, and Gordon Hanson. 2019. "When Work Disappears: Manufacturing Decline and the Falling Marriage Market Value of Young Men.” American Economic Review: Insights 1(2):161-78.

Van Bavel, Jan. 2021. "Partner Choice and Partner Markets.” Pp. 219-31 in Research Handbook on the Sociology of the Family. Edward Elgar.

Van Bavel, Jan, Christine R. Schwartz, and Albert Esteve. 2018. "The Reversal of the Gender Gap in Education and Its Consequences for Family Life.” Annual Review of Sociology 44(1):341-60.

Becker, Gary S. 1973. “A Theory of Marriage: Part I.” Journal of Political Economy 81(4):81346.

Bumpass, Larry L., James A. Sweet, and Andrew Cherlin. 1991. "The Role of Cohabitation in Declining Rates of Marriage." Journal of Marriage and the Family 53(4):913.

Van Buuren, S. 2018. Flexible Imputation of Missing Data. Boca Raton, FL: CRC Press.

Caltabiano, Marcantonio, C. L. Comolli, and Alessandro Rosina. 2017. "The Effect of the Great Recession on Permanent Childlessness in Italy.” Demographic Research 37(1):635-68.

Charles, Kerwin Kofi, Erik Hurst, and Alexandra Killewald. 2013. "Marital Sorting and Parental Wealth.” Demography 50(1):51-70.

Cherlin, Andrew J. 2004. "The Deinstitutionalization of American Marriage.” Journal of Marriage and Family 66(4):848-61.

Cherlin, Andrew J. 2020. "Degrees of Change: An Assessment of the Deinstitutionalization of Marriage Thesis." Journal of Marriage and Family 82(1):62-80.

Choo, Eugene, and Aloysius Siow. 2006. "Estimating a Marriage Matching Model with Spillover Effects." Demography 43(3):463-90. 
Comolli, C. L. 2017. "The Fertility Response to the Great Recession in Europe and the United States: Structural Economic Conditions and Perceived Economic Uncertainty." Demographic Research 36(1):1549-1600.

Davies, Alastair P. C., and Todd K. Shackelford. 2017. "Don’t You Wish Your Partner Was Hot like Me?: The Effectiveness of Mate Poaching across Relationship Types Considering the Relative Mate-Values of the Poacher and the Partner of the Poached." Personality and Individual Differences 106:32-35.

Esping-Andersen, Gøsta, and Francesco C. Billari. 2015. "Re-Theorizing Family Demographics." Population and Development Review 41(1):1-31.

Eurostat. 2018. "Rising Proportion of Single Person Households in the EU - Products Eurostat News - Eurostat.” Retrieved April 12, 2021 (https://ec.europa.eu/eurostat/web/productseurostat-news/-/DDN-20180706-1).

Fallesen, Peter. 2021. "Who Reacts to Less Restrictive Divorce Laws?” Journal of Marriage and Family 83(2):608-19.

Farmer, Amy, and Andrew W. Horowitz. 2015. "Strategic Non-Marital Cohabitation: Theory and Empirical Implications.” Journal of Population Economics 28(1):219-37.

Frisch, Morten, Ellen Moseholm, Mikael Andersson, Josefine Bernhard Andersen, and Christian Graugaard. 2019. Sex i Danmark. Nøgletal.

Gassen, Nora Sánchez, and Brienna Perelli-Harris. 2015. "The Increase in Cohabitation and the Role of Union Status in Family Policies: A Comparison of 12 European Countries.” Journal of European Social Policy 25(4):431-49.

Grow, André, and Jan Van Bavel. 2015. “Assortative Mating and the Reversal of Gender Inequality in Education in Europe: An Agent-Based Model.” PLOS ONE 10(6):e0127806. 
Hellstrand, Julia, Jessica Nisén, Vitor Miranda, Peter Fallesen, Lars Dommermuth, and Mikko Myrskylä. 2021. "Not Just Later, but Fewer: Novel Trends in Cohort Fertility in the Nordic Countries.” Demography 58(4):1373-99.

Heuveline, Patrick, and Jeffrey M. Timberlake. 2004. "The Role of Cohabitation in Family Formation: The United States in Comparative Perspective." Journal of Marriage and the Family 66(5):1214-30.

Kalmijn, M. 1994. "Assortative Mating by Cultural and Economic Occupational Status.” American Journal of Sociology 100(2):422-52.

Kalmijn, M., and H. Flap. 2001. "Assortative Meeting and Mating: Unintended Consequences of Organized Settings for Partner Choices." Social Forces 79(4):1289-1312.

Kirkebøen, Lars, Edwin Leuven, and Magne Mogstad. 2021. College as a Marriage Market. 28688. Cambridge, MA.

Klinenberg, E. 2012. Going Solo: The Extraordinary Rise and Surprising Appeal of Living Alone. Penguin.

Lahad, Kinneret. 2017. A Table for One. Manchester University Press.

Lichter, Daniel T., Joseph P. Price, and Jeffrey M. Swigert. 2020. "Mismatches in the Marriage Market." Journal of Marriage and Family 82(2):796-809.

Lichter, Daniel T., Zhenchao Qian, and Haoming Song. 2021. "Gender, Union Formation, and Assortative Mating among Older Women.” Social Science Research 102656.

Lundberg, Shelly, Robert A. Pollak, and Jenna Stearns. 2016. "Family Inequality: Diverging Patterns in Marriage, Cohabitation, and Childbearing." Journal of Economic Perspectives 30(2):79-102.

Manning, Wendy D. 2020. "Young Adulthood Relationships in an Era of Uncertainty: A Case 
for Cohabitation." Demography 57(3):799-819.

Mare, Robert D. 1991. "Five Decades of Educational Assortative Mating." American Sociological Review 56(1):15-32.

Miller, Geoffrey F., and Peter M. Todd. 1998. "Mate Choice Turns Cognitive.” Trends in Cognitive Sciences 2(5):190-98.

Mortensen, Dale T. 1988. "Matching: Finding a Partner for Life or Otherwise.” American Journal of Sociology 94:S215-40.

Nielsen, Helena Skyt, and Michael Svarer. 2009. "Educational Homogamy: How Much Is Opportunities?" Journal of Human Resources 44(4):1066-86.

Oppenheimer, Valerie Kincade. 1988. “A Theory of Marriage Timing.” American Journal of Sociology 94(3):563-91.

Perelli-Harris, Brienna, and Nora Sánchez Gassen. 2012. "How Similar Are Cohabitation and Marriage? Legal Approaches to Cohabitation across Western Europe." Population and Development Review 38(3):435-67.

Raymo, James M., Marcia J. Carlson, Alicia VanOrman, So Jung Lim, Brienna Perelli-Harris, and Miho Iwasawa. 2015. "Educational Differences in Early Childbearing: A CrossNational Comparative Study.” Demographic Research 33(1):65-92.

Raymo, James M., and Miho Iwasawa. 2005. “Marriage Market Mismatches in Japan: An Alternetive View of the Relationship between Women's Education and Marriage." American Sociological Review 70(5):801-22.

Raymo, James M., Fumiya Uchikoshi, and Shohei Yoda. 2020. "Marriage Intentions, Desires, and Pathways to Later and Less Marriage in Japan.” Demographic Research 41:67-98. Rosenbeck, Bente. 2017. "Liberalization of Divorce: No-Fault Divorce in Denmark and the 
Nordic Countries in the Early 20th Century.” Scandinavian Journal of History 43(1):18-39.

Schwartz, Christine R. 2013. "Trends and Variation in Assortative Mating: Causes and Consequences." Annual Review of Sociology 39(1):451-70.

Smith, Lones. 2006. "The Marriage Model with Search Frictions." Journal of Political Economy 114(6):1124-44.

Tranæs, Torben. 2001. "Raiding Opportunities and Unemployment." Journal of Labor Economics 19(4):773-98.

Uggla, Caroline, and Gunnar Andersson. 2018. "Higher Divorce Risk When Mates Are Plentiful? Evidence from Denmark.” Biology Letters 14(9):20180475.

Verweij, Renske M., Gert Stulp, Harold Snieder, and Melinda C. Mills. 2021. "Explaining the Associations of Education and Occupation with Childlessness: The Role of Desires and Expectations to Remain Childless.” Population Review 60(2):166-94.

Wagner, Sander, Diederik Boertien, and Mette Gørtz. 2020. "The Wealth of Parents: Trends Over Time in Assortative Mating Based on Parental Wealth." Demography 57(5):1809-31. 
Figure 1 Share of single, cohabiting and, married men and women aged 25-45 and marriage and relationship rates in Denmark 1986-2018

A: Share of Single, Cohabiting and Married
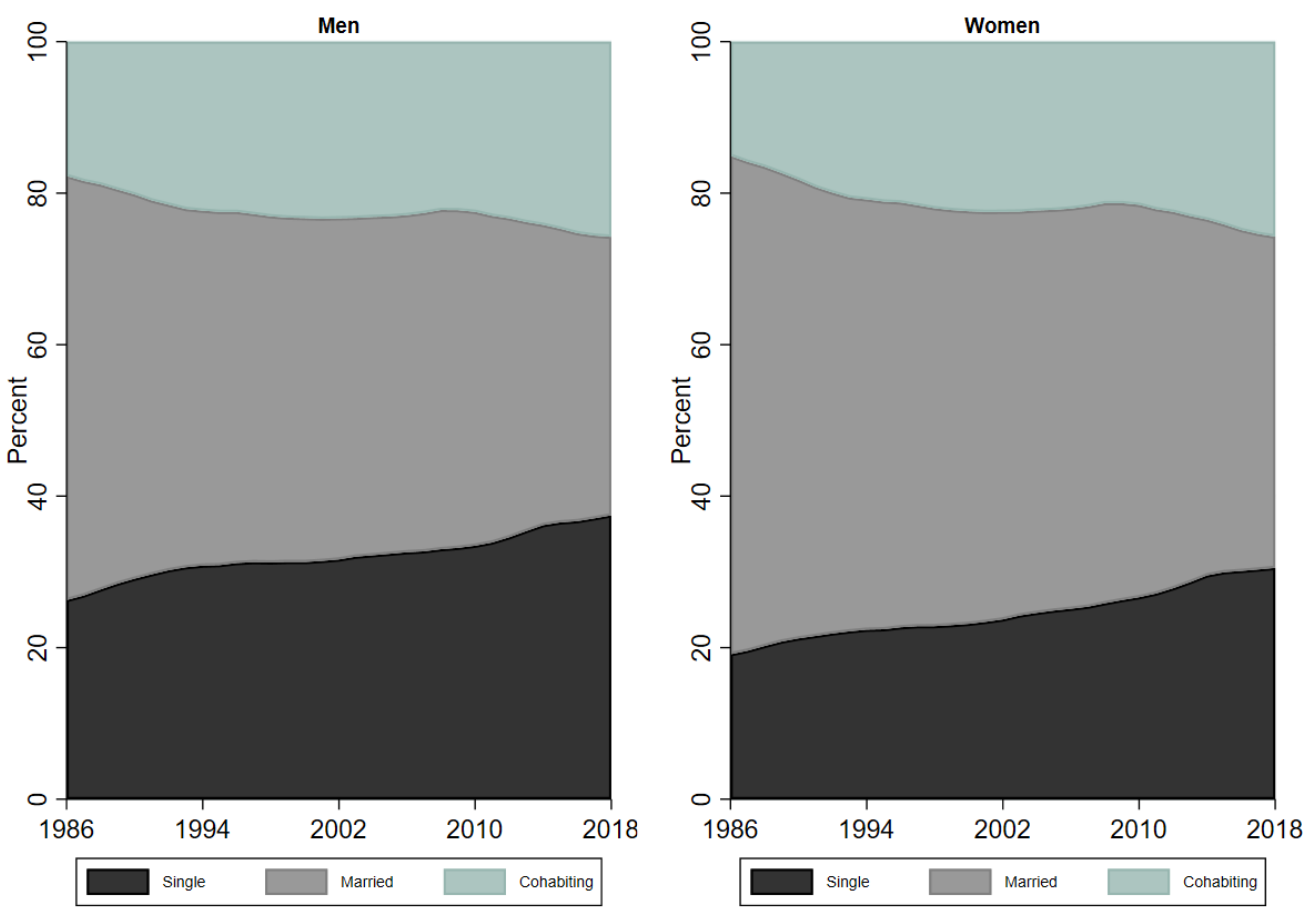

B: Marriage and Relationship Rates
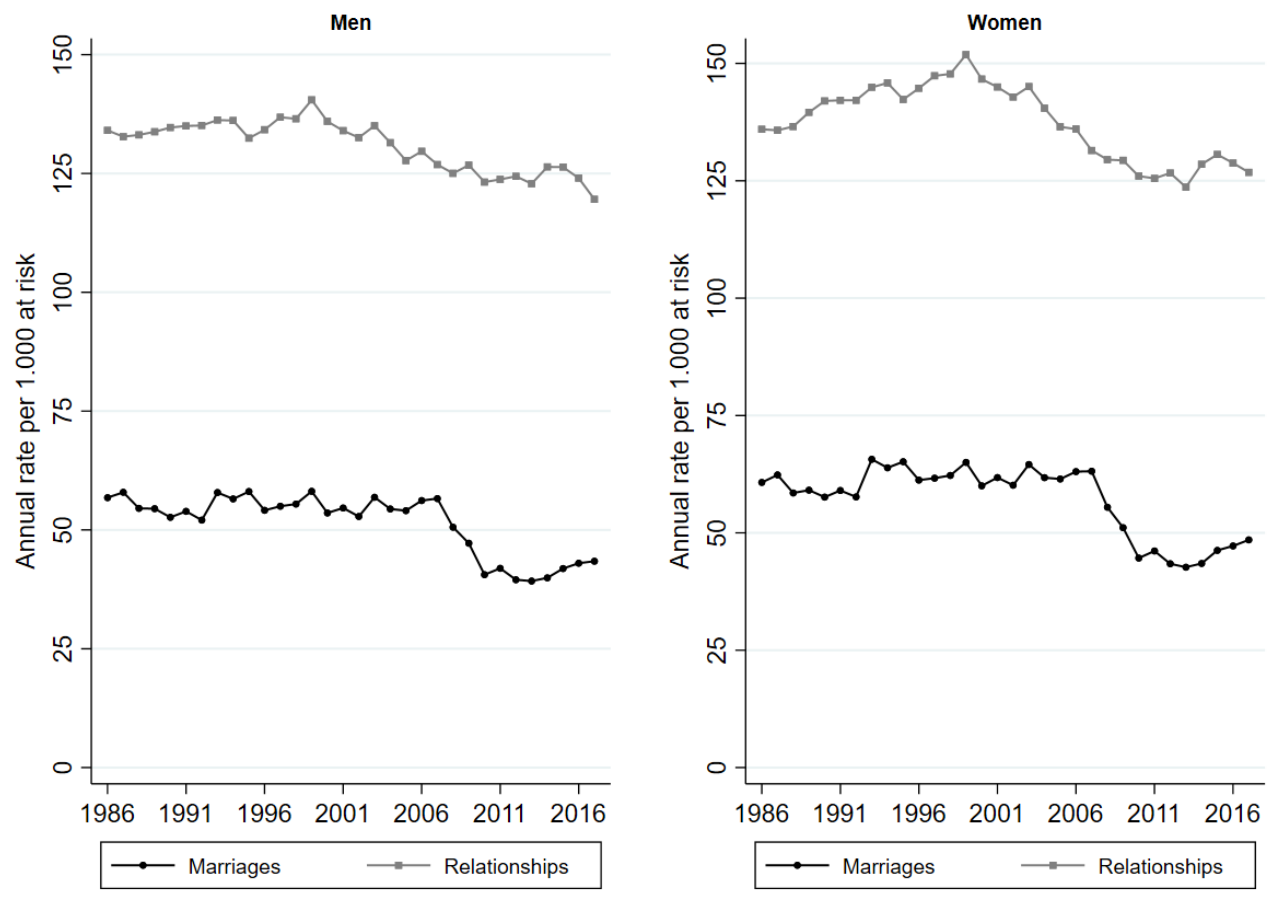

Source: Own calculations on data from Statistics Denmark. 
Figure 2. Matching approach used to obtain estimate of relationship market mismatch using women as example

Unmarried Women

(Single women)

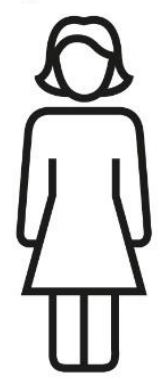

1)

Match unmarried (single) women to women that

have married in the last 5

years, based on

observable

characteristics using CEM.
Synthetic Spouses
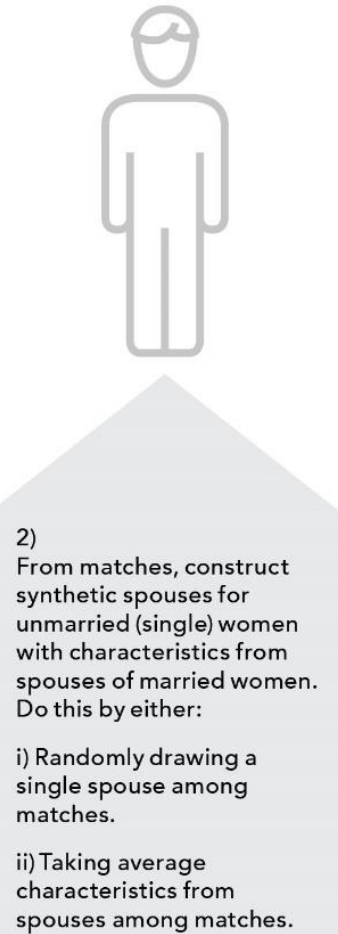

3)

Match synthetic spouses one-to-one to unmarried

(single) men based on

observable

characteristics using

CEM.
Unmarried Men

(Single men)

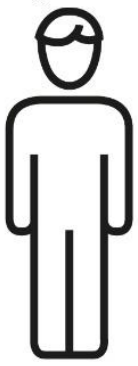

Married Women

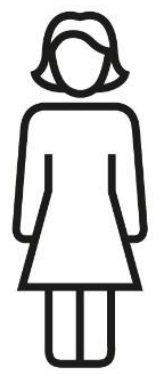

Their Spouses
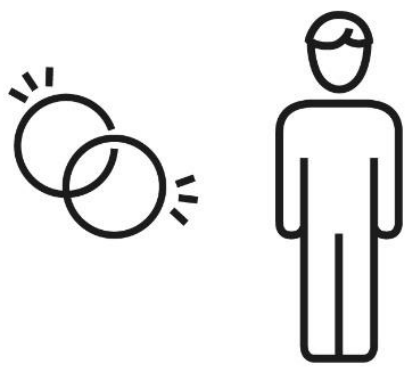
Figure 3 Percentage with a successful match over time across partner market definitions and gender

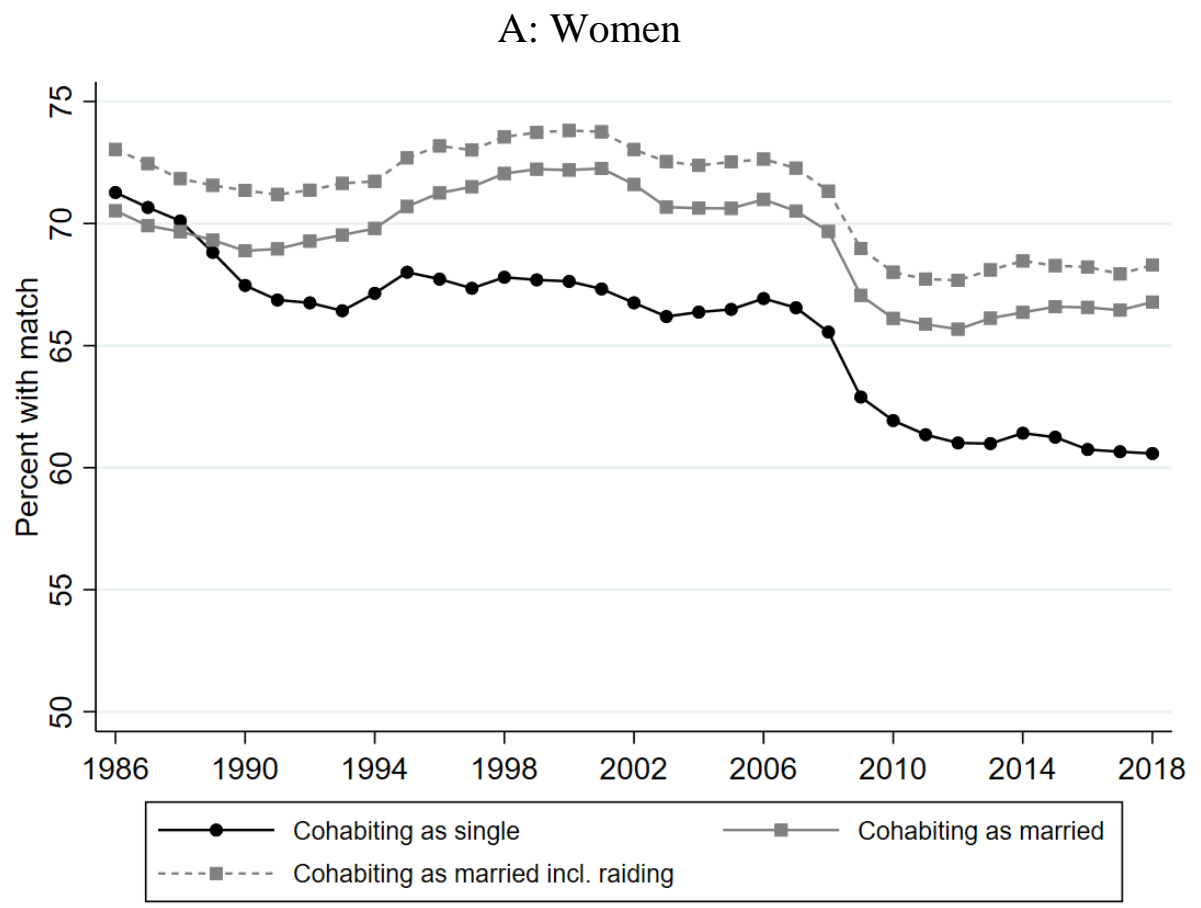

\section{B: Men}

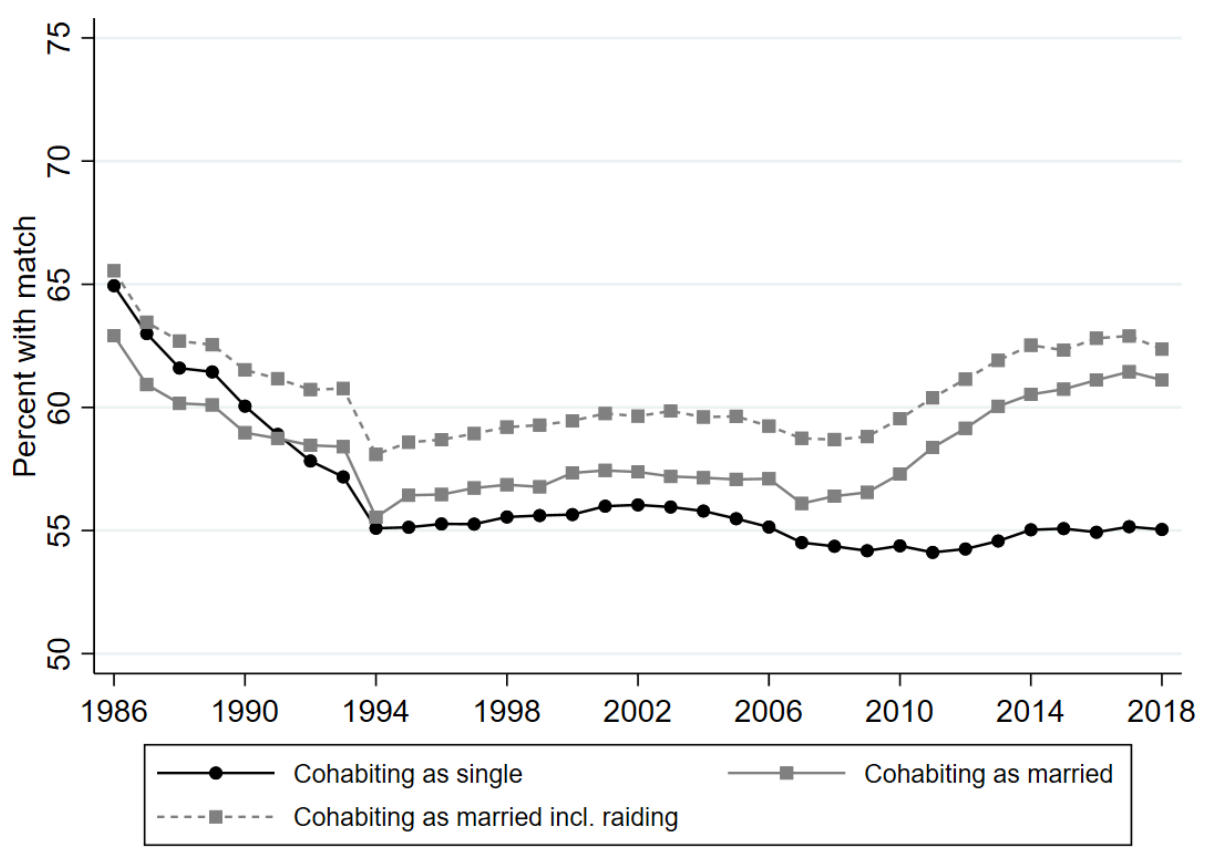

Note: Fraction matched from the model with cohabiting as married including raiding is the average of share matched over 100 simulations. Matches between synthetic and actual potential partners (spouses) forced to be within the same NUTS2 region.

Source: Own calculations on data from Statistics Denmark. 
Figure 4 Share matched within NUTS-2 Region and the Whole Country

\section{A: Women}
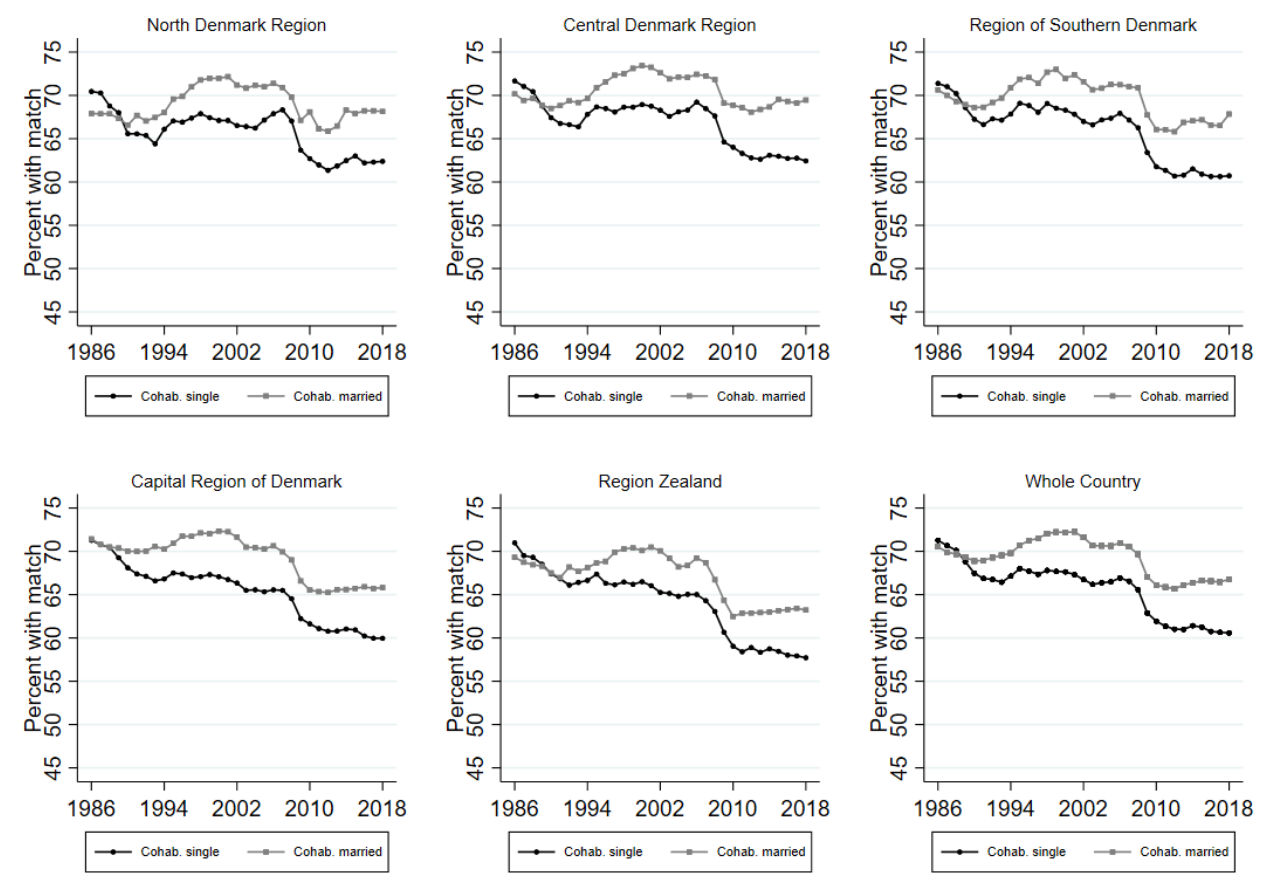

\section{Panel B: Men}
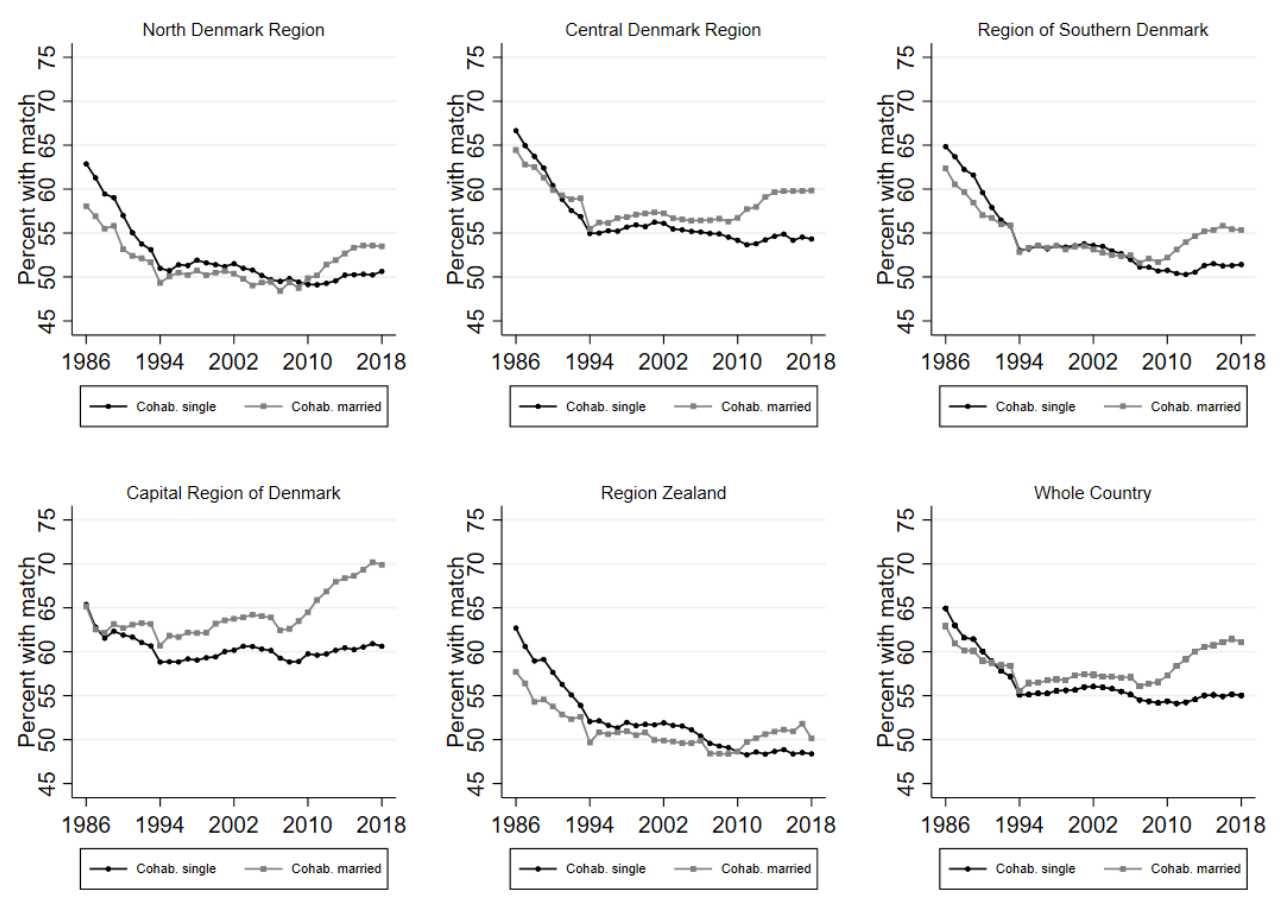
Figure 5 Surplus of characteristics in the relationship market compared to demand for women and men, 1986-2018

A: Women's relationship market
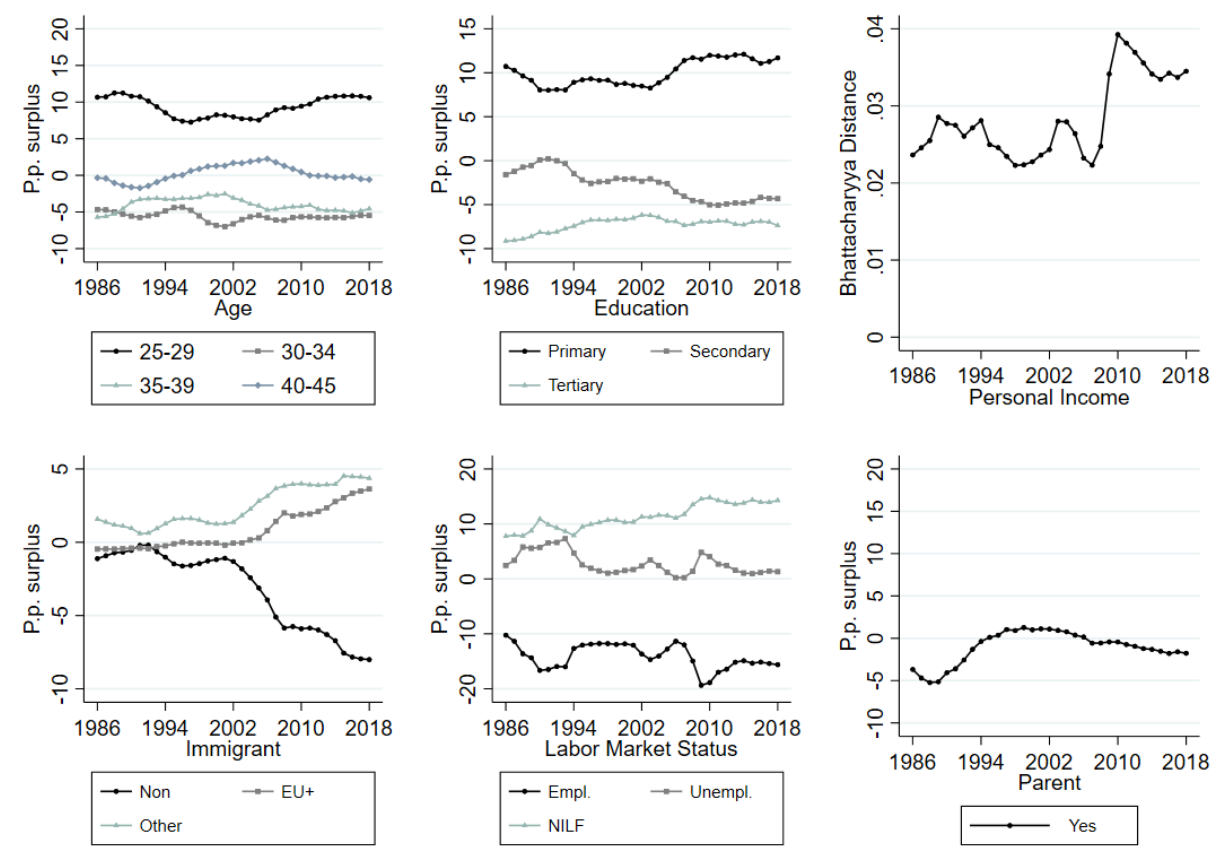

B: Men's relationship market
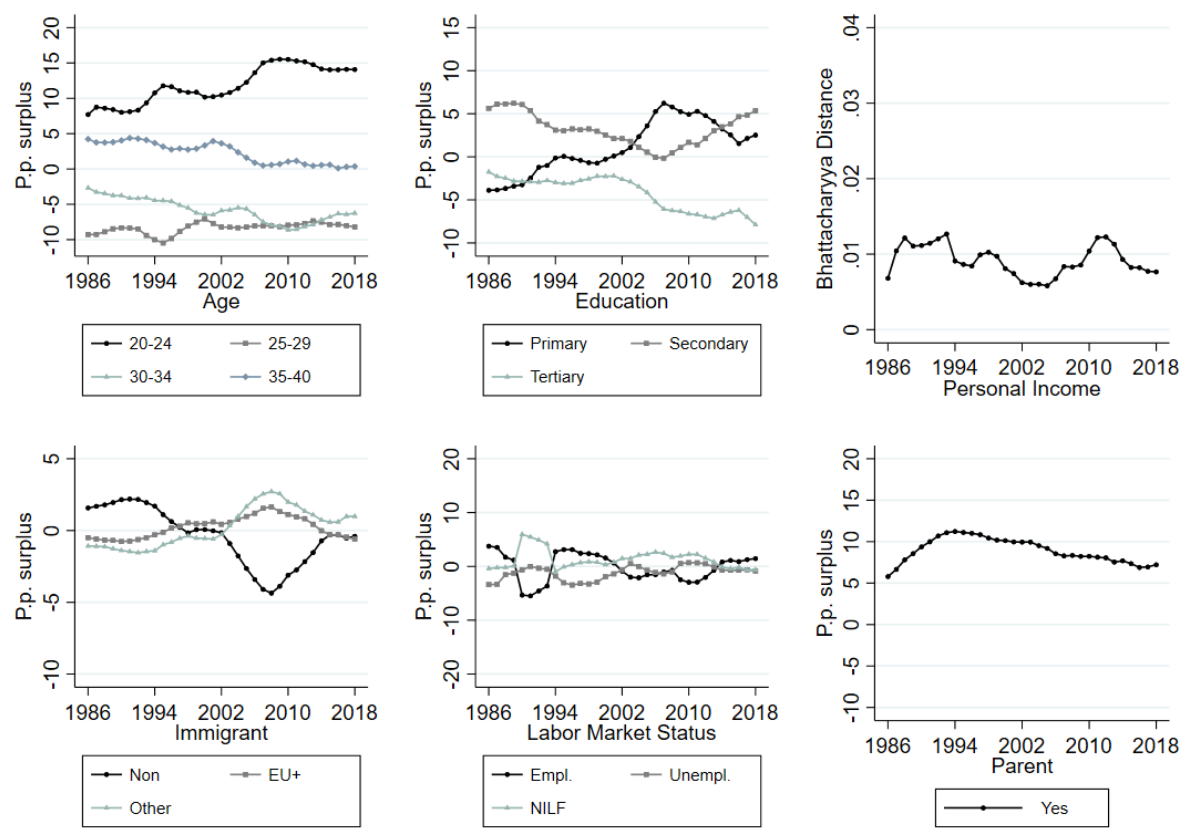

Note: Bhattacharyya distance is calculated with 250 bins. Age range of synthetic spouses for women restricted to 25-45, for men restricted to 20-40.

Source: Own calculations on data from Statistics Denmark. 
Figure 6: Probability of match probability of raiding for people single in 1986, 1993, 2000, and 2007

\section{A: Women}
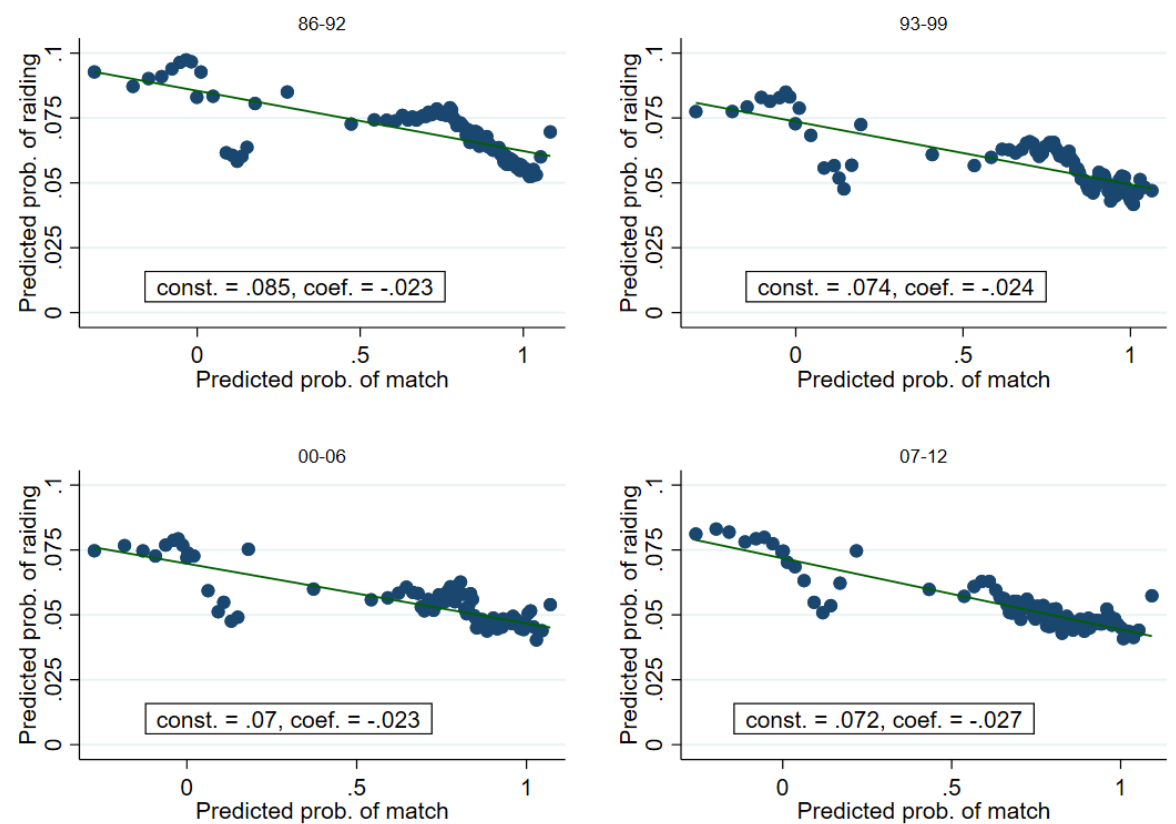

B: Men
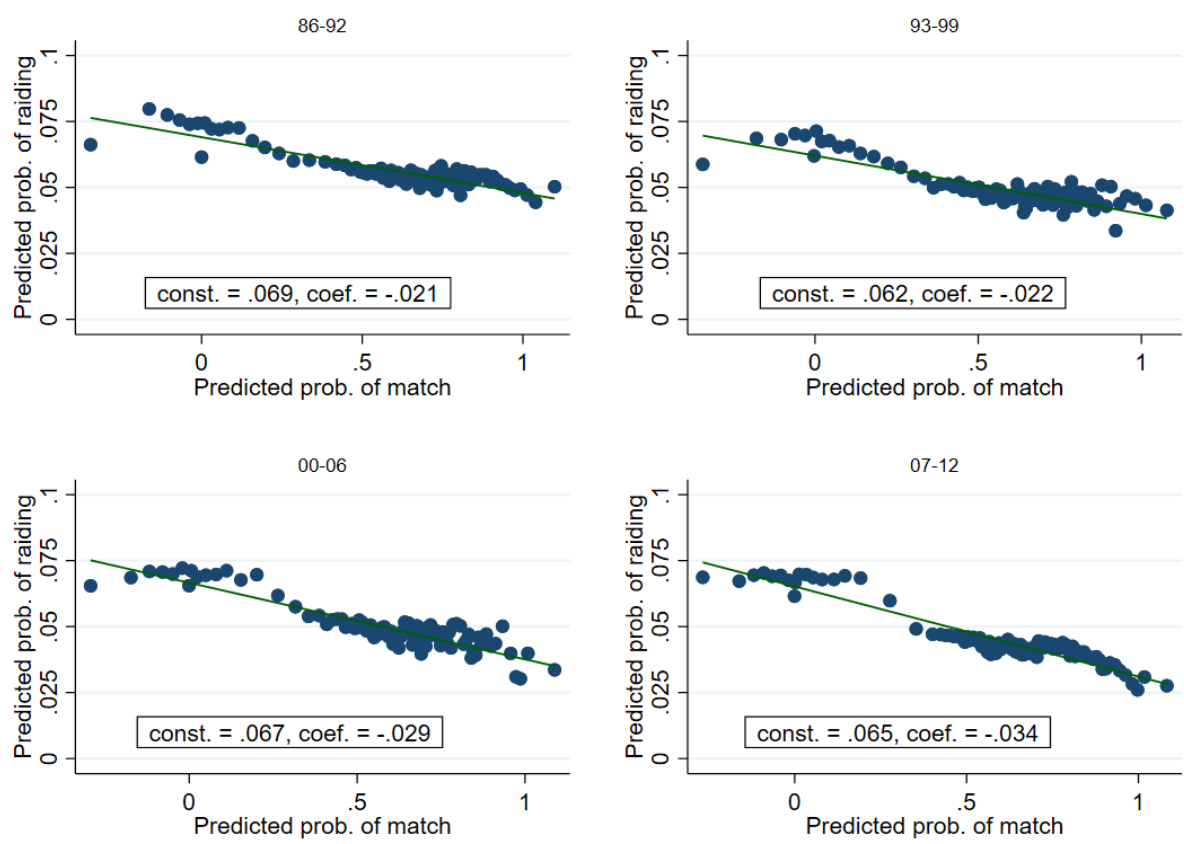

Source: Own calculations on data from Statistics Denmark. 
Figure 7 Coefficients for a single person for having a match on the partner market, 1986-2018 A: Women's relationship market
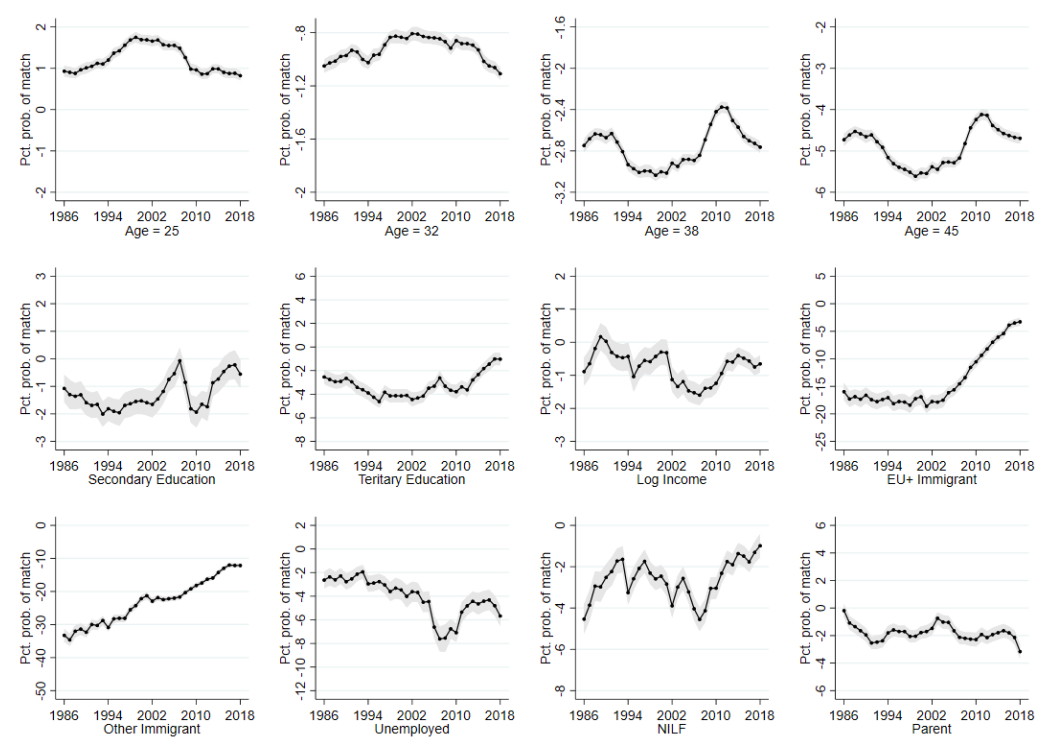

B: Men's relationship market
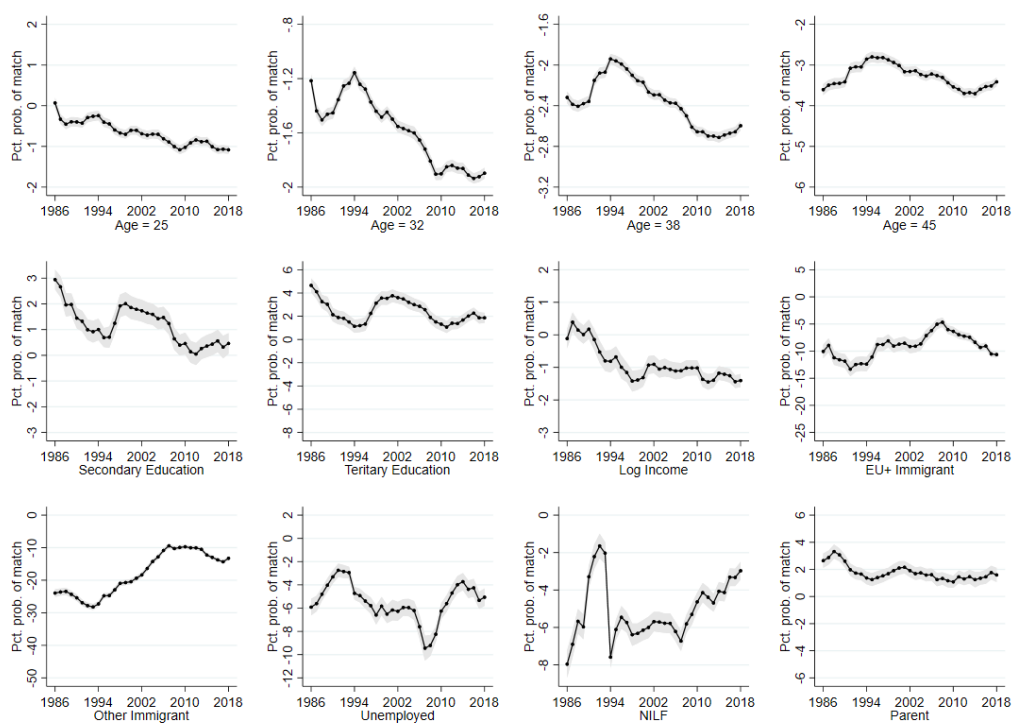

Note: Shading indicates $95 \% \mathrm{CI}$ calculated using bootstrap replication of matching procedure and estimation jointly with 250 iterations for each year. Age enters the estimation models as linear and squared terms and gross income as $\log (+1)$-transformed. For dummy variables and the income measure, we report the parameter estimates directly, for age we report the linear combination of parameters at three different ages (ages 25, 32, 38, and 45). Note differences in y-axes across plots.

Source: Own calculations on data from Statistics Denmark. 
Table 1: Average characteristics of Danish married, cohabiting, and single men and women (25-45) for 1986, 1996, 2006, and 2016

\begin{tabular}{|c|c|c|c|c|c|c|c|c|c|c|c|c|c|c|}
\hline & & $\begin{array}{c}\text { Employed } \\
\%\end{array}$ & $\begin{array}{c}\text { Unemployed } \\
\%\end{array}$ & $\begin{array}{c}\text { Not in the } \\
\text { Labor Force } \\
\%\end{array}$ & $\begin{array}{l}\text { Personal } \\
\text { Income } \\
\text { (1K EUR) }\end{array}$ & $\begin{array}{c}\text { Non- } \\
\text { immigrant } \\
\%\end{array}$ & $\begin{array}{c}\text { EU+ } \\
\text { Immigrant } \\
\%\end{array}$ & $\begin{array}{c}\text { Other } \\
\text { Immigrant } \\
\%\end{array}$ & $\begin{array}{c}\text { Age } \\
\%\end{array}$ & $\begin{array}{c}\text { Primary } \\
\text { Education } \\
\%\end{array}$ & $\begin{array}{c}\text { Secondary } \\
\text { Education } \\
\%\end{array}$ & $\begin{array}{c}\text { Tertiary } \\
\text { Education } \\
\%\end{array}$ & $\begin{array}{c}\text { Child from } \\
\text { previous } \\
\text { relationship } \\
\% \\
\end{array}$ & $\begin{array}{c}\mathrm{N} \\
\text { (within } \\
\text { gender } \\
\text { share) }\end{array}$ \\
\hline \multirow[t]{6}{*}{1986} & $\begin{array}{l}\text { Married } \\
\text { Women }\end{array}$ & 84.80 & 6.14 & 9.06 & $\begin{array}{c}30.45 \\
(14.16)\end{array}$ & 95.38 & 2.29 & 2.32 & $\begin{array}{l}36.24 \\
(5.62)\end{array}$ & 42.32 & 37.48 & 20.19 & 9.95 & $\begin{array}{c}512,352 \\
(.638)\end{array}$ \\
\hline & $\begin{array}{c}\text { Married } \\
\text { Men }\end{array}$ & 95.28 & 2.50 & 2.22 & $\begin{array}{c}53.01 \\
(20.10)\end{array}$ & 95.08 & 2.16 & 2.76 & $\begin{array}{l}37.01 \\
(5.34)\end{array}$ & 28.51 & 50.46 & 21.04 & 8.66 & $\begin{array}{c}455,747 \\
(.544)\end{array}$ \\
\hline & $\begin{array}{c}\text { Cohabiting } \\
\text { Women }\end{array}$ & 82.40 & 10.53 & 7.07 & $\begin{array}{c}33.80 \\
(12.62)\end{array}$ & 97.64 & 1.82 & 0.54 & $\begin{array}{l}31.70 \\
(5.59)\end{array}$ & 41.18 & 35.01 & 23.81 & 29.37 & $\begin{array}{c}120,728 \\
(.150)\end{array}$ \\
\hline & $\begin{array}{c}\text { Cohabiting } \\
\text { Men }\end{array}$ & 91.39 & 5.46 & 3.15 & $\begin{array}{c}44.76 \\
(17.66)\end{array}$ & 97.09 & 1.95 & 0.96 & $\begin{array}{l}32.04 \\
(5.51)\end{array}$ & 31.68 & 50.56 & 17.76 & 19.59 & $\begin{array}{c}148,209 \\
(.177)\end{array}$ \\
\hline & $\begin{array}{c}\text { Single } \\
\text { Women }\end{array}$ & 76.87 & 9.68 & 13.44 & $\begin{array}{c}34.78 \\
(14.79)\end{array}$ & 96.18 & 2.54 & 1.28 & $\begin{array}{l}34.09 \\
(6.25)\end{array}$ & 42.83 & 34.01 & 23.16 & 55.06 & $\begin{array}{c}170,436 \\
(.212)\end{array}$ \\
\hline & Single Men & 78.28 & 9.35 & 12.37 & $\begin{array}{c}38.68 \\
(19.63)\end{array}$ & 94.37 & 2.37 & 3.26 & $\begin{array}{l}33.28 \\
(6.12)\end{array}$ & 40.94 & 44.74 & 14.32 & 28.56 & $\begin{array}{r}233,972 \\
(.279) \\
\end{array}$ \\
\hline \multirow[t]{6}{*}{1996} & $\begin{array}{l}\text { Married } \\
\text { Women }\end{array}$ & 81.64 & 6.06 & 12.29 & $\begin{array}{c}38.26 \\
(14.87)\end{array}$ & 90.57 & 2.39 & 7.04 & $\begin{array}{l}36.24 \\
(5.58)\end{array}$ & 31.6 & 41.91 & 26.49 & 10.79 & $\begin{array}{c}444,016 \\
(.543)\end{array}$ \\
\hline & $\begin{array}{c}\text { Married } \\
\text { Men }\end{array}$ & 91.02 & 3.62 & 5.36 & $\begin{array}{c}50.95 \\
(21.71)\end{array}$ & 89.81 & 2.17 & 2.17 & $\begin{array}{l}36.91 \\
(5.35)\end{array}$ & 24.95 & 51.28 & 23.77 & 8.56 & $\begin{array}{c}382,960 \\
(.451)\end{array}$ \\
\hline & $\begin{array}{c}\text { Cohabiting } \\
\text { Women }\end{array}$ & 80.04 & 8.19 & 11.77 & $\begin{array}{c}36.54 \\
(13.30)\end{array}$ & 97.28 & 1.69 & 1.03 & $\begin{array}{l}32.41 \\
(5.70)\end{array}$ & 30.11 & 46.67 & 23.23 & 21.44 & $\begin{array}{c}171,947 \\
(.210)\end{array}$ \\
\hline & $\begin{array}{c}\text { Cohabiting } \\
\text { Men }\end{array}$ & 89.85 & 5.26 & 4.89 & $\begin{array}{c}45.59 \\
(18.55)\end{array}$ & 96.39 & 2.01 & 1.60 & $\begin{array}{l}32.74 \\
(5.67)\end{array}$ & 27.27 & 53.61 & 19.12 & 14.67 & $\begin{array}{c}189,487 \\
(.223)\end{array}$ \\
\hline & $\begin{array}{c}\text { Single } \\
\text { Women }\end{array}$ & 70.75 & 8.84 & 20.41 & $\begin{array}{c}36.88 \\
(15.01)\end{array}$ & 93.82 & 2.50 & 3.68 & $\begin{array}{l}33.92 \\
(6.22)\end{array}$ & 36.42 & 40.48 & 23.1 & 49.29 & $\begin{array}{c}201,638 \\
(.247)\end{array}$ \\
\hline & Single Men & 73.65 & 9.52 & 16.82 & $\begin{array}{c}38.71 \\
(18.74)\end{array}$ & 92.92 & 2.23 & 4.84 & $\begin{array}{l}33.39 \\
(6.07)\end{array}$ & 37.7 & 46.9 & 15.4 & 26.39 & $\begin{array}{c}276,736 \\
(.326)\end{array}$ \\
\hline \multirow[t]{6}{*}{2006} & $\begin{array}{l}\text { Married } \\
\text { Women }\end{array}$ & 86.45 & 2.47 & 11.08 & $\begin{array}{c}44.12 \\
(18.21)\end{array}$ & 86.54 & 2.62 & 10.84 & $\begin{array}{l}36.98 \\
(5.31)\end{array}$ & 18.05 & 45.62 & 36.33 & 10.91 & $\begin{array}{c}411,766 \\
(.511)\end{array}$ \\
\hline & $\begin{array}{c}\text { Married } \\
\text { Men }\end{array}$ & 93.93 & 1.47 & 4.60 & $\begin{array}{c}57.61 \\
(23.64)\end{array}$ & 88.05 & 2.35 & 9.60 & $\begin{array}{l}37.72 \\
(4.98)\end{array}$ & 19.28 & 49.77 & 30.95 & 8.80 & $\begin{array}{c}352,357 \\
(.432)\end{array}$ \\
\hline & $\begin{array}{c}\text { Cohabiting } \\
\text { Women }\end{array}$ & 86.25 & 3.32 & 10.43 & $\begin{array}{c}40.07 \\
(16.56)\end{array}$ & 94.61 & 2.76 & 2.63 & $\begin{array}{l}33.25 \\
(5.94)\end{array}$ & 20.02 & 46.23 & 33.75 & 21.14 & $\begin{array}{c}175,631 \\
(.218)\end{array}$ \\
\hline & $\begin{array}{c}\text { Cohabiting } \\
\text { Men }\end{array}$ & 93.03 & 1.85 & 5.12 & $\begin{array}{c}49.60 \\
(21.67)\end{array}$ & 94.72 & 2.52 & 2.76 & $\begin{array}{l}33.56 \\
(5.81)\end{array}$ & 22.38 & 52.46 & 25.15 & 15.69 & $\begin{array}{c}185,834 \\
(.228)\end{array}$ \\
\hline & $\begin{array}{c}\text { Single } \\
\text { Women }\end{array}$ & 75.92 & 4.06 & 20.02 & $\begin{array}{l}40.06 \\
(18.25)\end{array}$ & 88.94 & 3.51 & 7.55 & $\begin{array}{l}34.61 \\
(6.26)\end{array}$ & 27.73 & 42.61 & 29.65 & 47.68 & $\begin{array}{c}217,642 \\
(.270)\end{array}$ \\
\hline & Single Men & 78.58 & 3.45 & 17.98 & $\begin{array}{c}41.84 \\
(22.16) \\
\end{array}$ & 89.4 & 3.36 & 7.24 & $\begin{array}{l}34.26 \\
(6.22) \\
\end{array}$ & 34.48 & 45.94 & 19.58 & 27.54 & $\begin{array}{c}277,846 \\
(.340) \\
\end{array}$ \\
\hline \multirow[t]{3}{*}{2016} & $\begin{array}{l}\text { Married } \\
\text { Women }\end{array}$ & 82.53 & 2.89 & 14.58 & $\begin{array}{c}46.18 \\
(21.82)\end{array}$ & 77.94 & 5.83 & 16.24 & $\begin{array}{l}37.29 \\
(5.40)\end{array}$ & 14.1 & 34.06 & 51.84 & 8.87 & $\begin{array}{c}330,437 \\
(.440)\end{array}$ \\
\hline & $\begin{array}{c}\text { Married } \\
\text { Men }\end{array}$ & 92.12 & 2.15 & 5.73 & $\begin{array}{c}59.13 \\
(24.97)\end{array}$ & 81.51 & 5.42 & 13.07 & $\begin{array}{l}37.97 \\
(5.12)\end{array}$ & 15.63 & 42.3 & 42.07 & 7.14 & $\begin{array}{c}279,057 \\
(.366)\end{array}$ \\
\hline & $\begin{array}{l}\text { Cohabiting } \\
\text { Women }\end{array}$ & 81.89 & 4.47 & 13.64 & $\begin{array}{c}41.16 \\
(18.93)\end{array}$ & 88.73 & 6.52 & 4.76 & $\begin{array}{l}33.02 \\
(6.00)\end{array}$ & 15.5 & 36.29 & 48.21 & 17.03 & $\begin{array}{c}186,756 \\
(.249)\end{array}$ \\
\hline
\end{tabular}




\begin{tabular}{|c|c|c|c|c|c|c|c|c|c|c|c|c|c|}
\hline $\begin{array}{c}\text { Cohabiting } \\
\text { Men }\end{array}$ & 81.89 & 3.26 & 7.19 & $\begin{array}{c}49.22 \\
(23.36)\end{array}$ & 89.99 & 5.29 & 4.73 & $\begin{array}{l}33.42 \\
(5.94)\end{array}$ & 19.01 & 46.33 & 34.66 & 13.62 & $\begin{array}{c}194,370 \\
(.255)\end{array}$ \\
\hline $\begin{array}{c}\text { Single } \\
\text { Women }\end{array}$ & 71.57 & 4.84 & 23.58 & $\begin{array}{c}38.52 \\
(20.67)\end{array}$ & 81.44 & 7.61 & 10.95 & $\begin{array}{l}34.04 \\
(6.56)\end{array}$ & 24.12 & 34.74 & 41.14 & 41.95 & $\begin{array}{c}233,195 \\
(.311)\end{array}$ \\
\hline Single Men & 71.93 & 4.92 & 23.15 & $\begin{array}{c}37.98 \\
(23.63) \\
\end{array}$ & 79.55 & 9.42 & 11.03 & $\begin{array}{l}33.48 \\
(6.41) \\
\end{array}$ & 33.18 & 40.26 & 26.56 & 22.95 & $\begin{array}{c}288,145 \\
(.378) \\
\end{array}$ \\
\hline
\end{tabular}


Table 2. Average characteristics of partners for Danish men and women (25-45) across relationship for 1986, 1996, 2006, and 2016

\begin{tabular}{|c|c|c|c|c|c|c|c|c|c|c|c|c|c|c|}
\hline & & $\begin{array}{c}\text { Employed } \\
\%\end{array}$ & $\begin{array}{c}\text { Unemployed } \\
\%\end{array}$ & $\begin{array}{c}\text { Not in the } \\
\text { Labor Force } \\
\%\end{array}$ & $\begin{array}{l}\text { Personal } \\
\text { Income } \\
\text { (1K EUR) }\end{array}$ & $\begin{array}{c}\text { Non- } \\
\text { immigrant } \\
\%\end{array}$ & $\begin{array}{c}\text { EU+ } \\
\text { Immigrant } \\
\%\end{array}$ & $\begin{array}{c}\text { Other } \\
\text { Immigrant } \\
\%\end{array}$ & $\begin{array}{l}\text { Age } \\
\%\end{array}$ & $\begin{array}{c}\text { Primary } \\
\text { Education } \\
\%\end{array}$ & $\begin{array}{c}\text { Secondary } \\
\text { Education } \\
\%\end{array}$ & $\begin{array}{c}\text { Tertiary } \\
\text { Education } \\
\%\end{array}$ & $\begin{array}{l}\text { Child from } \\
\text { previous } \\
\text { relationship } \\
\%\end{array}$ & $\begin{array}{c}\mathrm{N} \\
\text { (within } \\
\text { gender } \\
\text { share) }\end{array}$ \\
\hline \multirow[t]{4}{*}{1986} & $\begin{array}{c}\text { Spouses of Married } \\
\text { Women }\end{array}$ & 94.98 & 2.44 & 2.58 & $\begin{array}{c}53.23 \\
(20.40)\end{array}$ & 95.47 & 2.15 & 2.38 & $\begin{array}{l}39.17 \\
(6.75)\end{array}$ & 30.26 & 48.84 & 20.90 & 9.83 & $\begin{array}{c}512,352 \\
(.809)\end{array}$ \\
\hline & $\begin{array}{c}\text { Spouses of Married } \\
\text { Men }\end{array}$ & 84.44 & 6.74 & 8.82 & $\begin{array}{c}30.52 \\
(13.90)\end{array}$ & 95.12 & 2.26 & 2.62 & $\begin{array}{l}34.97 \\
(6.03)\end{array}$ & 41.30 & 38.21 & 20.50 & 9.90 & $\begin{array}{c}455,747 \\
(.755)\end{array}$ \\
\hline & $\begin{array}{c}\text { Spouses of } \\
\text { Cohabiting Women }\end{array}$ & 90.75 & 5.45 & 3.80 & $\begin{array}{l}45.44 \\
(18.65)\end{array}$ & 96.78 & 2.22 & 1.00 & $\begin{array}{l}33.84 \\
(6.90)\end{array}$ & 31.74 & 48.42 & 19.84 & 23.79 & $\begin{array}{c}120,728 \\
(.191)\end{array}$ \\
\hline & $\begin{array}{c}\text { Spouses of } \\
\text { Cohabiting Men }\end{array}$ & 82.26 & 10.97 & 6.77 & $\begin{array}{c}31.93 \\
(12.44)\end{array}$ & 97.95 & 1.60 & 0.45 & $\begin{array}{l}29.46 \\
(6.67)\end{array}$ & 42.89 & 38.08 & 19.03 & 22.77 & $\begin{array}{c}148,209 \\
(.254) \\
\end{array}$ \\
\hline \multirow[t]{4}{*}{1996} & $\begin{array}{c}\text { Spouses of Married } \\
\text { Women }\end{array}$ & 90.81 & 3.48 & 5.71 & $\begin{array}{l}51.48 \\
(21.97)\end{array}$ & 90.88 & 2.28 & 6.84 & $\begin{array}{l}39.28 \\
(6.97)\end{array}$ & 25.52 & 50.43 & 24.05 & 12.28 & $\begin{array}{c}444,016 \\
(.721)\end{array}$ \\
\hline & $\begin{array}{c}\text { Spouses of Married } \\
\text { Men }\end{array}$ & 80.31 & 6.37 & 13.33 & $\begin{array}{c}37.69 \\
(14.72)\end{array}$ & 89.84 & 2.34 & 2.34 & $\begin{array}{l}35.09 \\
(6.05)\end{array}$ & 31.01 & 43.1 & 25.88 & 11.14 & $\begin{array}{c}382,960 \\
(.669)\end{array}$ \\
\hline & $\begin{array}{c}\text { Spouses of } \\
\text { Cohabiting Women }\end{array}$ & 89.32 & 5.12 & 5.55 & $\begin{array}{c}46.30 \\
(19.33)\end{array}$ & 96.25 & 2.18 & 1.56 & $\begin{array}{l}34.54 \\
(7.17)\end{array}$ & 27.67 & 52.02 & 20.31 & 18.56 & $\begin{array}{c}171,947 \\
(.279)\end{array}$ \\
\hline & $\begin{array}{c}\text { Spouses of } \\
\text { Cohabiting Men }\end{array}$ & 80.15 & 8.10 & 11.75 & $\begin{array}{l}34.50 \\
(13.43)\end{array}$ & 97.39 & 1.59 & 1.02 & $\begin{array}{l}30.67 \\
(6.65)\end{array}$ & 31.04 & 49.26 & 19.69 & 18.5 & $\begin{array}{c}189,487 \\
(.331) \\
\end{array}$ \\
\hline \multirow[t]{4}{*}{2006} & $\begin{array}{c}\text { Spouses of Married } \\
\text { Women }\end{array}$ & 93.07 & 1.47 & 5.46 & $\begin{array}{l}57.66 \\
(23.82)\end{array}$ & 87.9 & 2.41 & 9.69 & $\begin{array}{l}39.94 \\
(6.76)\end{array}$ & 20.02 & 49.28 & 30.70 & 12.41 & $\begin{array}{c}411,766 \\
(.701)\end{array}$ \\
\hline & $\begin{array}{c}\text { Spouses of Married } \\
\text { Men }\end{array}$ & 86.33 & 2.55 & 11.12 & $\begin{array}{c}43.60 \\
(18.07)\end{array}$ & 87.28 & 2.58 & 10.14 & $\begin{array}{l}36.21 \\
(5.79)\end{array}$ & 17.98 & 45.39 & 36.63 & 11.38 & $\begin{array}{c}352,357 \\
(.655)\end{array}$ \\
\hline & $\begin{array}{c}\text { Spouses of } \\
\text { Cohabiting Women }\end{array}$ & 92.76 & 1.80 & 5.44 & $\begin{array}{l}50.74 \\
(22.19)\end{array}$ & 94.67 & 2.66 & 2.68 & $\begin{array}{l}35.34 \\
(7.19)\end{array}$ & 22.65 & 51.06 & 26.29 & 19.07 & $\begin{array}{c}175,631 \\
(.299)\end{array}$ \\
\hline & $\begin{array}{c}\text { Spouses of } \\
\text { Cohabiting Men }\end{array}$ & 86.20 & 3.32 & 10.48 & $\begin{array}{c}37.81 \\
(16.76)\end{array}$ & 94.50 & 2.84 & 2.67 & $\begin{array}{l}31.73 \\
(6.87)\end{array}$ & 22.45 & 47.40 & 30.14 & 18.81 & $\begin{array}{c}185,834 \\
(.345)\end{array}$ \\
\hline \multirow[t]{4}{*}{2016} & $\begin{array}{c}\text { Spouses of Married } \\
\text { Women }\end{array}$ & 91.09 & 2.08 & 6.82 & $\begin{array}{c}59.37 \\
(25.16)\end{array}$ & 81.4 & 5.07 & 13.53 & $\begin{array}{l}40.36 \\
(6.90)\end{array}$ & 16.31 & 42.89 & 40.80 & 11.15 & $\begin{array}{c}330,437 \\
(.639)\end{array}$ \\
\hline & $\begin{array}{c}\text { Spouses of Married } \\
\text { Men }\end{array}$ & 82.49 & 3.00 & 14.50 & $\begin{array}{l}45.75 \\
(21.78)\end{array}$ & 79.48 & 6.22 & 14.3 & $\begin{array}{l}36.53 \\
(6.02)\end{array}$ & 13.55 & 33.37 & 53.09 & 8.92 & $\begin{array}{c}279,057 \\
(.589)\end{array}$ \\
\hline & $\begin{array}{c}\text { Spouses of } \\
\text { Cohabiting Women }\end{array}$ & 89.63 & 3.09 & 7.28 & $\begin{array}{l}50.84 \\
(23.84)\end{array}$ & 89.95 & 5.33 & 4.72 & $\begin{array}{l}35.24 \\
(7.39)\end{array}$ & 18.87 & 45.66 & 35.47 & 17.07 & $\begin{array}{c}186,756 \\
(.361)\end{array}$ \\
\hline & $\begin{array}{c}\text { Spouses of } \\
\text { Cohabiting Men }\end{array}$ & 81.98 & 4.30 & 13.72 & $\begin{array}{c}38.69 \\
(18.98)\end{array}$ & 89.22 & 6.40 & 4.38 & $\begin{array}{l}31.54 \\
(6.76)\end{array}$ & 17.25 & 38.89 & 43.85 & 14.65 & $\begin{array}{c}194,370 \\
(.411)\end{array}$ \\
\hline
\end{tabular}


ONLINE APPENDIX 
Figure A1 Age distributions of synthetic spouses for men and women

\section{A: Married vs. unmarried}
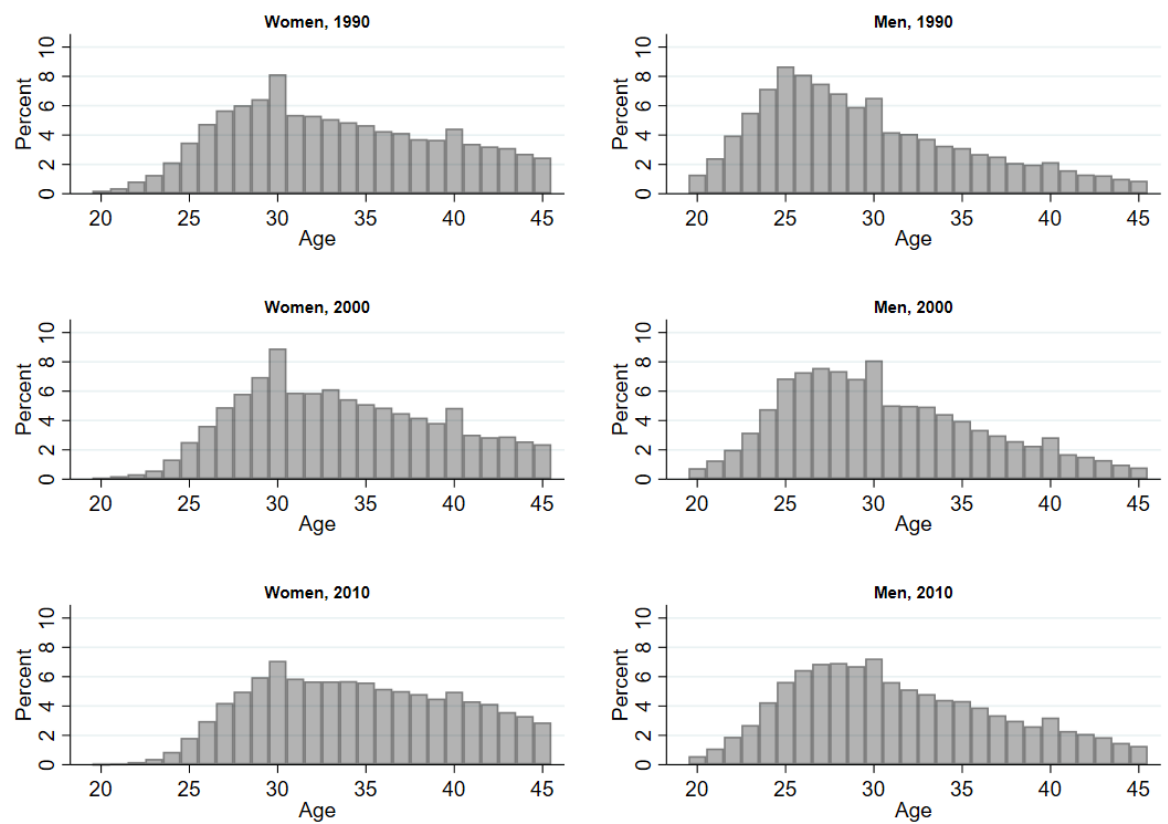

B: In relationship vs. single
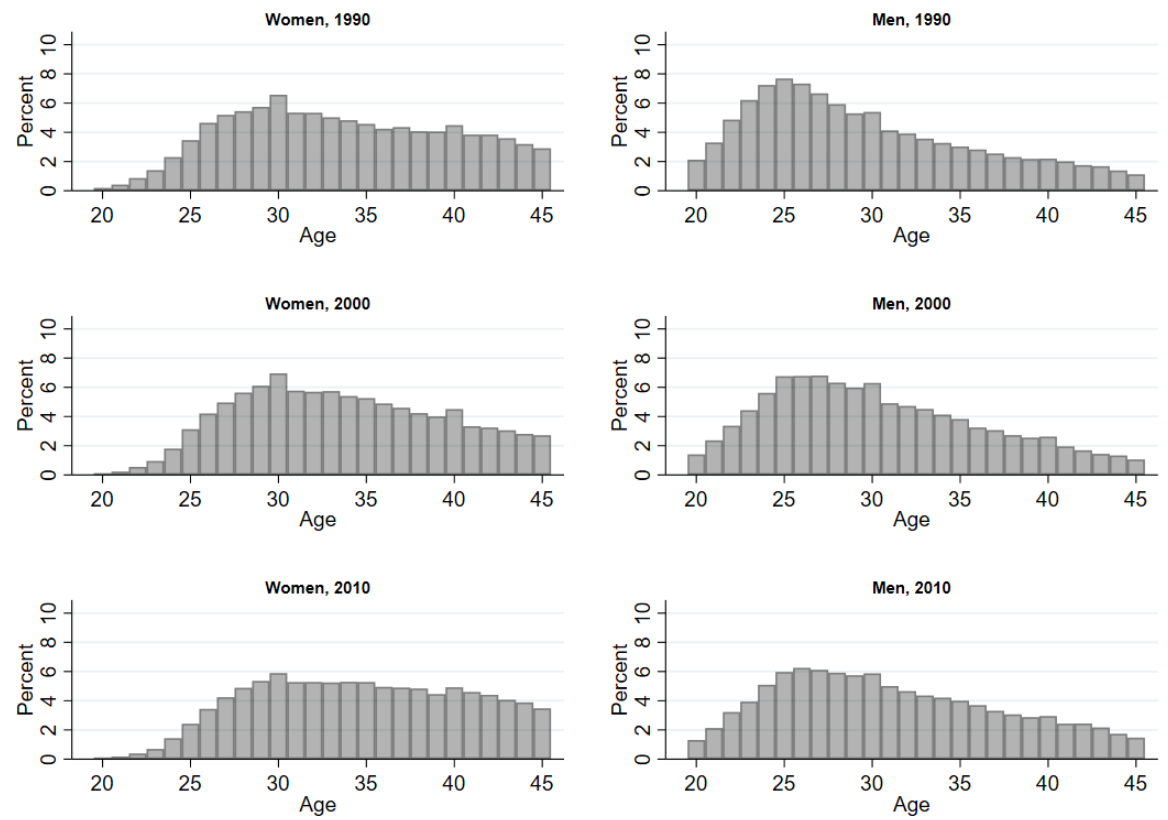
Figure A2 Sex ratios of males aged 25-45 to females aged 25-45 (Panel A) and aged 20-40 (Panel B), within regions as well as for the whole country:

Panel A: Men 25-45: Women 25-45
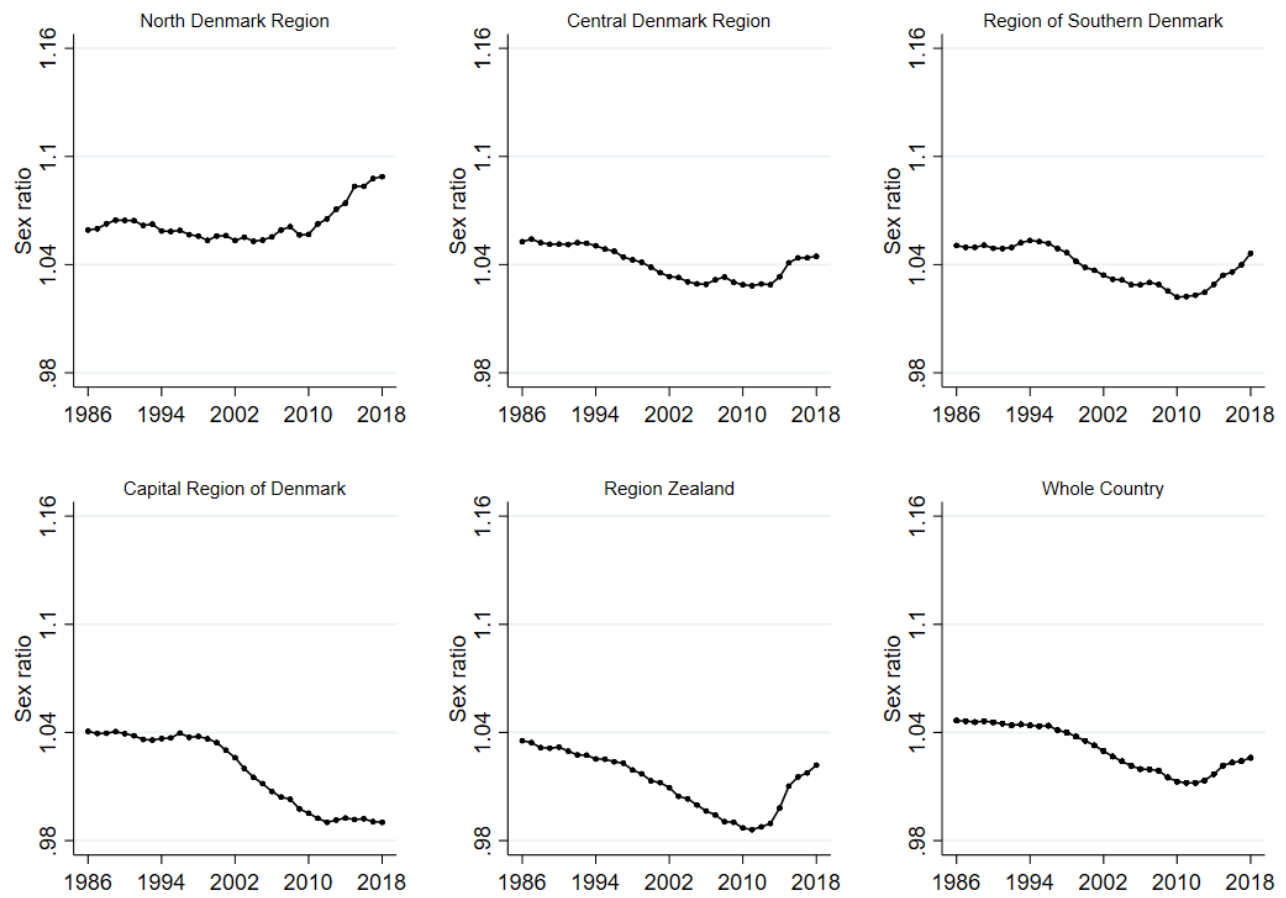

Panel B: Men 25-45: Women 20-40
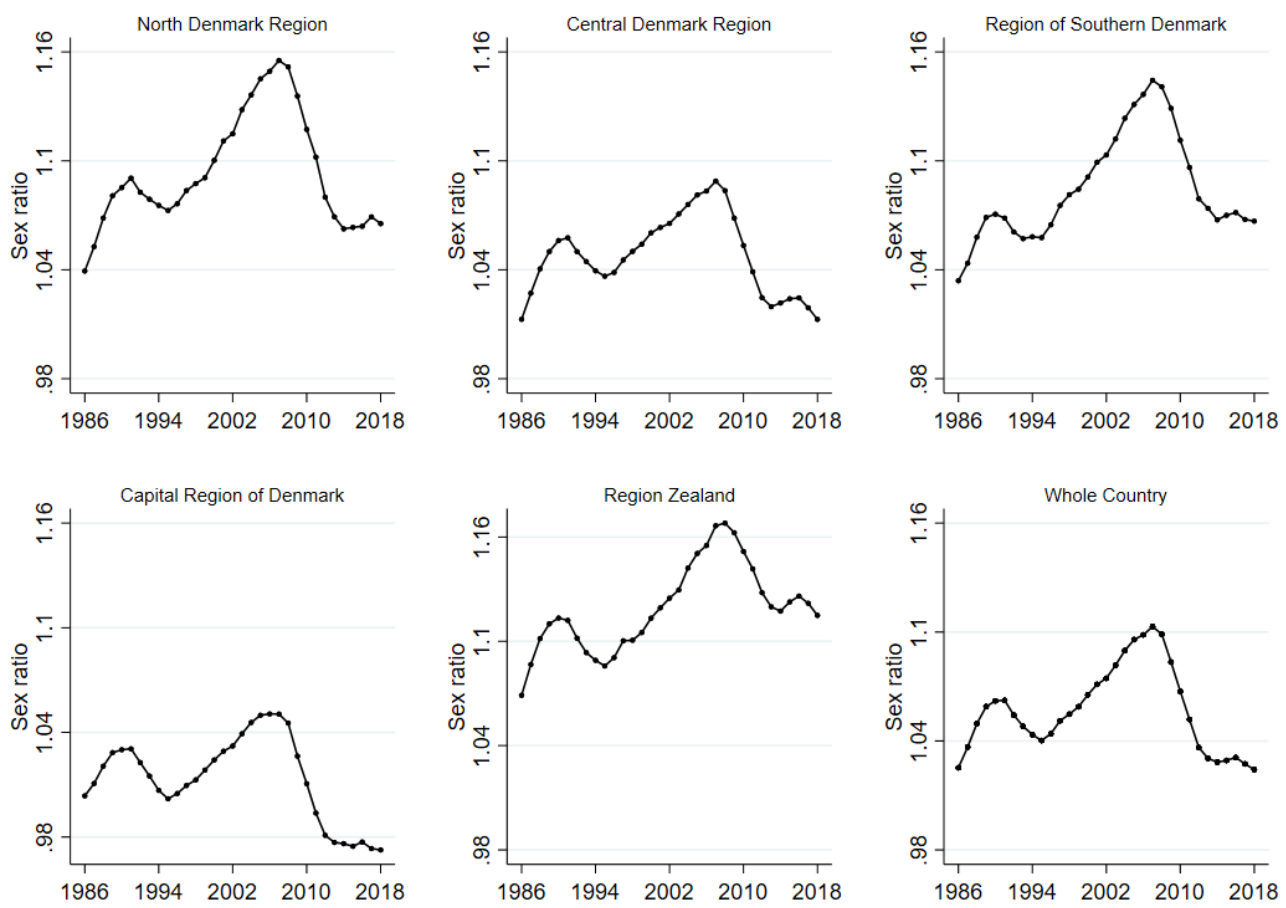
Figure A3 Surplus of characteristics in the marriage market compared to demand , 1986-2018

A: Women's marriage market
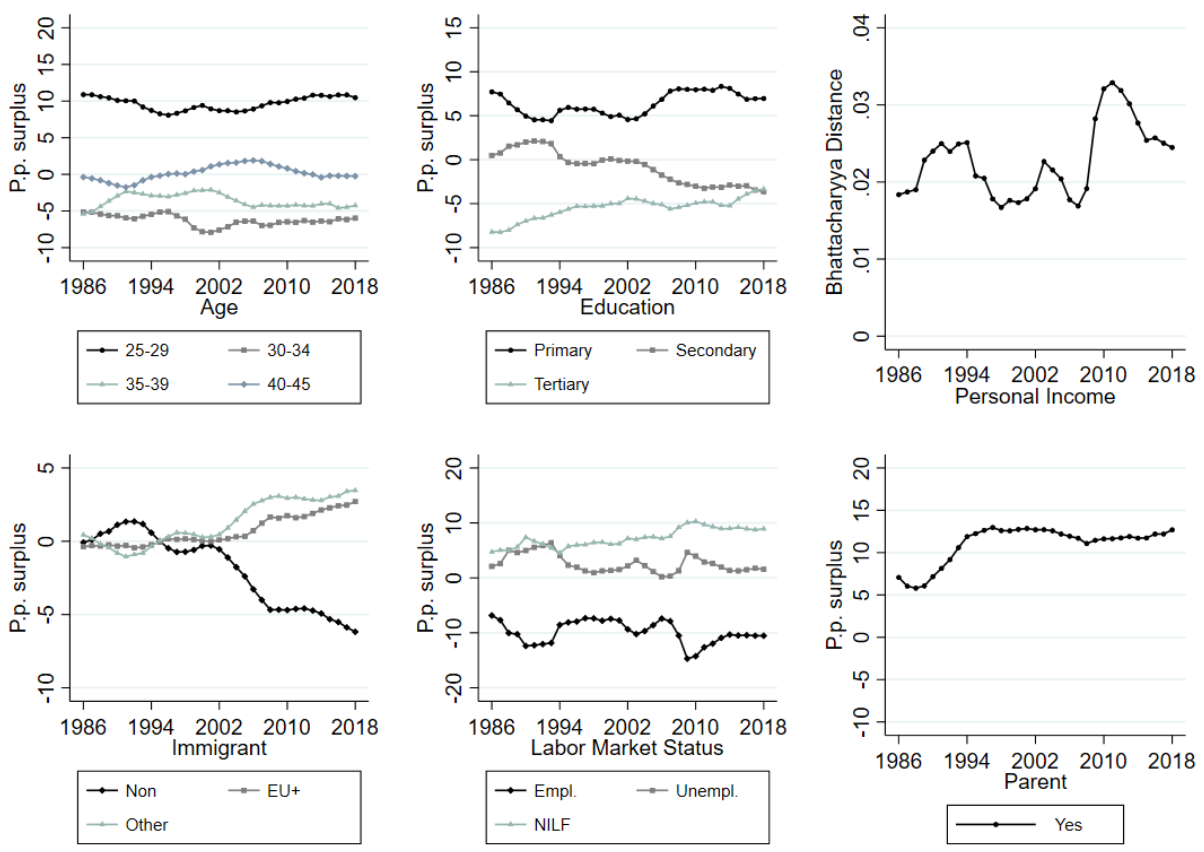

B: Men's marriage market
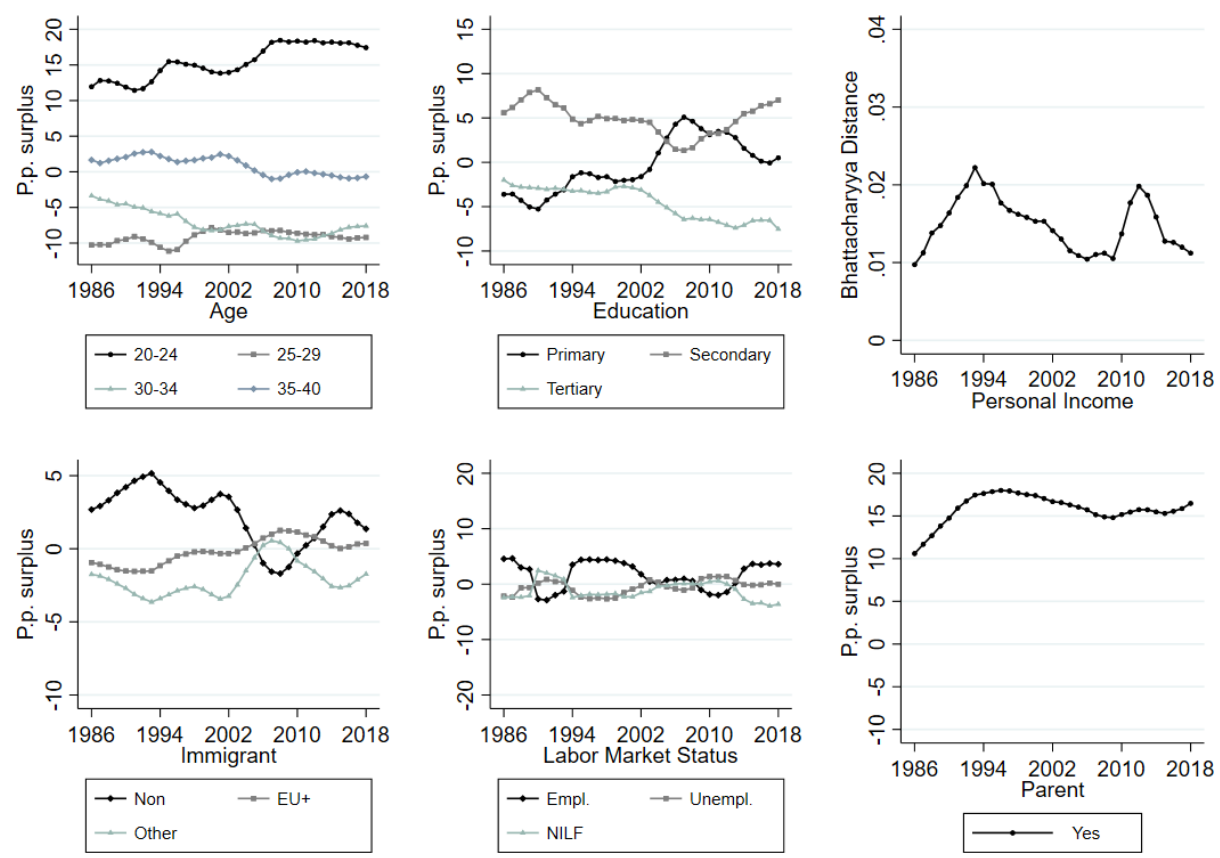

Note: Bhattacharyya distance is calculated with 250 bins. Age range of synthetic spouses restricted to 25-45 for women, 20-40 for men.

Source: Own calculations on data from Statistics Denmark. 
Figure A4 Plotting probability of match against observed probability of forming a relationship within the next five years across relationship market definitions for 1986,1993, 2000, and 2007.

A: Women
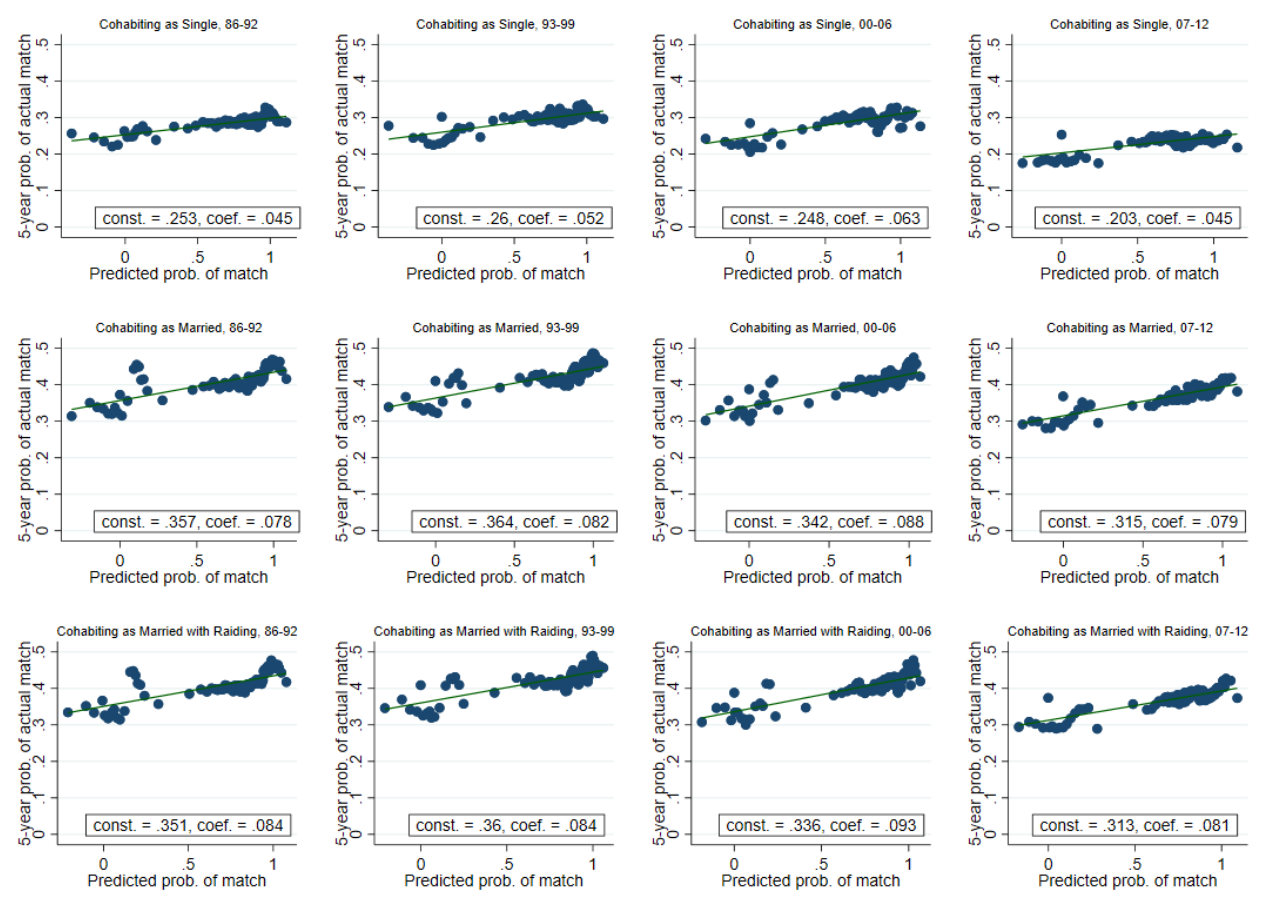

B: Men
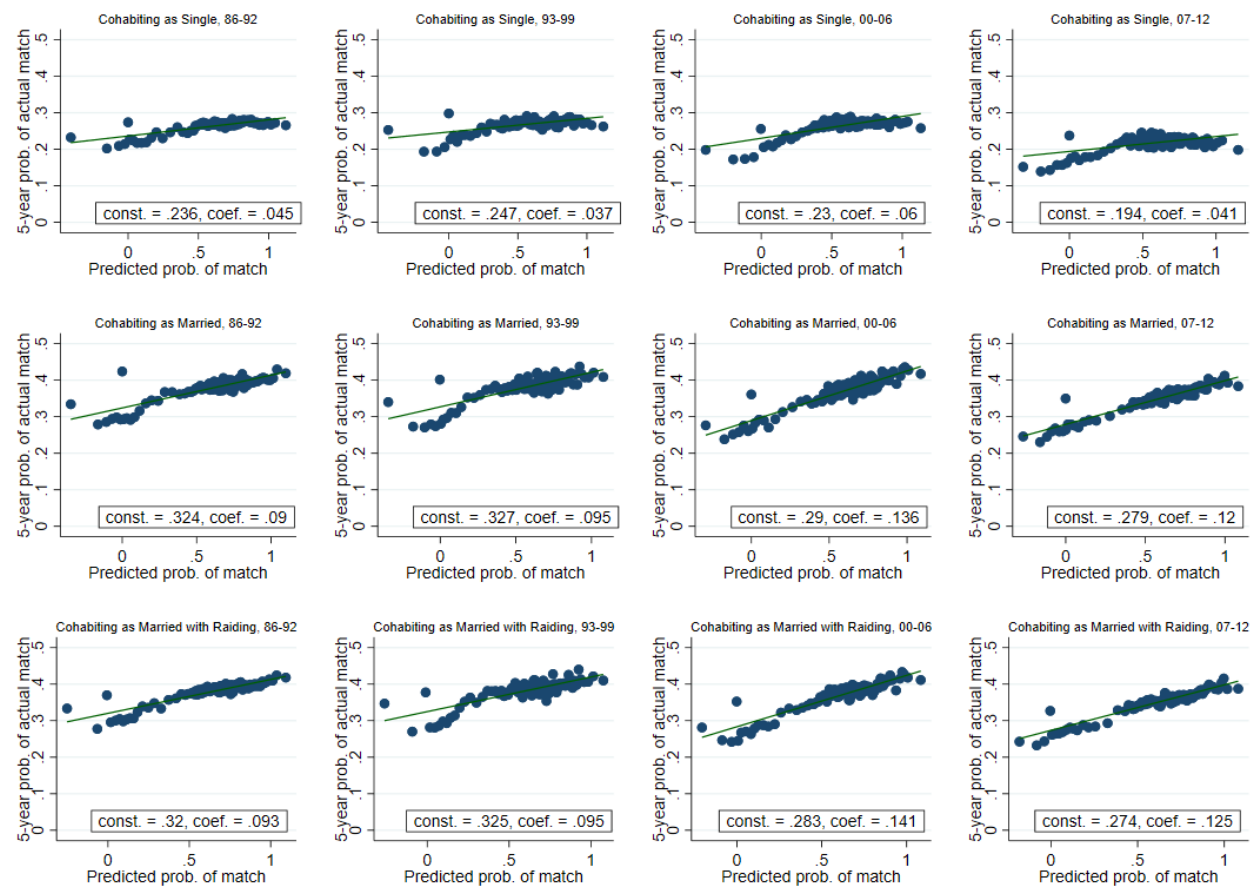

Source: Own calculations on data from Statistics Denmark.

Note: Cohabiting as married with raiding is simulated with 250 random draws. 
Figure A5 Coefficients for having a match on the marriage market, 1986-2018

A: Women's marriage market
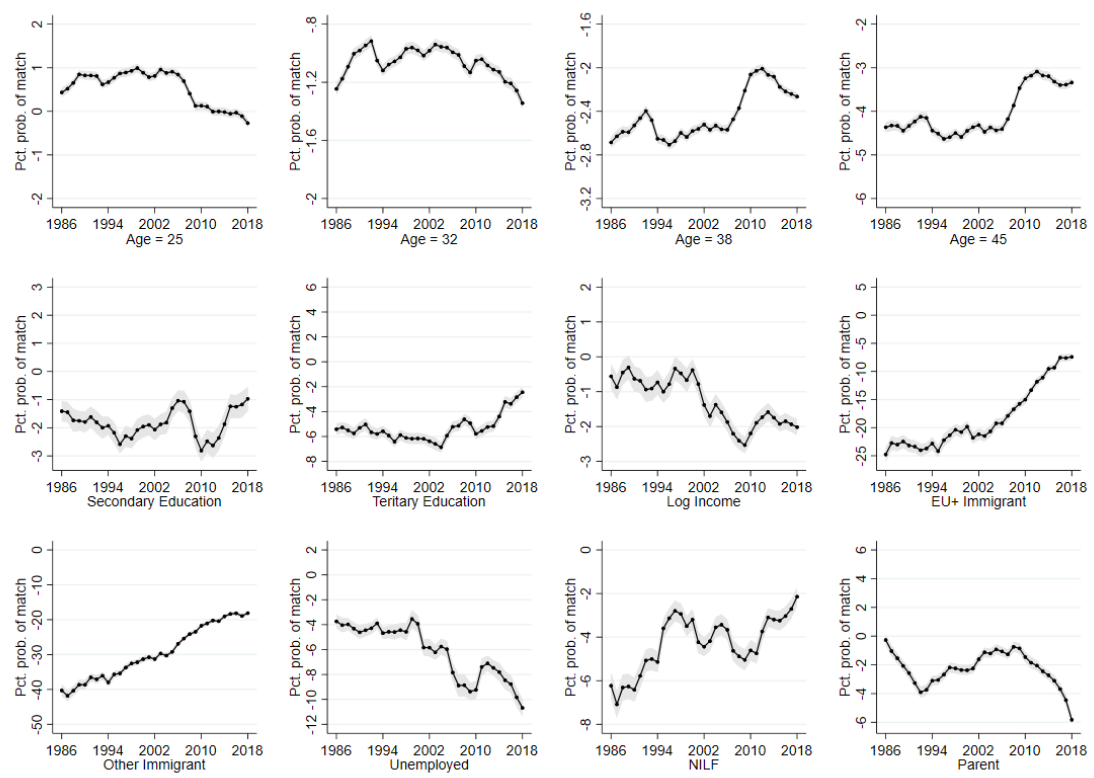

B: Men's marriage market
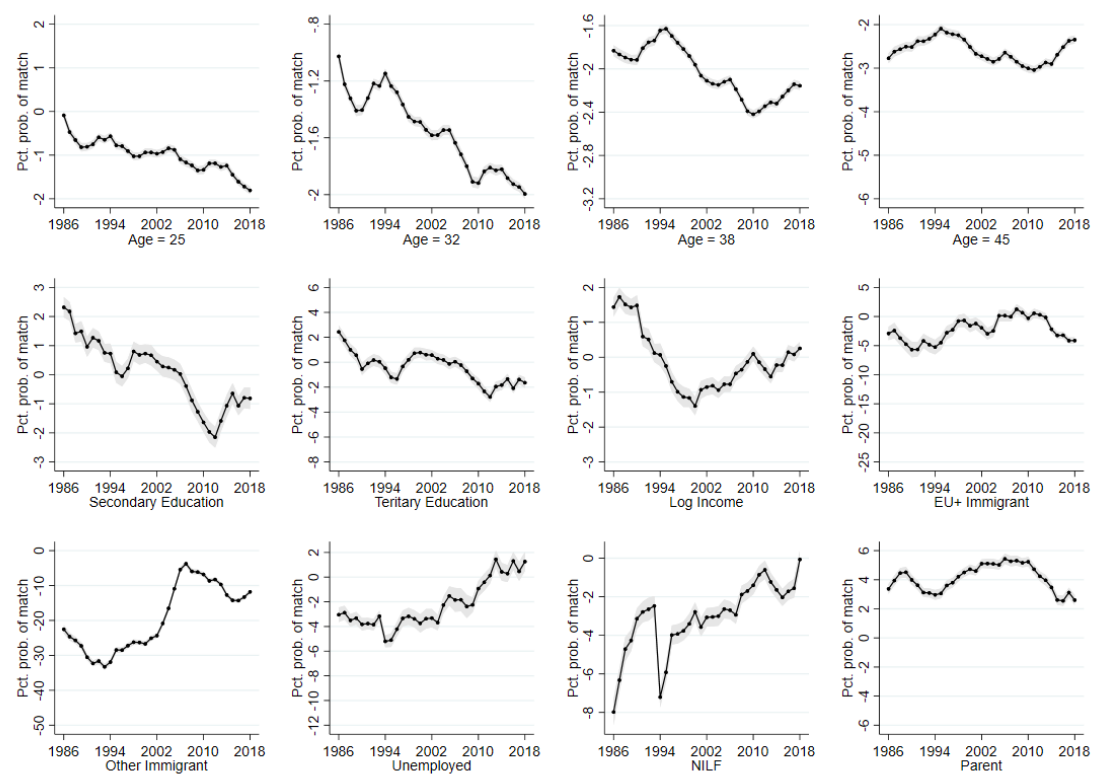

Note: Shading indicates $95 \% \mathrm{CI}$ calculated using bootstrap replication of matching procedure and estimation jointly with 250 iterations for each year. Age enters the estimation models as linear and squared terms and gross income as $\log (+1)$-transformed. For dummy variables and the income measure, we report the parameter estimates directly, for age we report the linear combination of parameters at three different ages (ages 25, 32, 38, and 45). Note differences in $\mathrm{y}$-axes across plots.

Source: Own calculations on data from Statistics Denmark. 
Figure A6 Fraction Matched 1986-2018, with supply and demand respectively held constant at values in 1986.
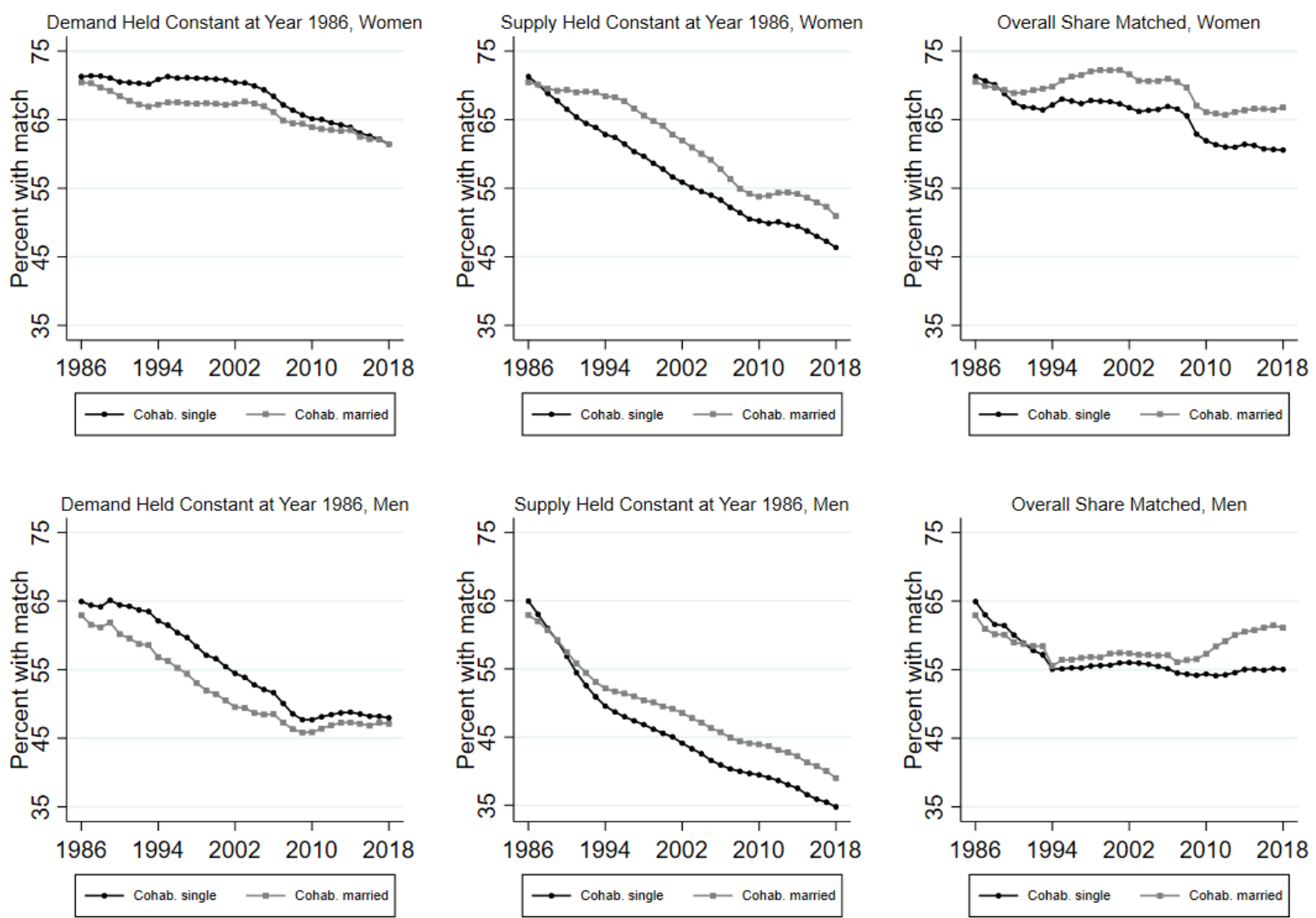
Figure A7 Surplus of characteristics in the relationship market compared to demand for women for different market definitions, with demand held constant at 1986 level, 1986-2018

\section{A: Married vs. unmarried}
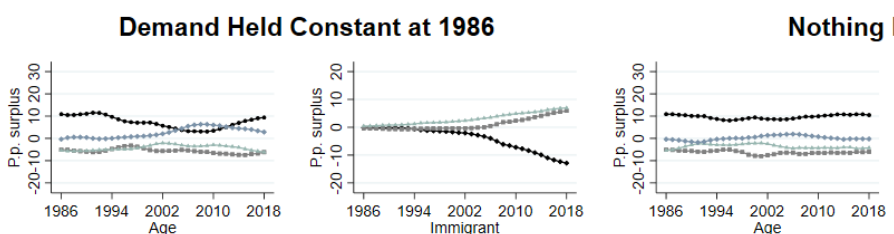

Nothing Held Constant
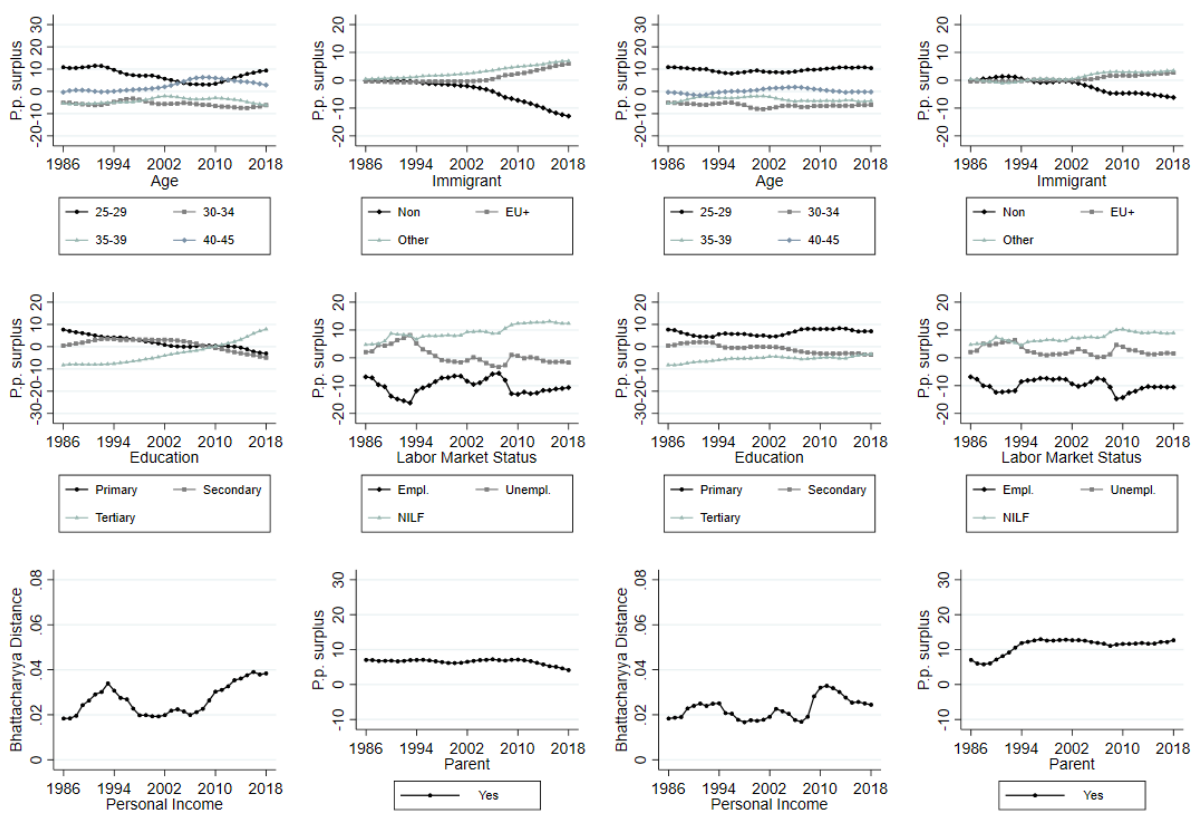

B: In relationship vs. single
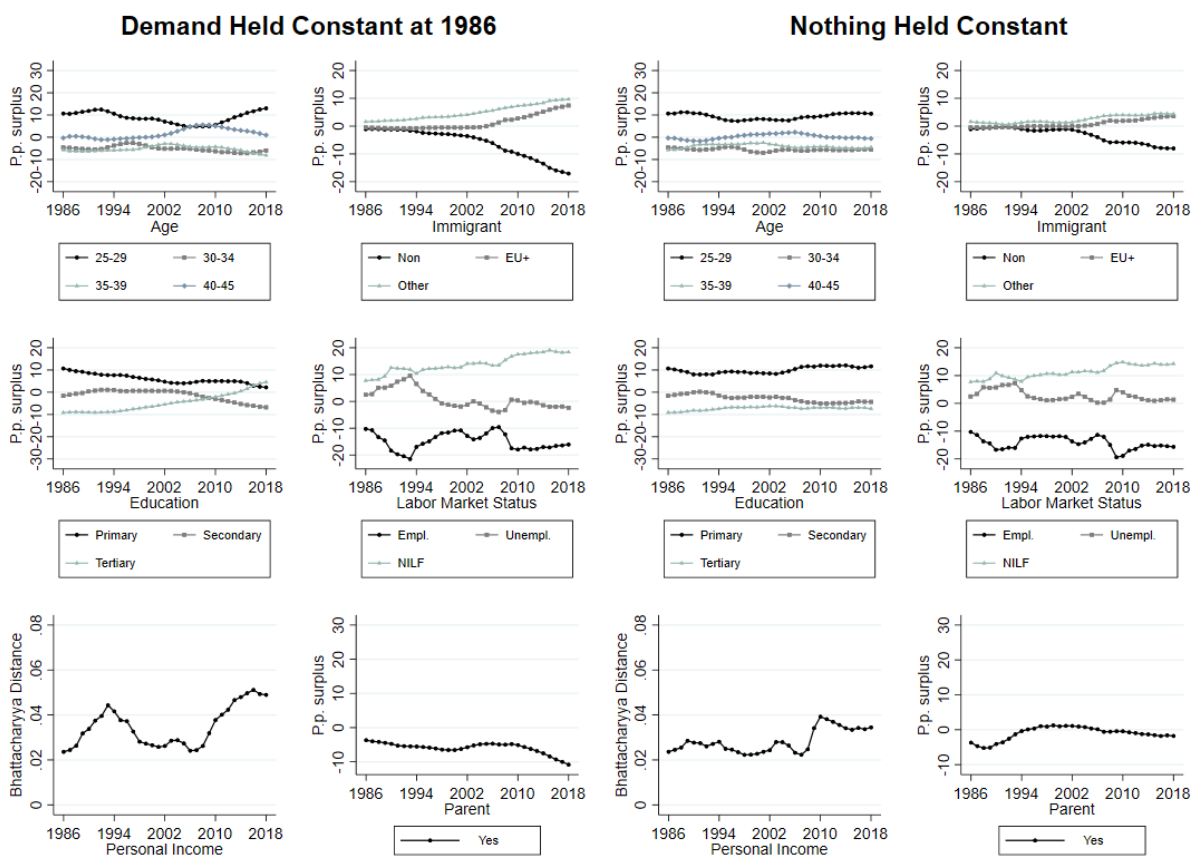
Figure A8 Surplus of characteristics in the relationship market compared to demand for men for different market definitions, with demand held constant at 1986 level, 1986-2018

A: Married vs. unmarried
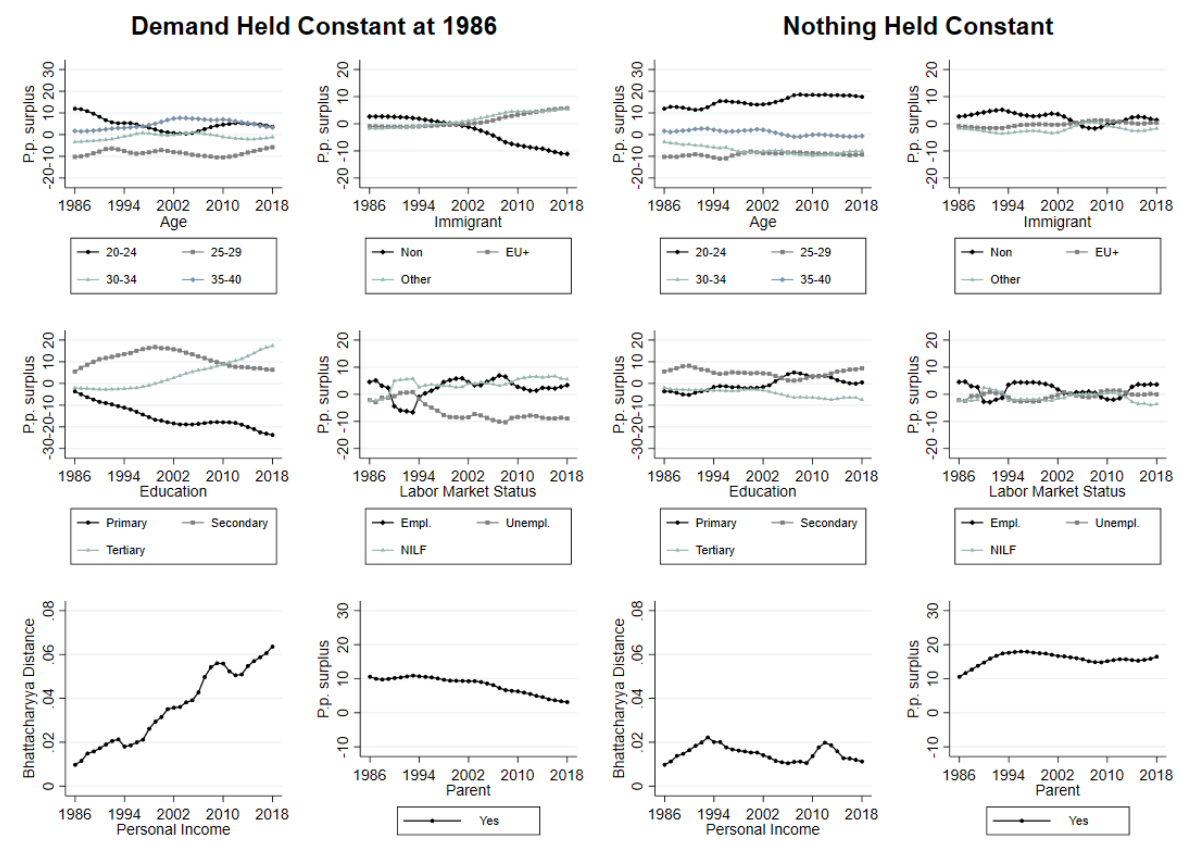

B: In relationship vs. single
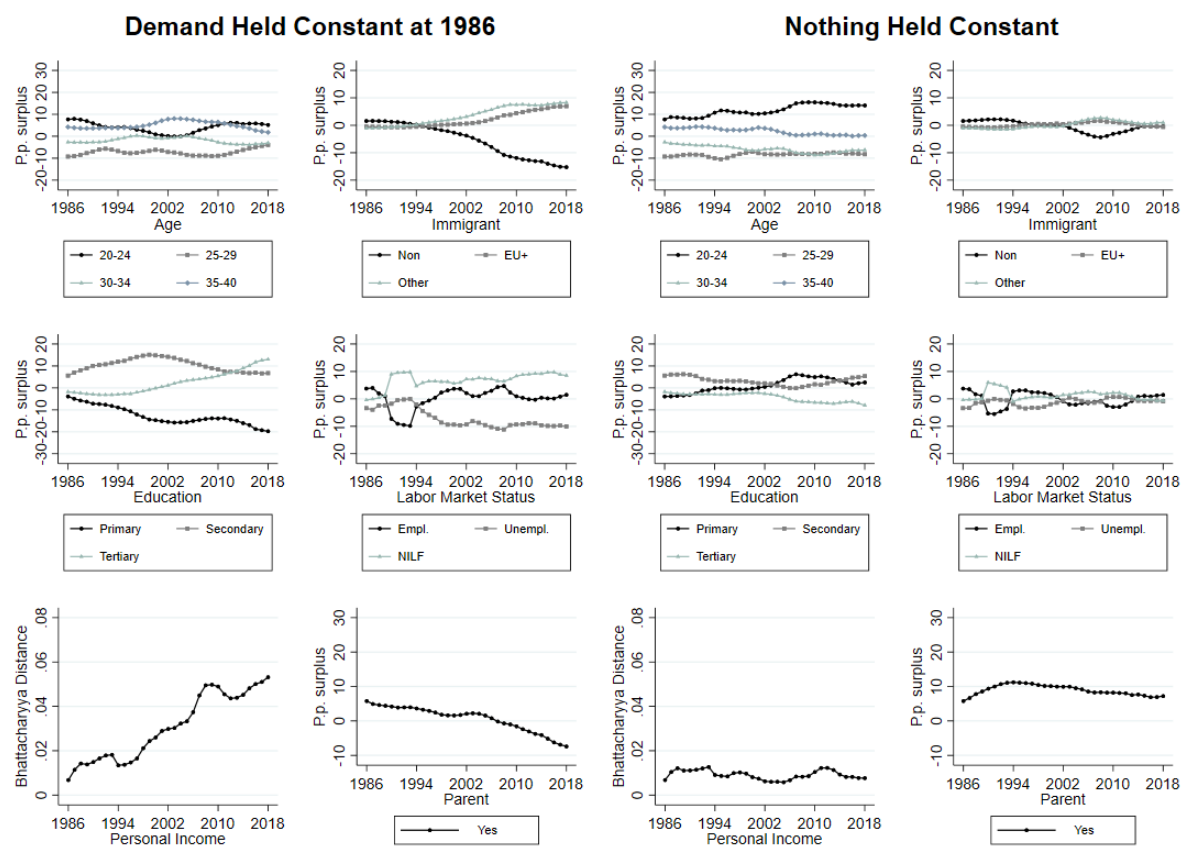
Figure A9 Surplus of characteristics in the relationship market compared to demand for women for different market definitions, with supply held constant at 1986 level, 1986-2018

A: Married vs. unmarried
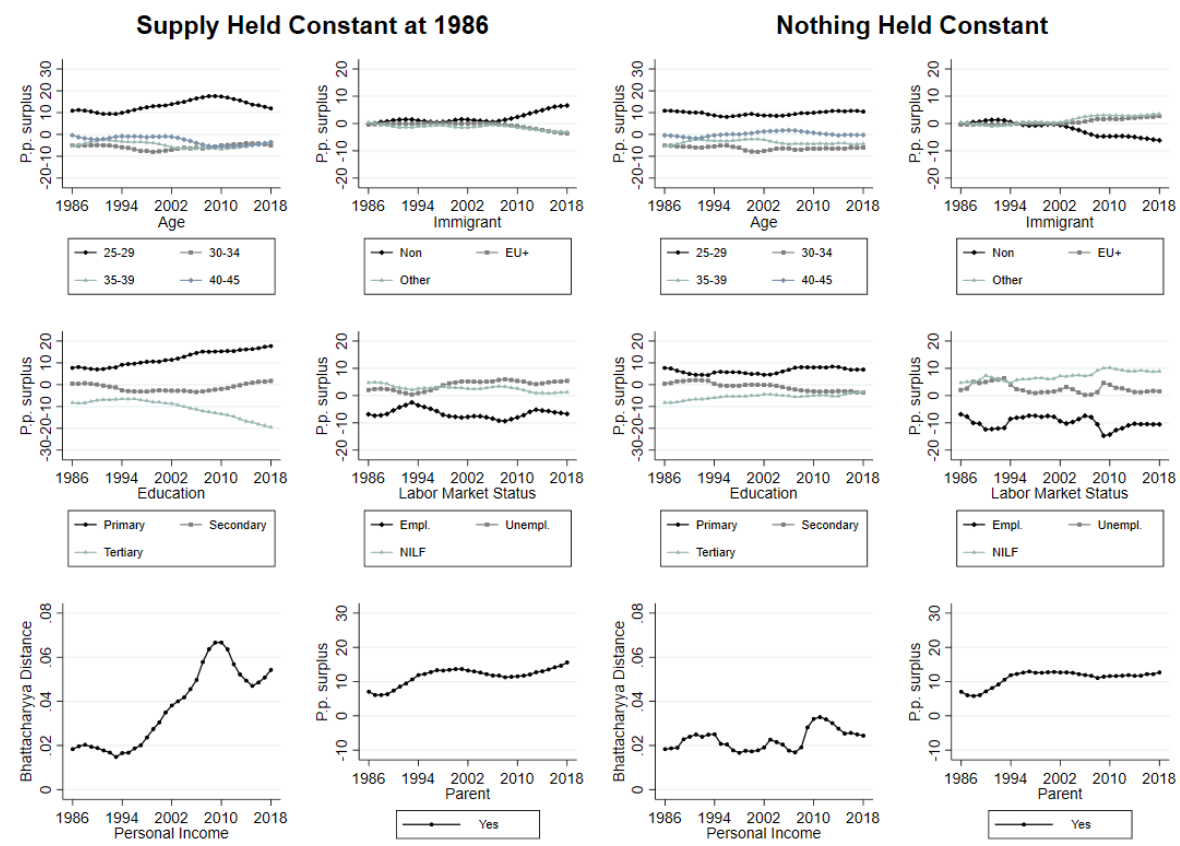

B: In relationship vs. single
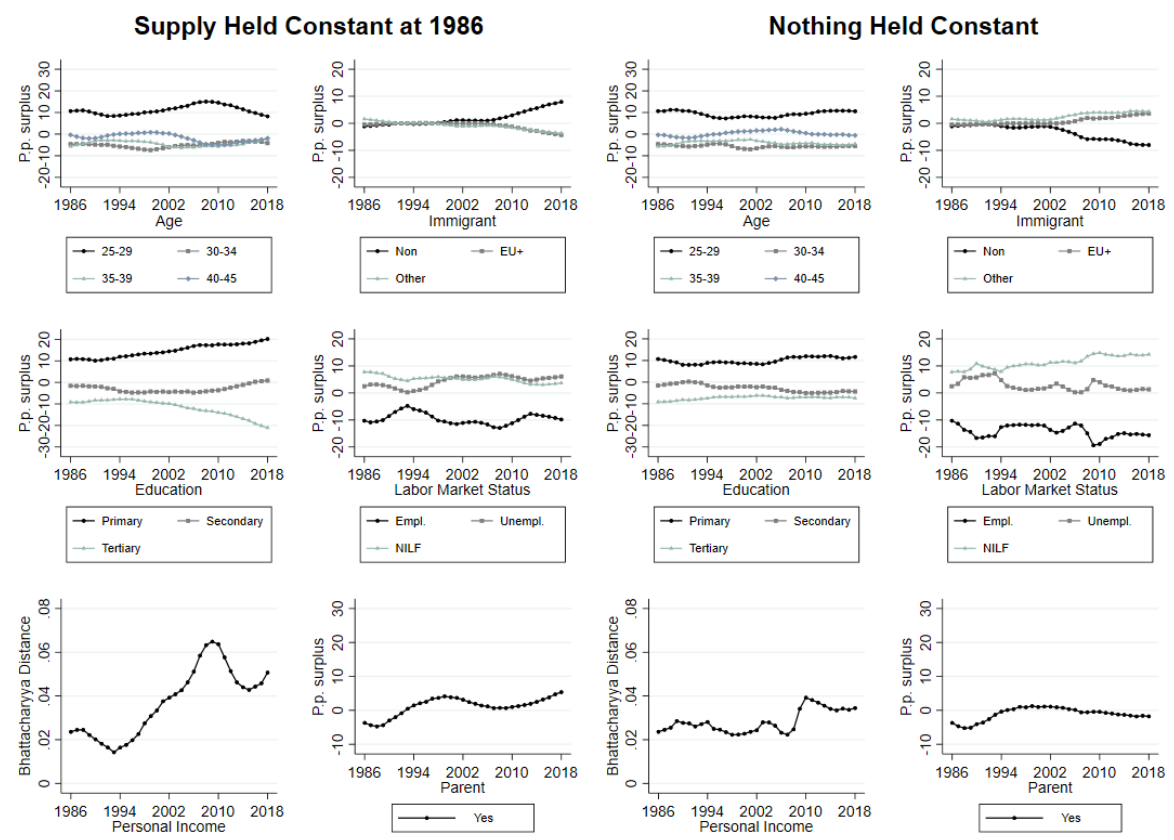
Figure A10 Surplus of characteristics in the relationship market compared to demand for men for different market definitions, with supply held constant at 1986 level, 1986-2018

A: Married vs. unmarried
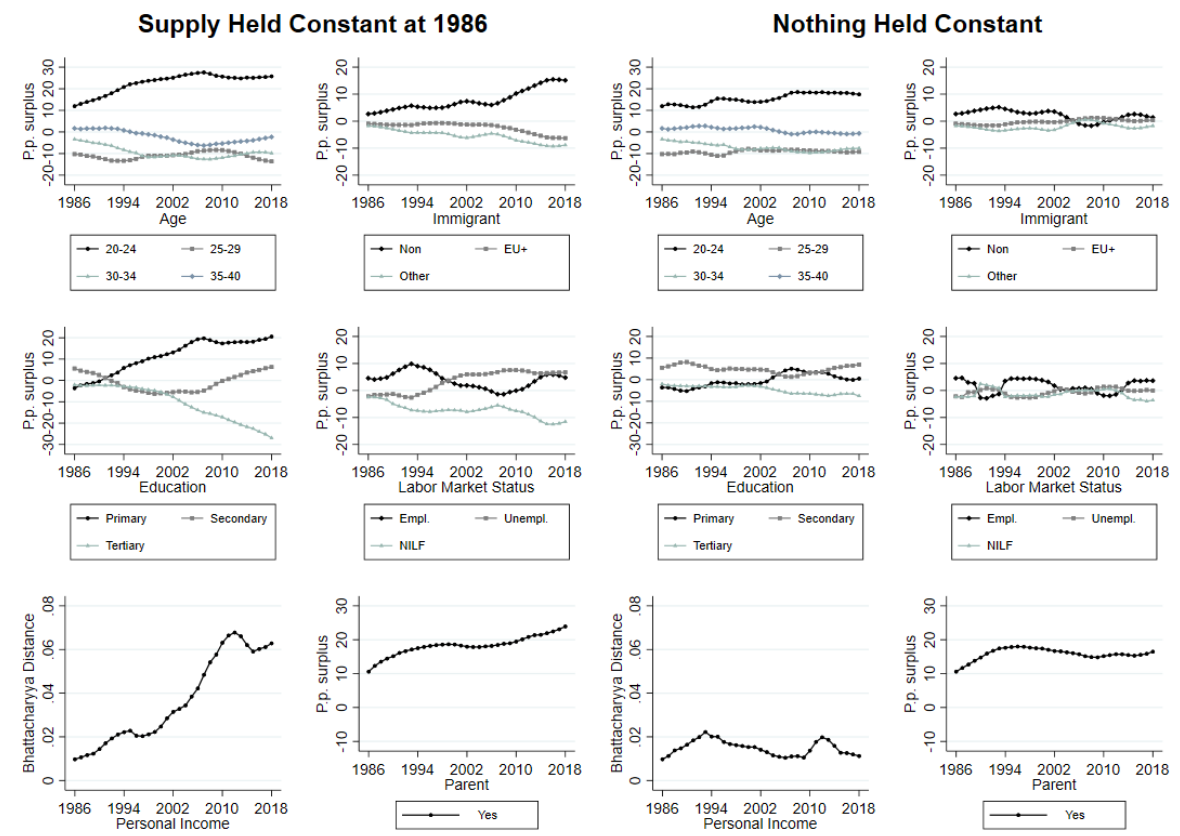

B: In relationship vs. single
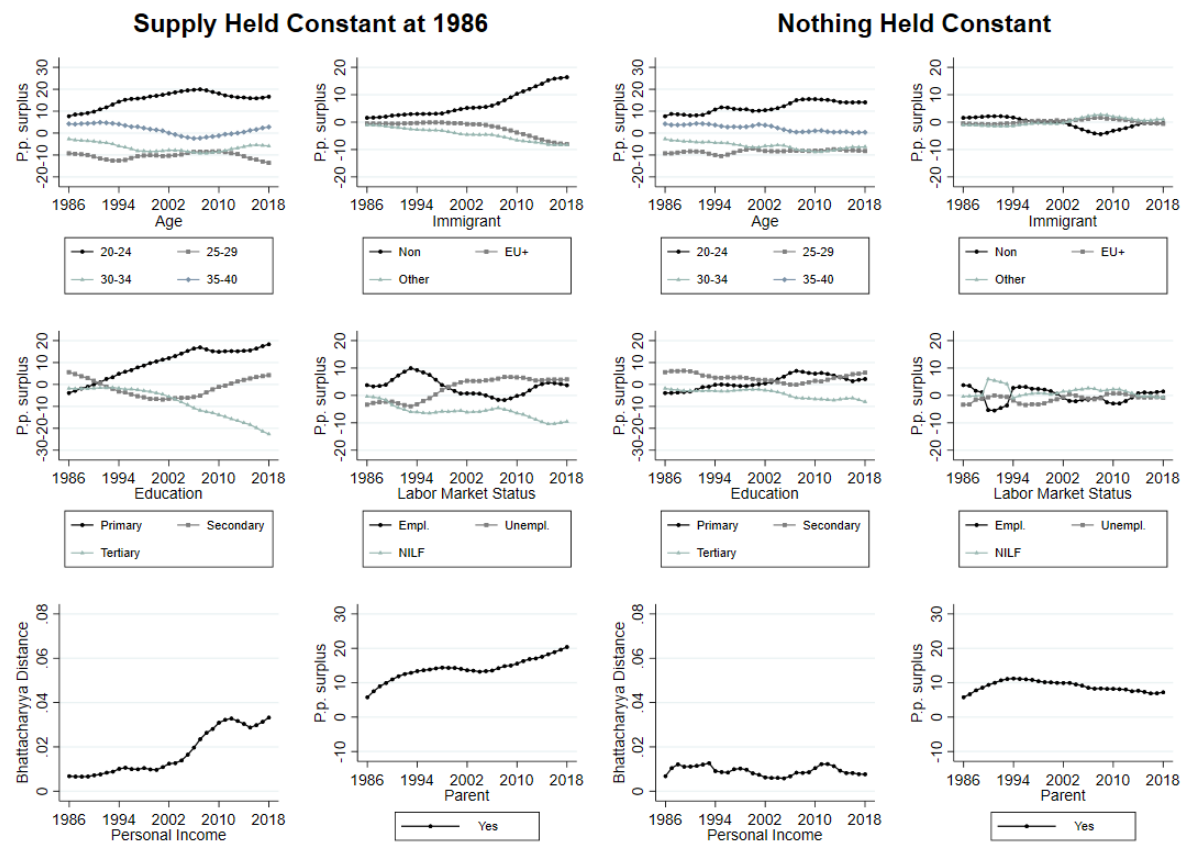
Figure A11 Fraction Matched 1986-2018, with supply and either tastes or characteristics respectively held constant at values in 1986.
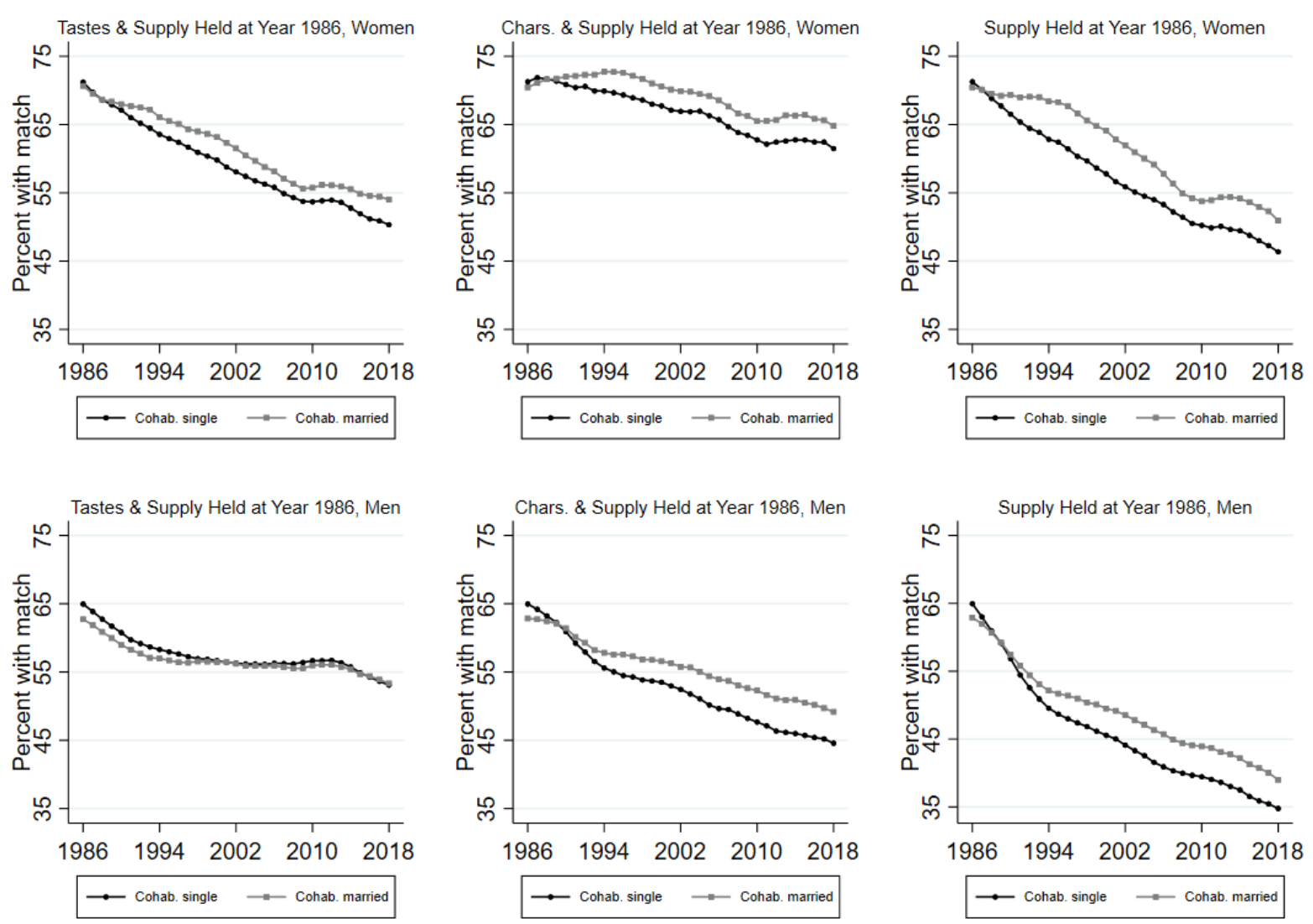
Figure A12 Surplus of characteristics in the relationship market compared to demand for women for different market definitions, with supply of men and women's tastes held constant at 1986 level, 1986-2018

\section{A: Married vs. unmarried}
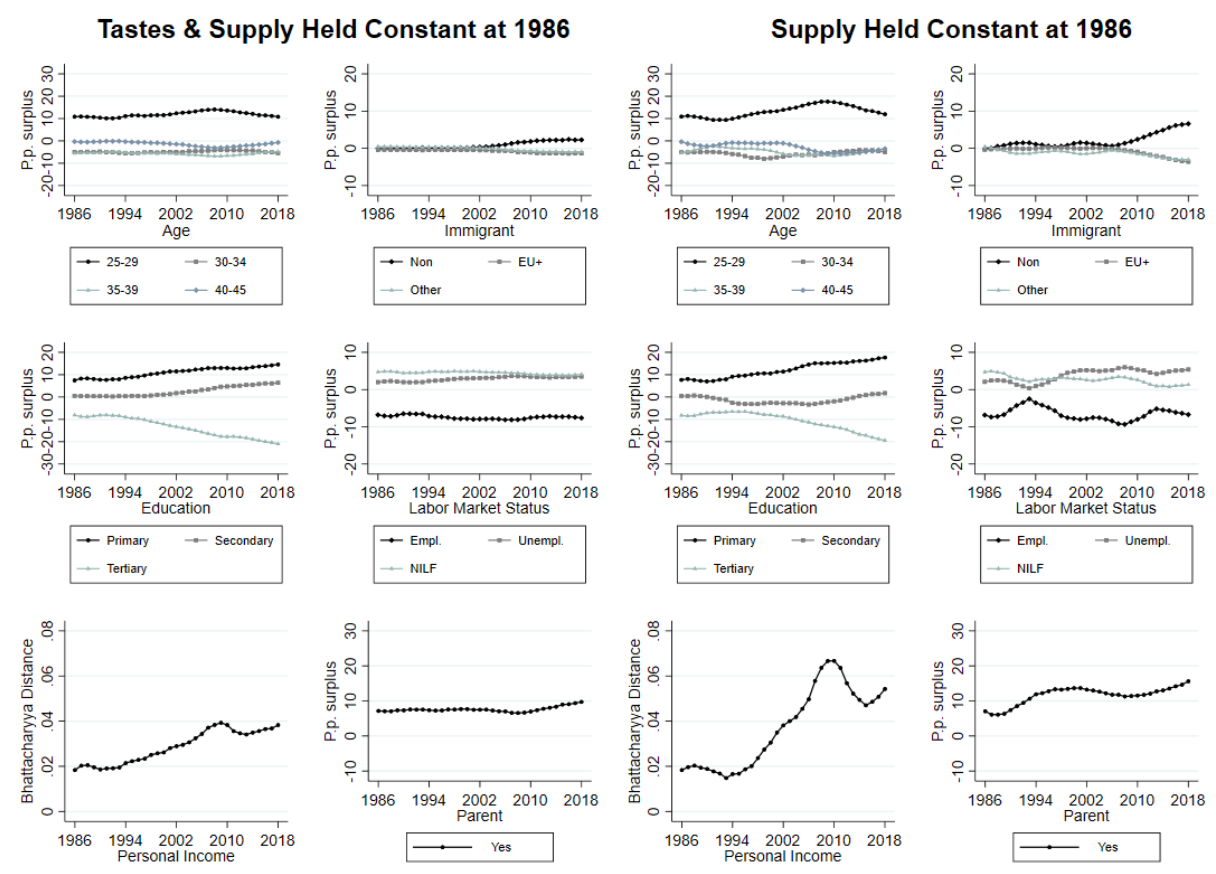

B: In relationship vs. single
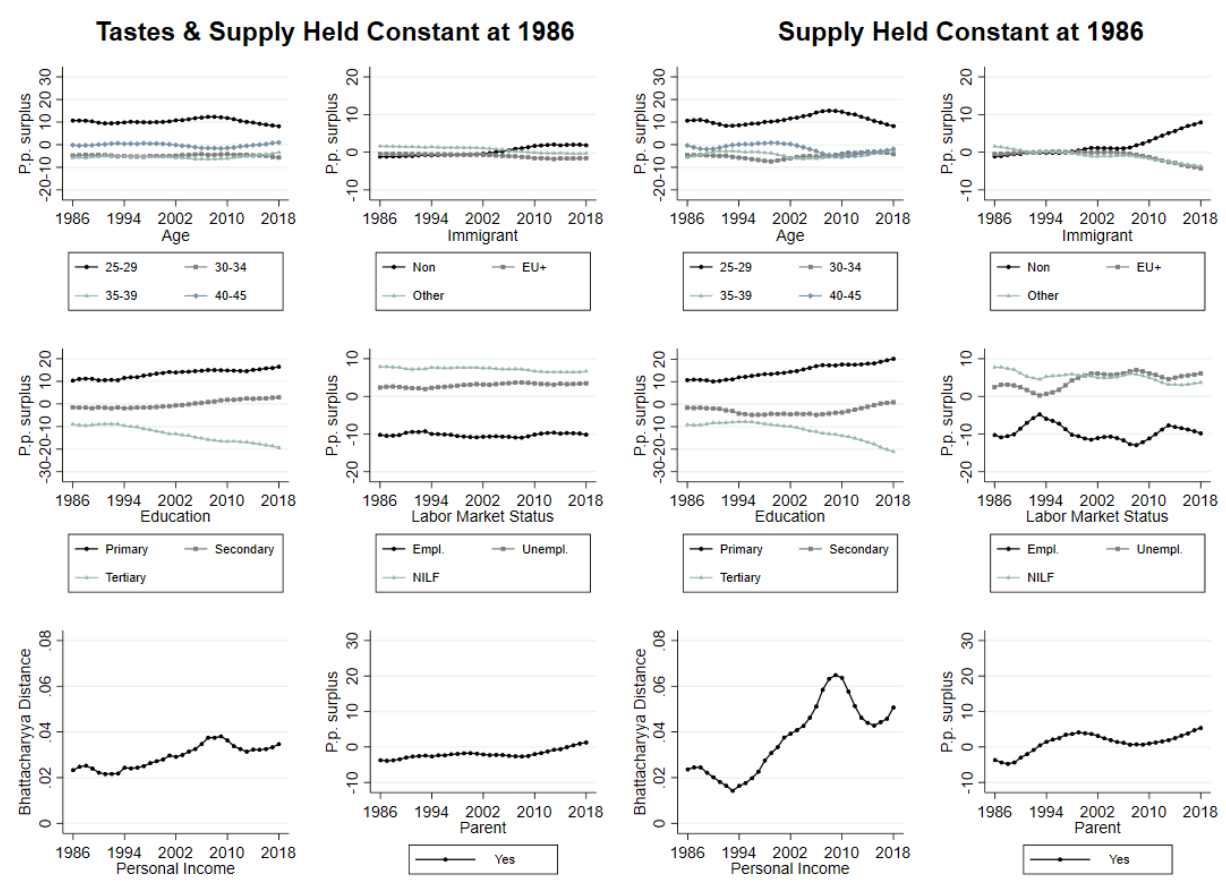
Figure A13 Surplus of characteristics in the relationship market compared to demand for men for different market definitions, with supply of women and men's tastes held constant at 1986 level, 1986-2018

\section{A: Married vs. unmarried}
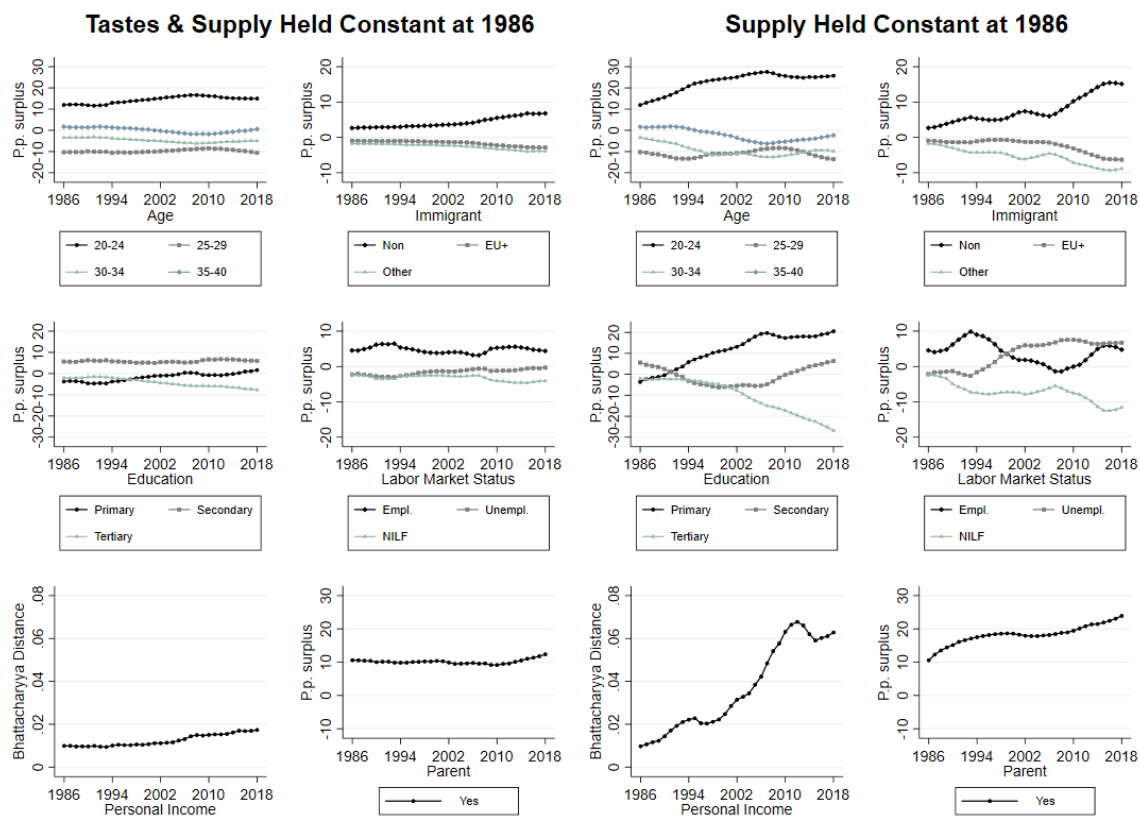

B: In relationship vs. single
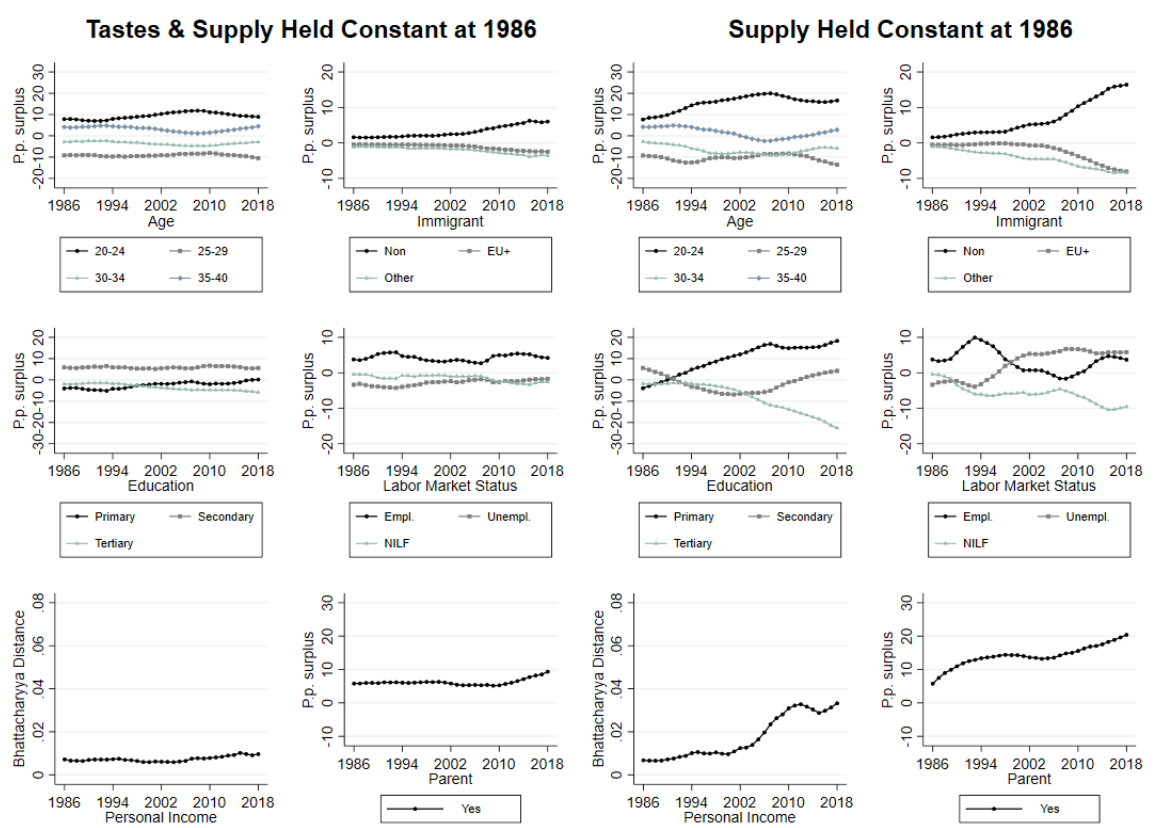
Figure A14 Surplus of characteristics in the relationship market compared to demand for women for different market definitions, with supply of men and characteristics of women held constant at 1986 level, 1986-2018

\section{A: Married vs. unmarried}
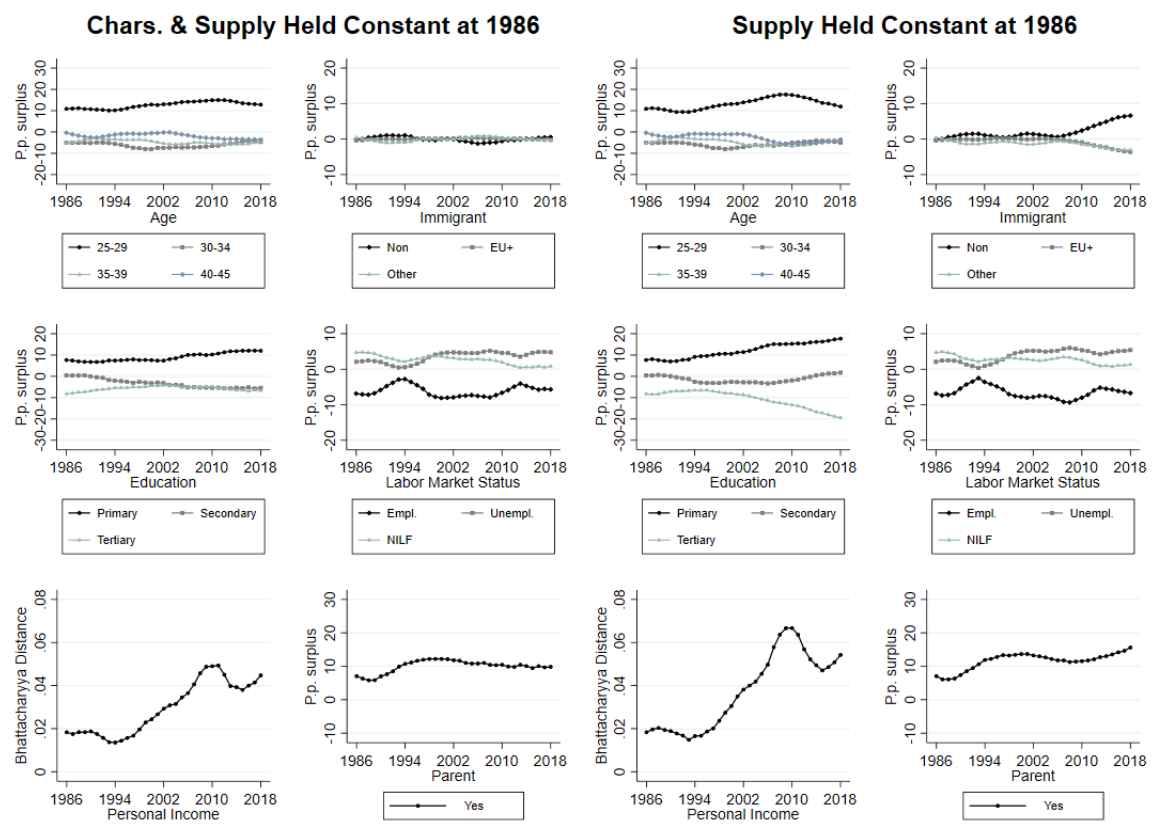

B: In relationship vs. single
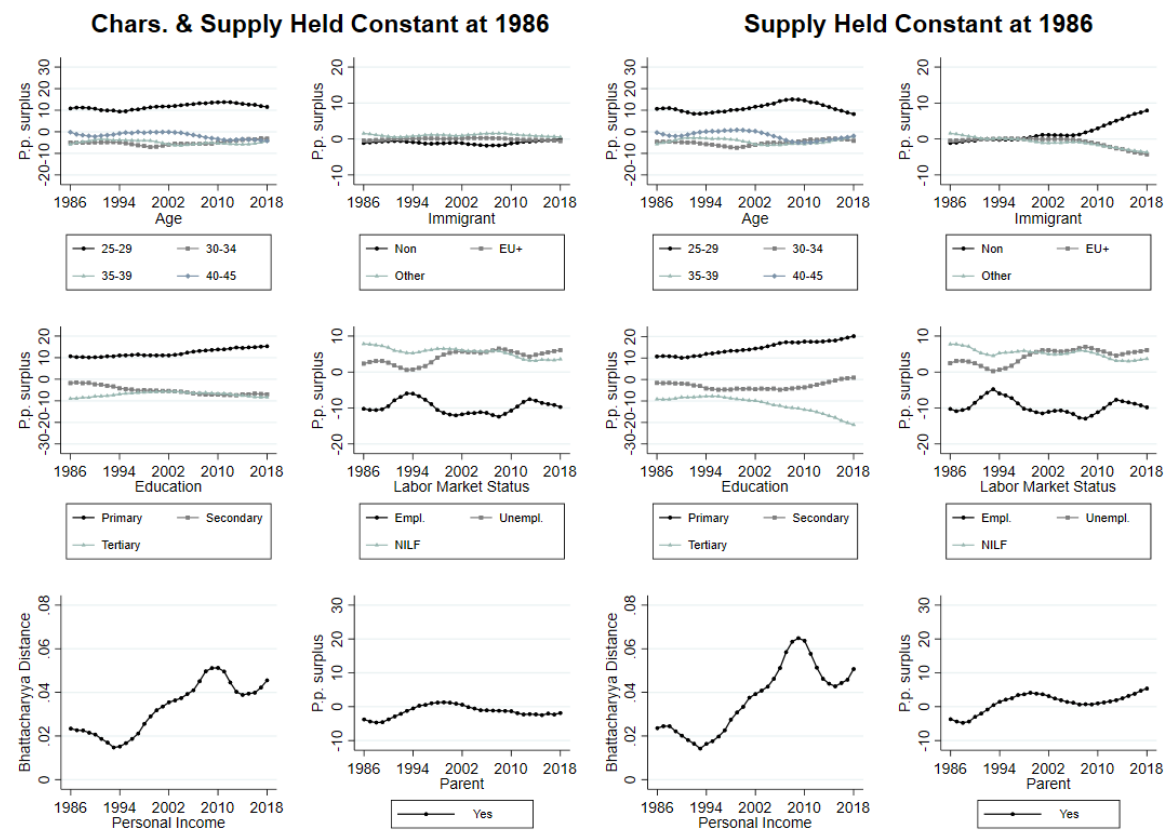
Figure A15 Surplus of characteristics in the relationship market compared to demand for men for different market definitions, with supply of women and characteristics of men held constant at 1986 level, 1986-2018

\section{A: Married vs. unmarried}
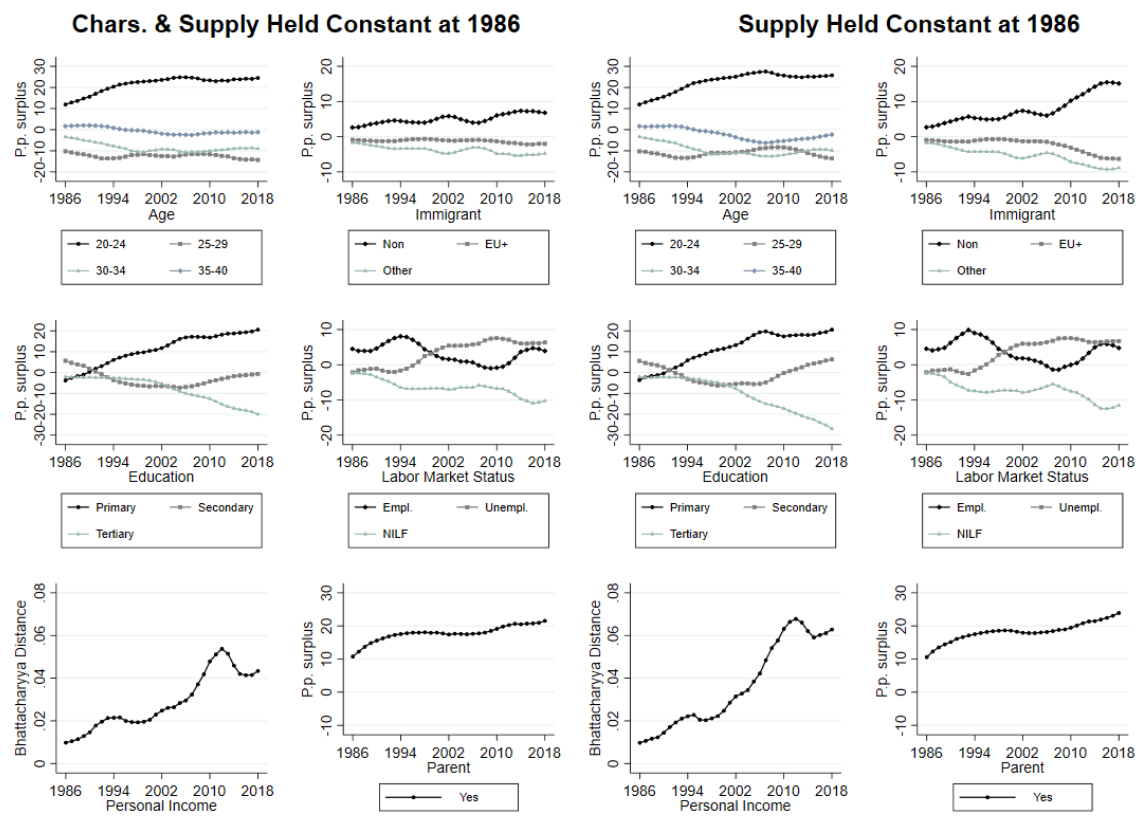

B: In relationship vs. single
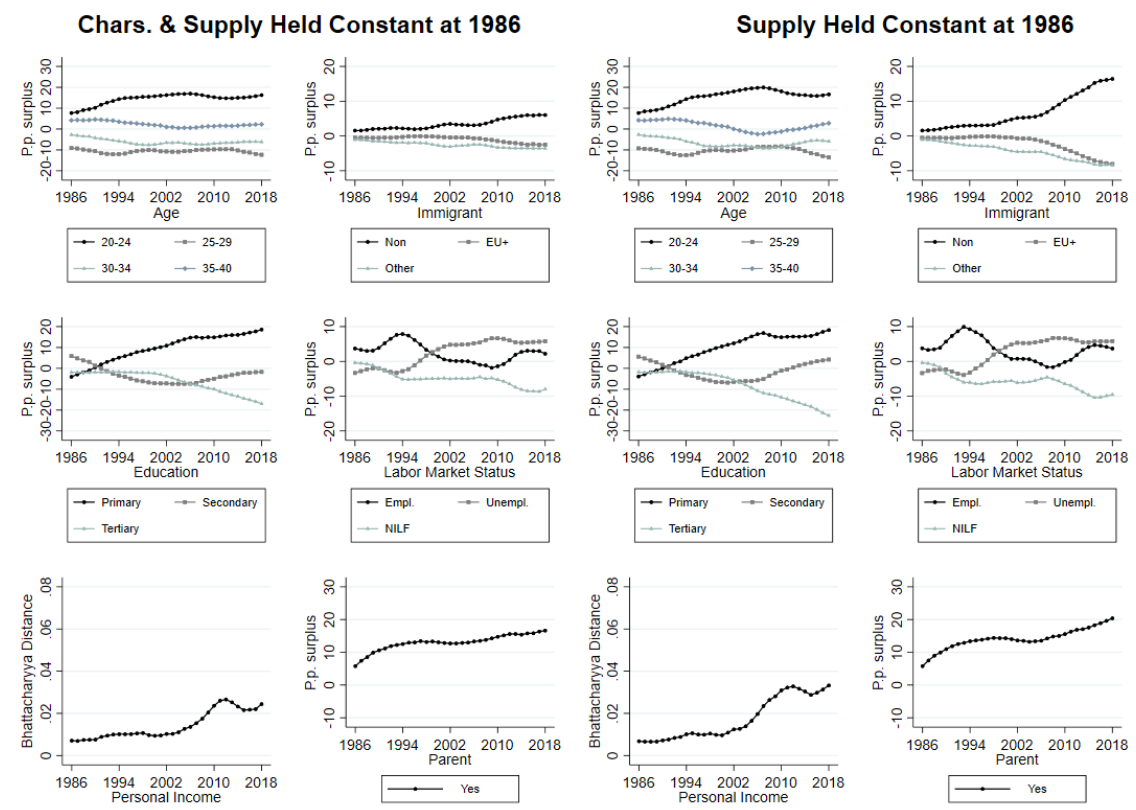
Figure A16 Time series graphs 1986-2018 for women, mean-imputation

\section{A: Married vs. unmarried}
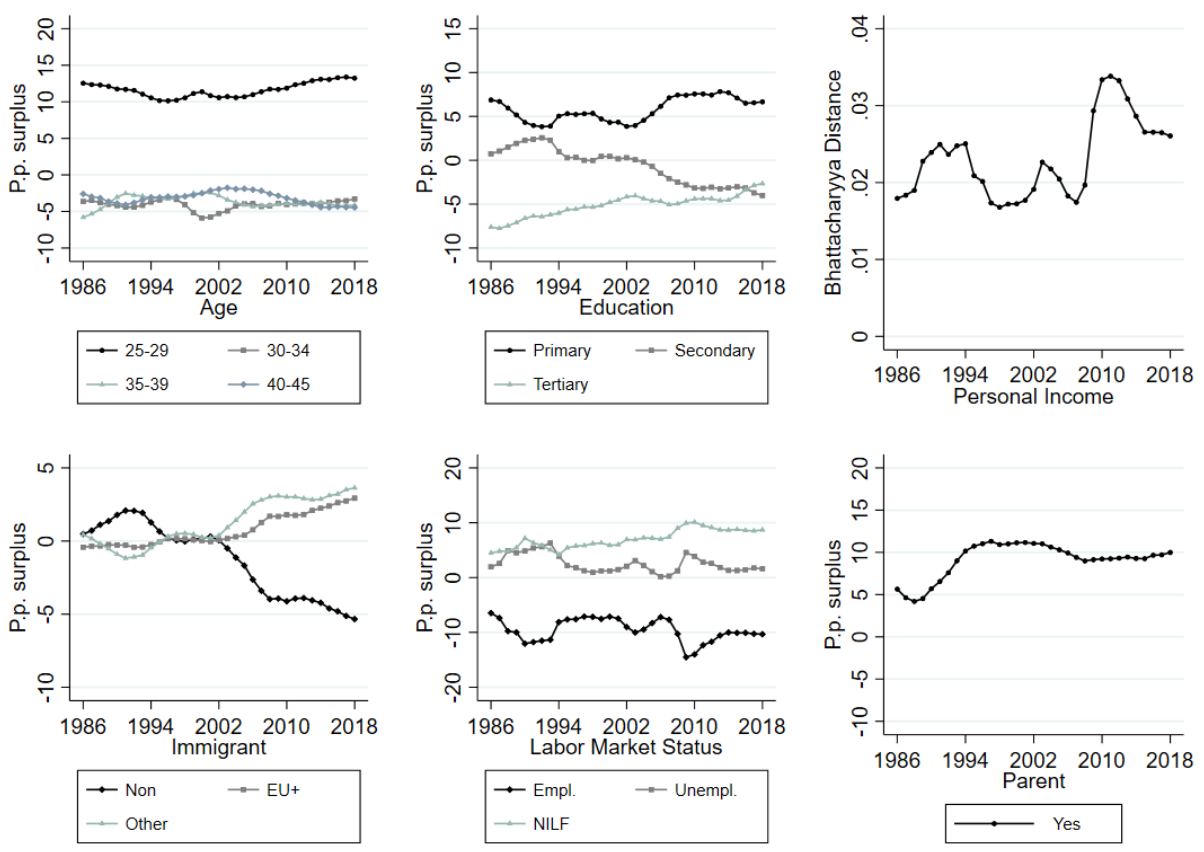

B: In relationship vs. single
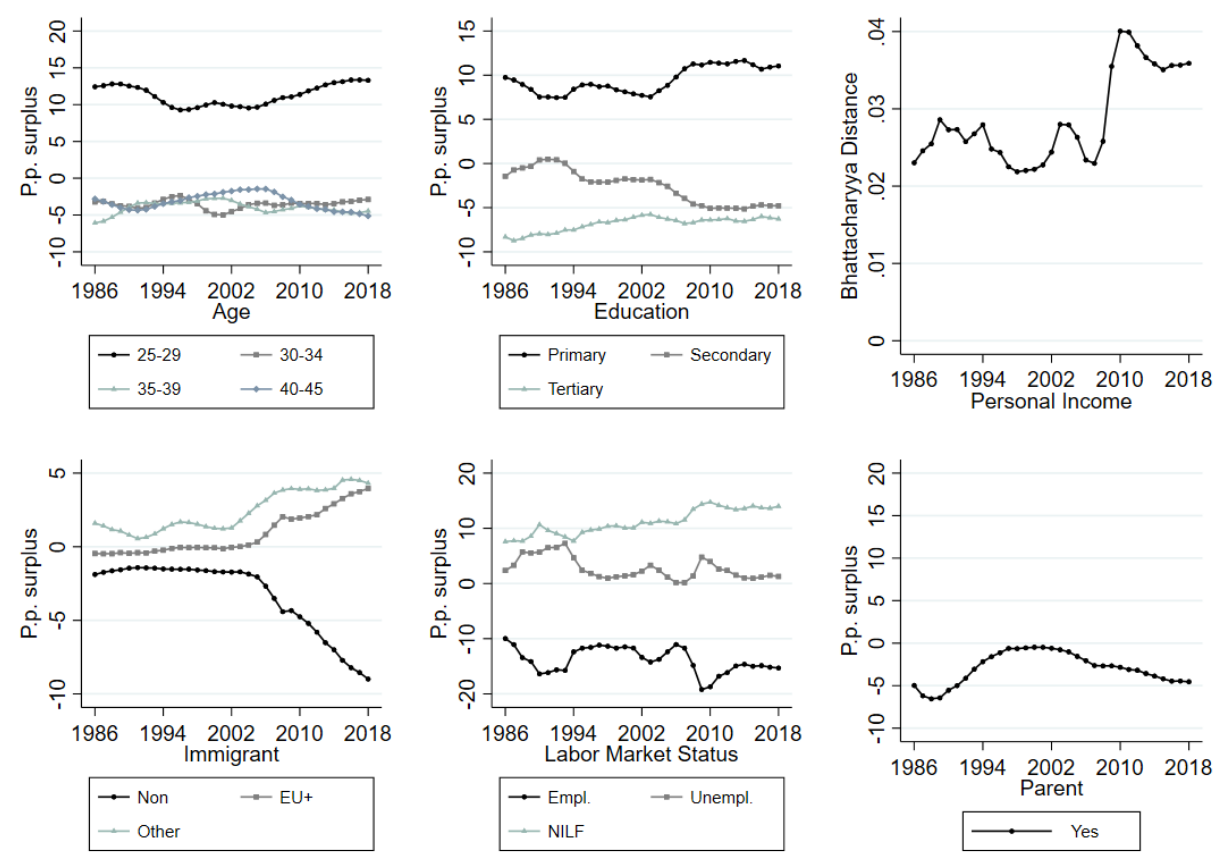
Figure A17 Time series graphs 1986-2018 for men, mean-imputation

\section{A: Married vs. unmarried}
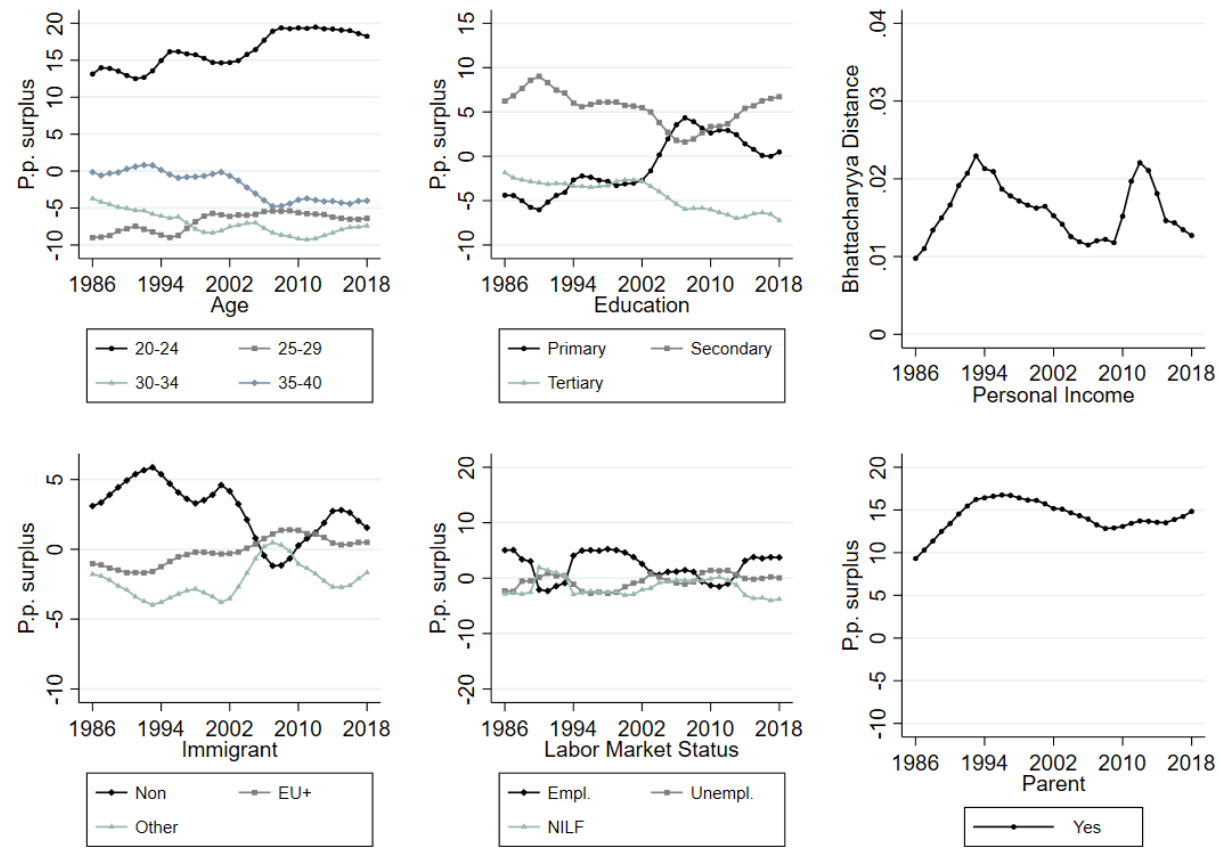

B: In relationship vs. single
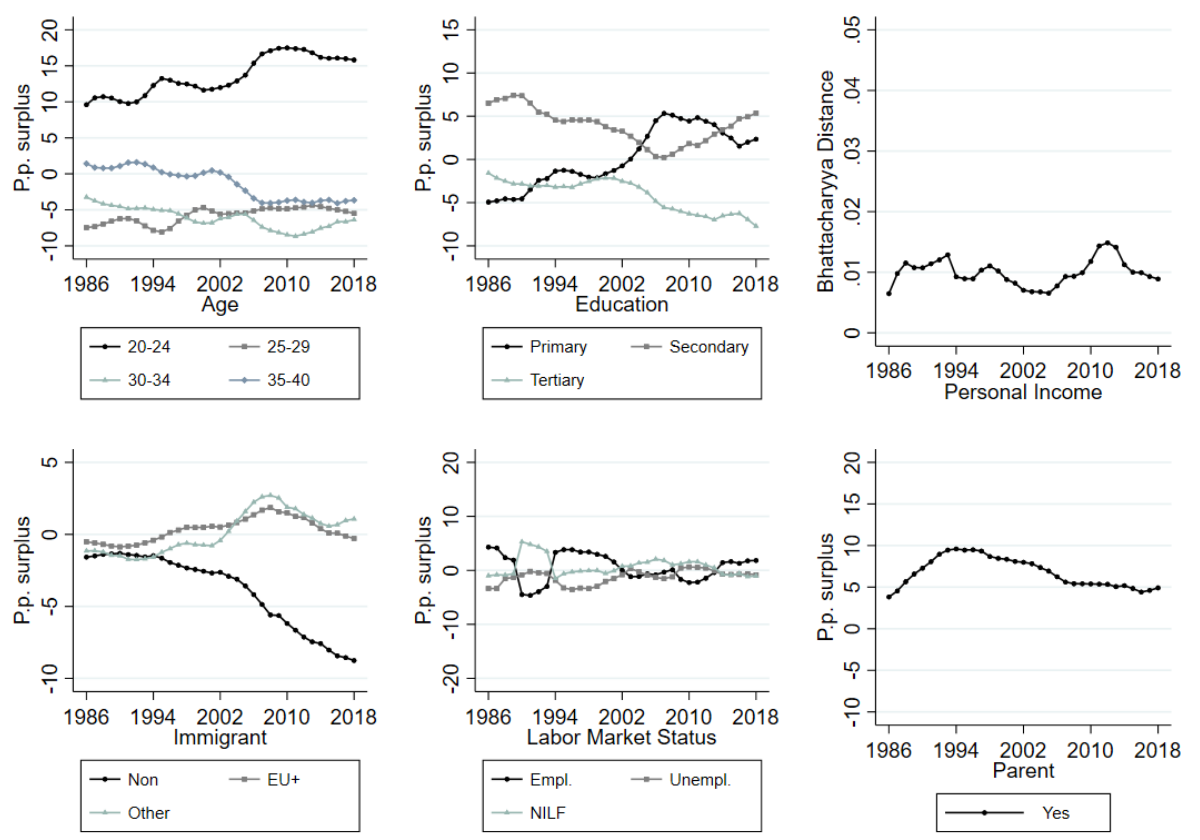
Figure A18 Percentage with a successful match over time with education specified alternatively A: Women

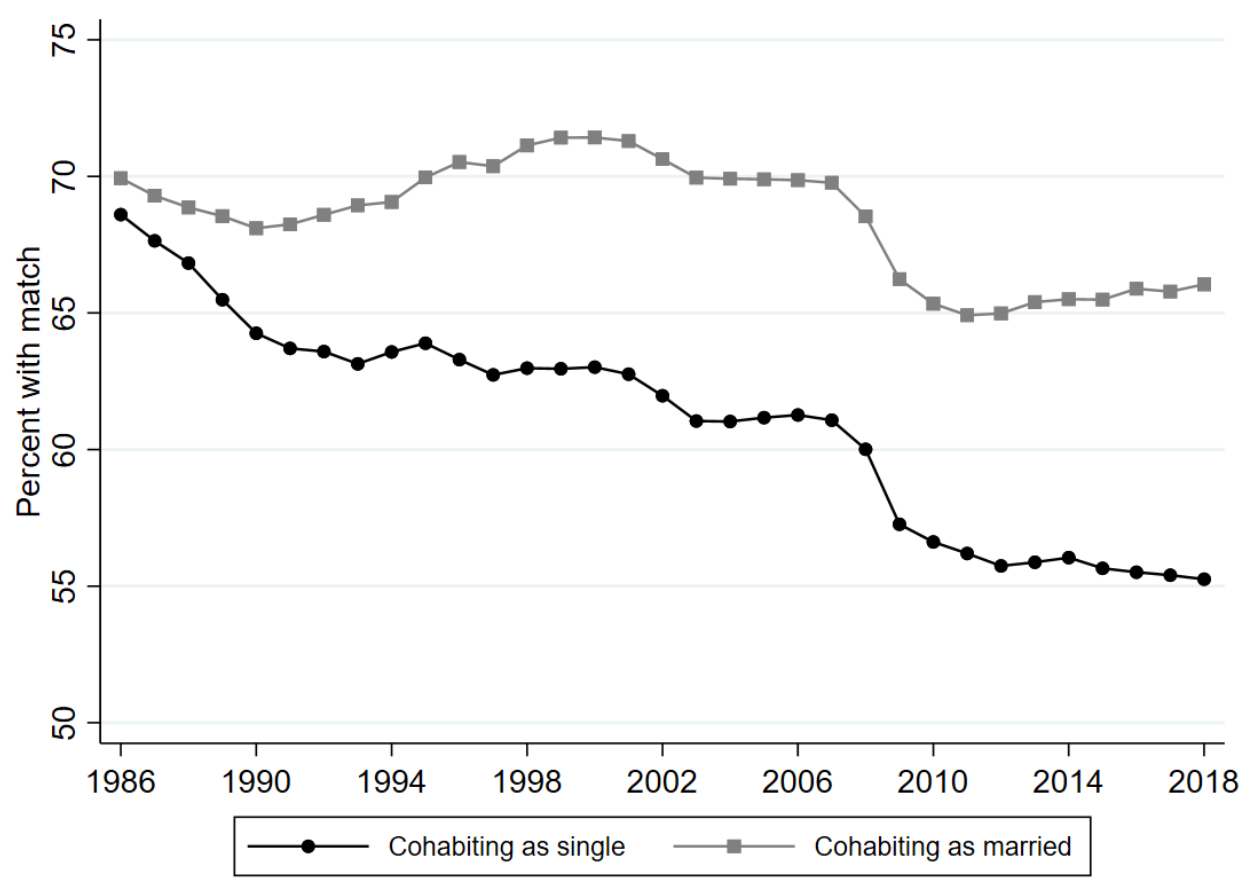

B: Men

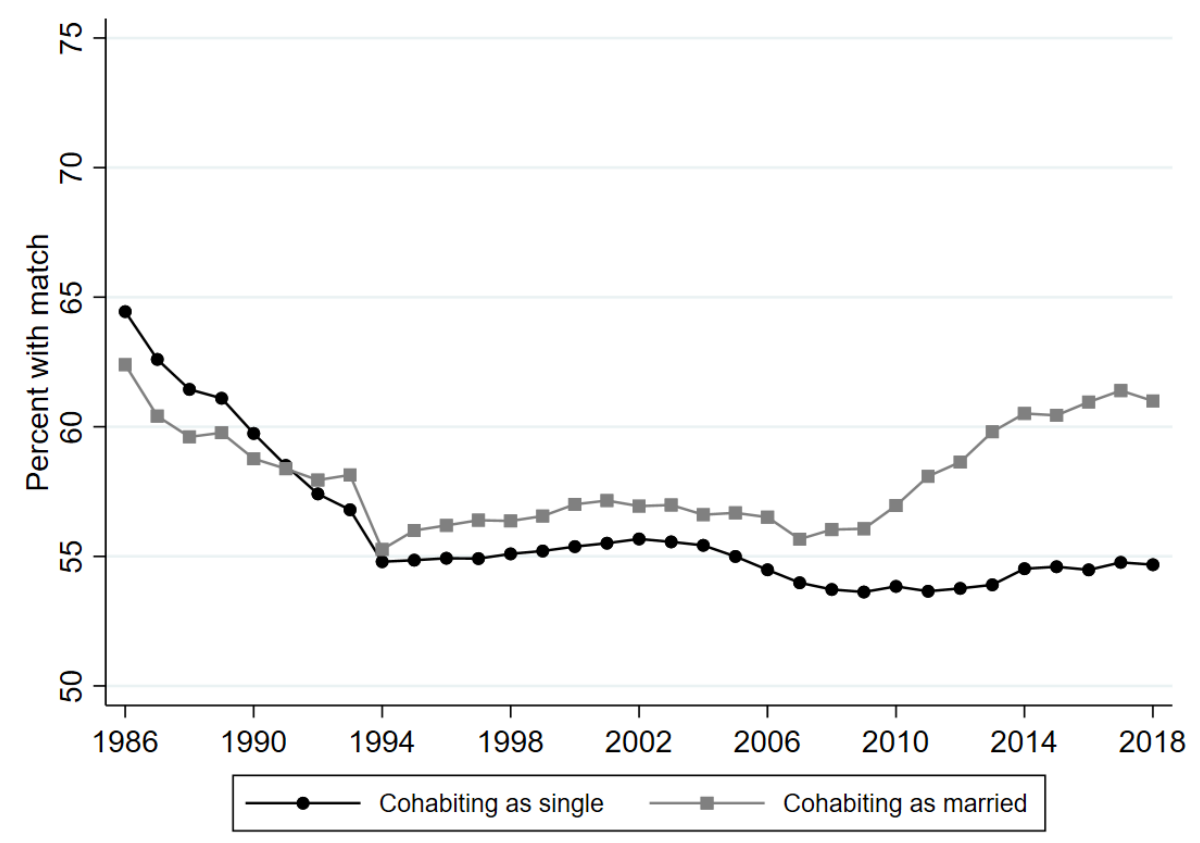

Note: Matches between synthetic and actual potential partners (spouses) forced to be within the same NUTS2 region.

Source: Own calculations on data from Statistics Denmark 
Figure A19 Surplus of characteristics, with education specified alternatively, in the marriage and relationship market compared to demand for women for different market definitions, 1986-2018

\section{A: Married vs. unmarried}
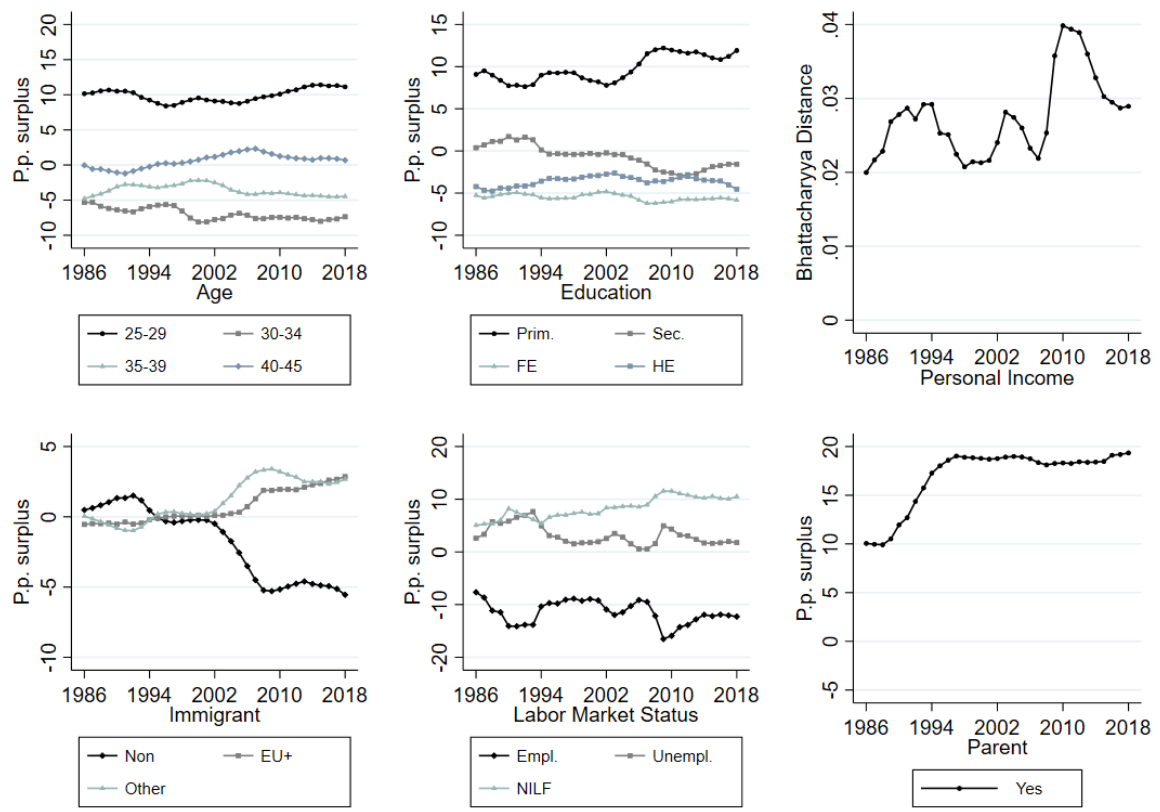

B: In relationship vs. single
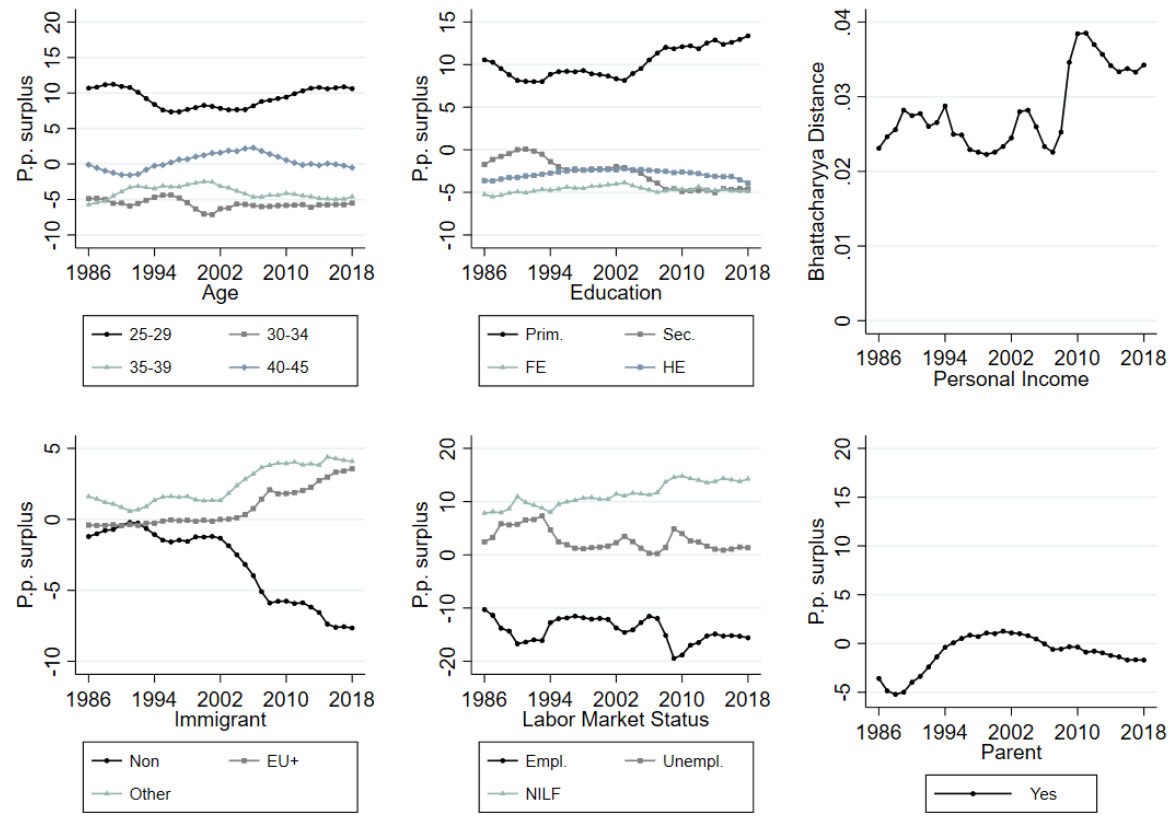

Note: Bhattacharyya distance is calculated with 250 bins. FE stands for "Further Education" and HE stands for "Higher Education".

Source: Own calculations on data from Statistics Denmark. 
Figure A20 Surplus of characteristics, with education specified alternatively, in the marriage and relationship market compared to demand for men for different market definitions, 1986-2018

\section{A: Married vs. unmarried}
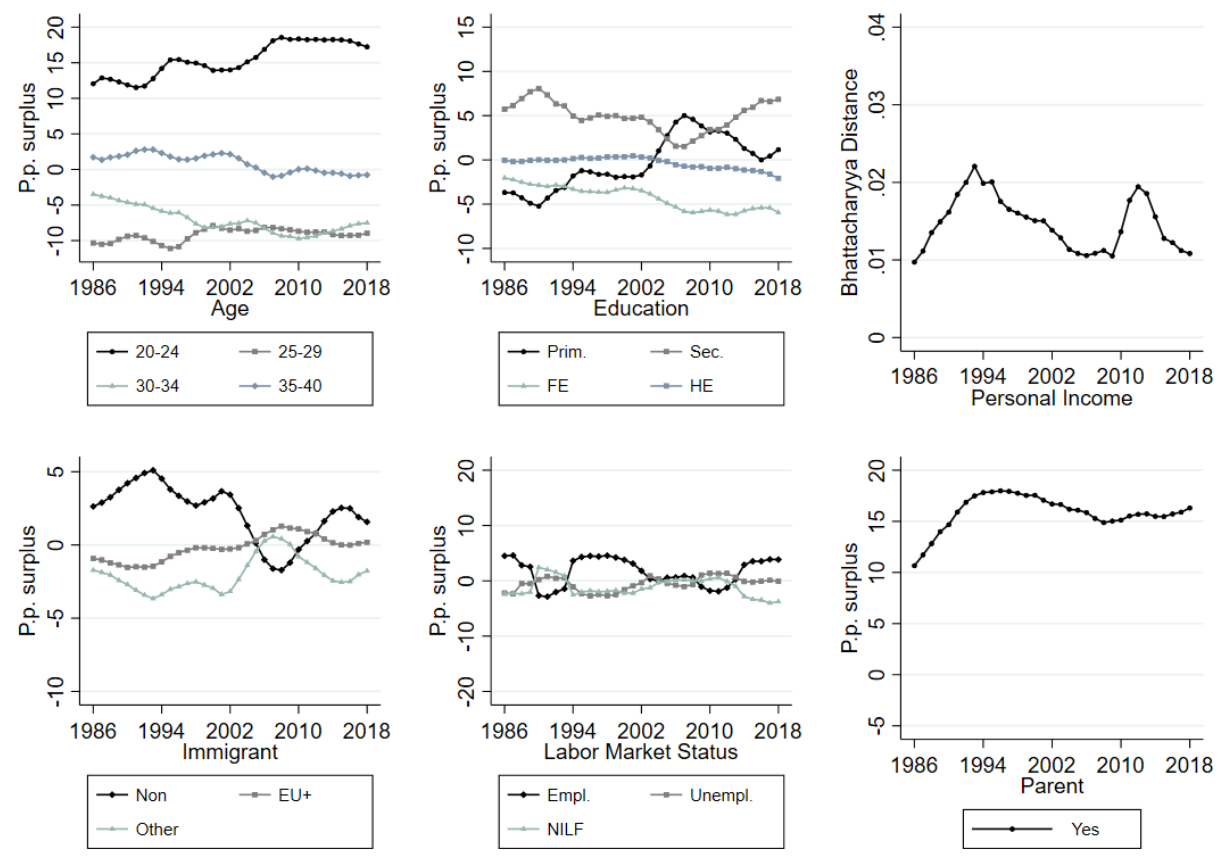

B: In relationship vs. single
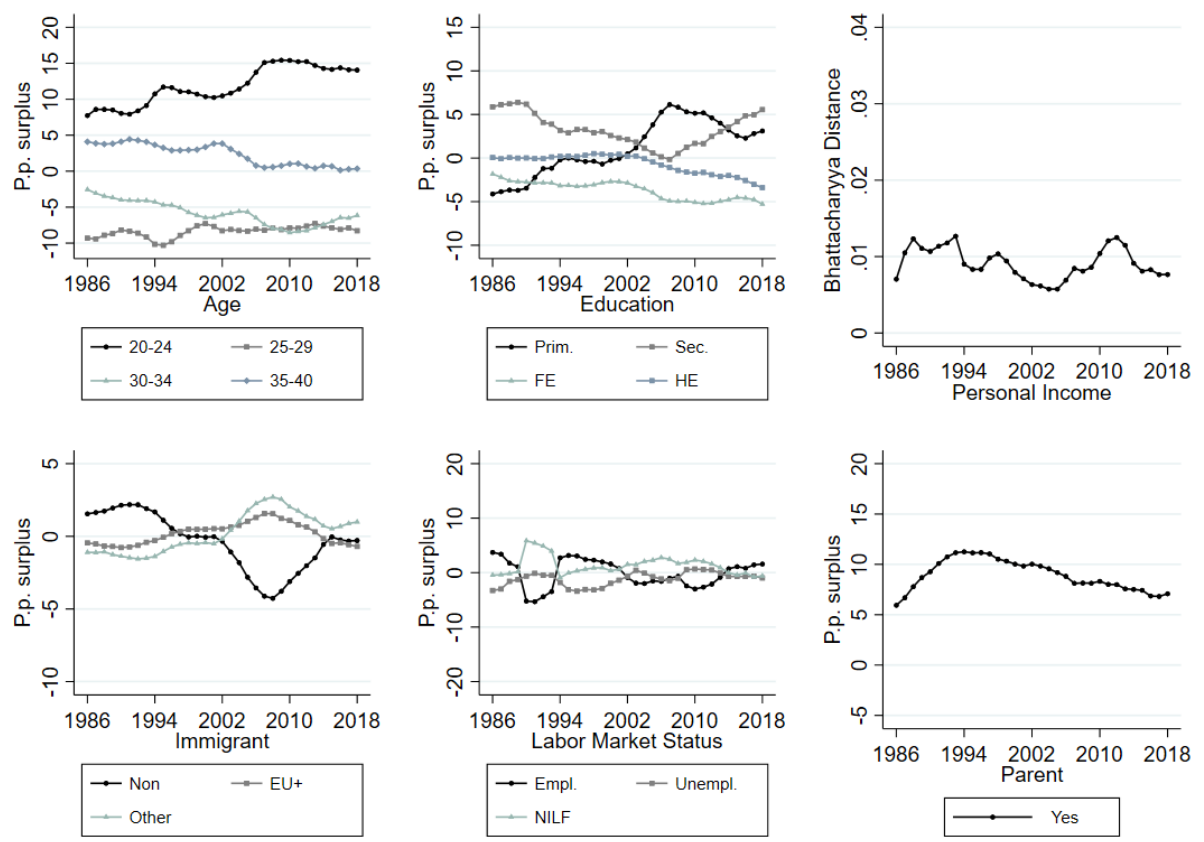

Note: Bhattacharyya distance is calculated with 250 bins. FE stands for "Further Education" and HE stands for "Higher Education".

Source: Own calculations on data from Statistics Denmark. 
Figure A21 Percentage with a successful match over time, with immigrant dummies replaced with immigrant or descendant dummies

A: Women

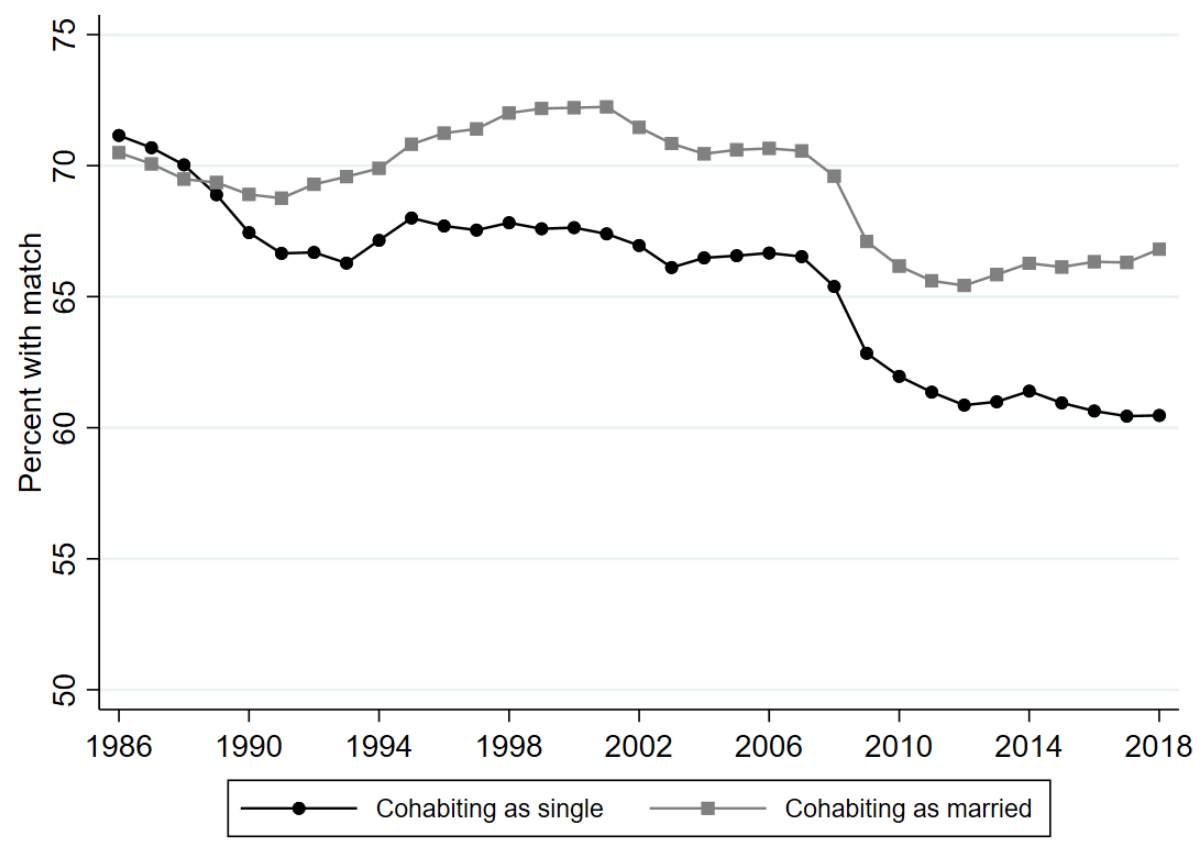

B: Men

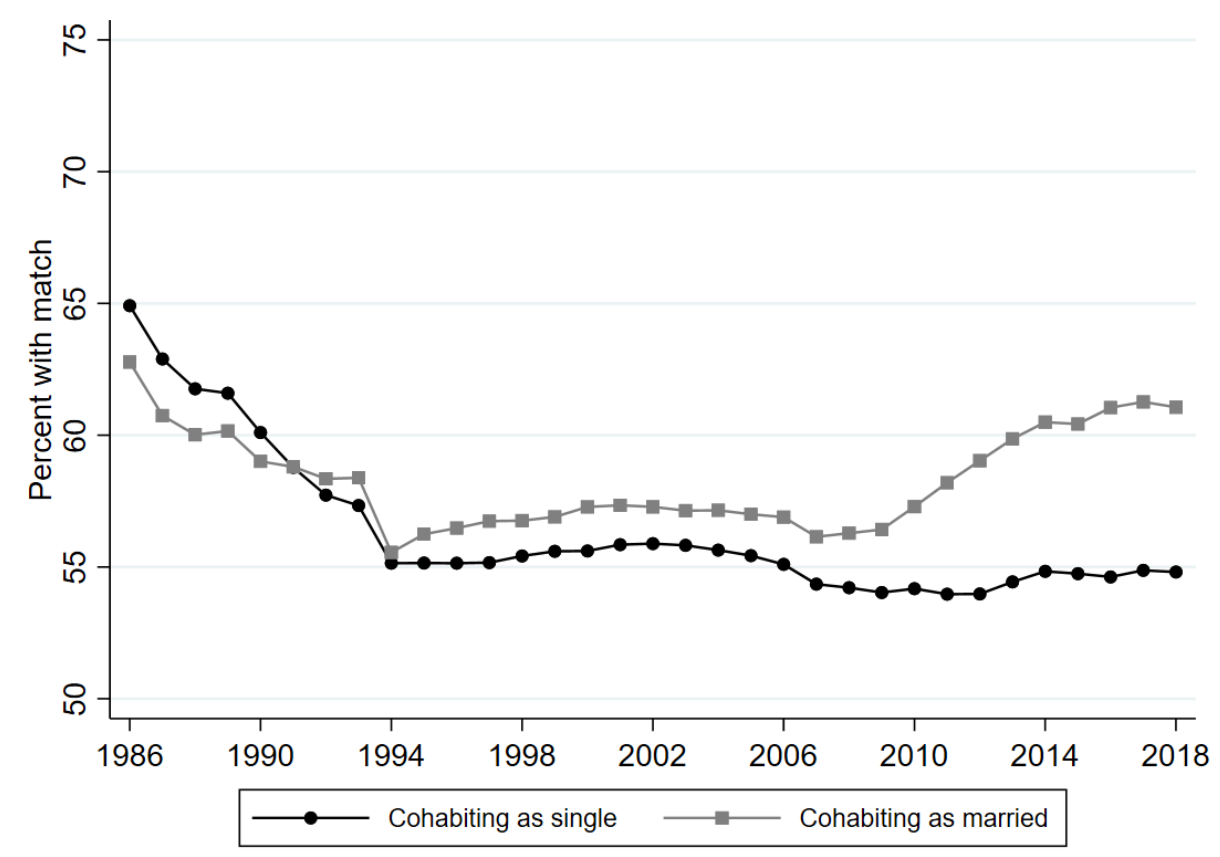

Note: Matches between synthetic and actual potential partners (spouses) forced to be within the same NUTS2 region.

Source: Own calculations on data from Statistics Denmark. 
Figure A22 Surplus of characteristics, with immigrant dummies replaced with immigrant or descendant dummies, in the marriage and relationship market compared to demand for women for different market definitions, 1986-2018

\section{A: Married vs. unmarried}
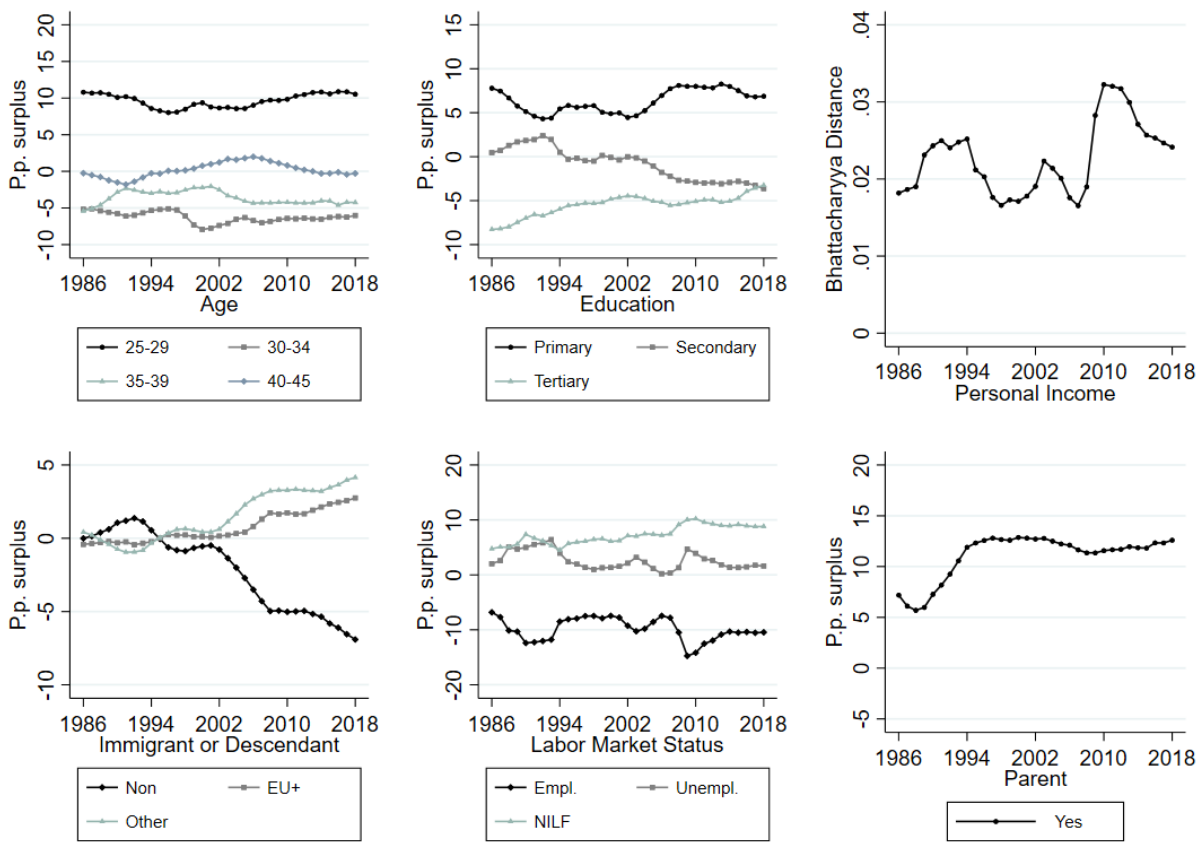

B: In relationship vs. single
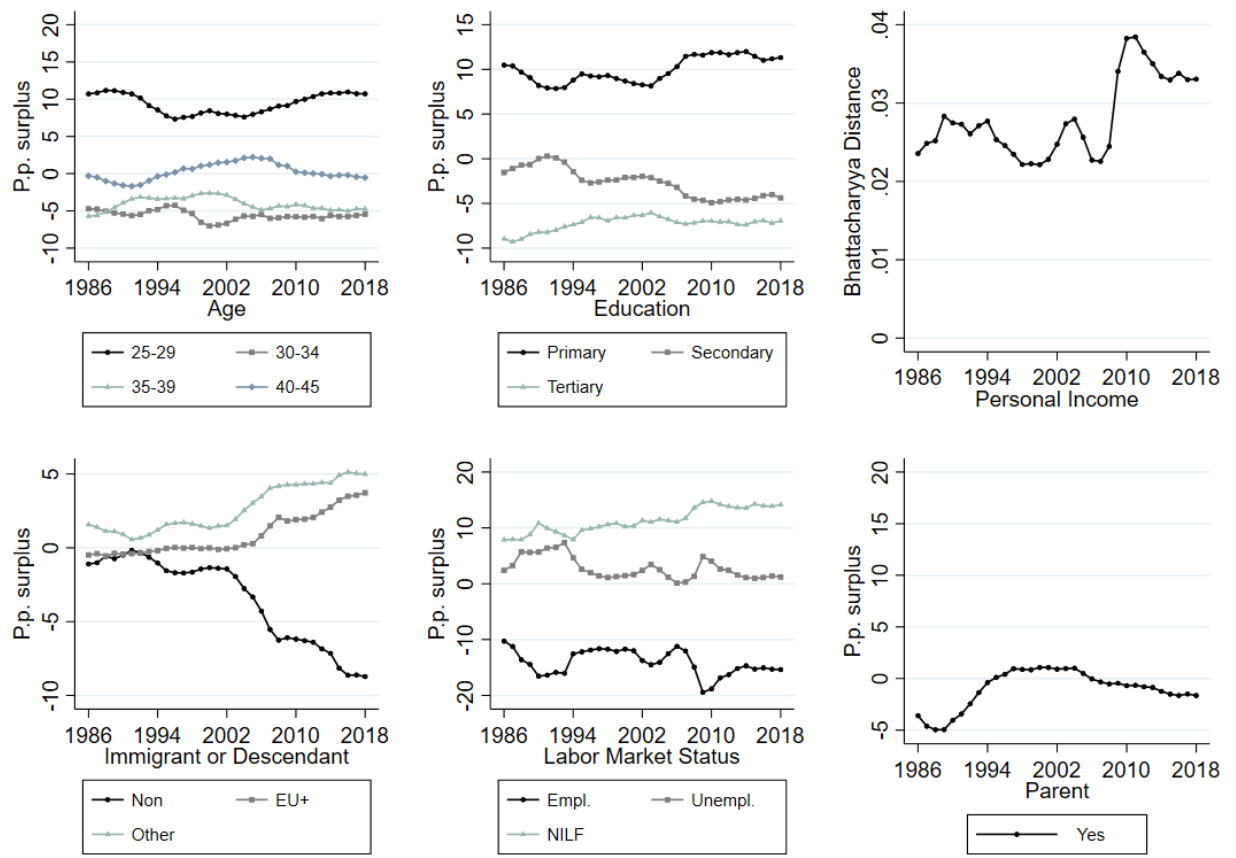

Note: Bhattacharyya distance is calculated with 250 bins. Source: Own calculations on data from Statistics Denmark. 
Figure A23 Surplus of characteristics, with immigrant dummies replaced with immigrant or descendant dummies, in the marriage and relationship market compared to demand for men for different market definitions, 1986-2018

\section{A: Married vs. unmarried}
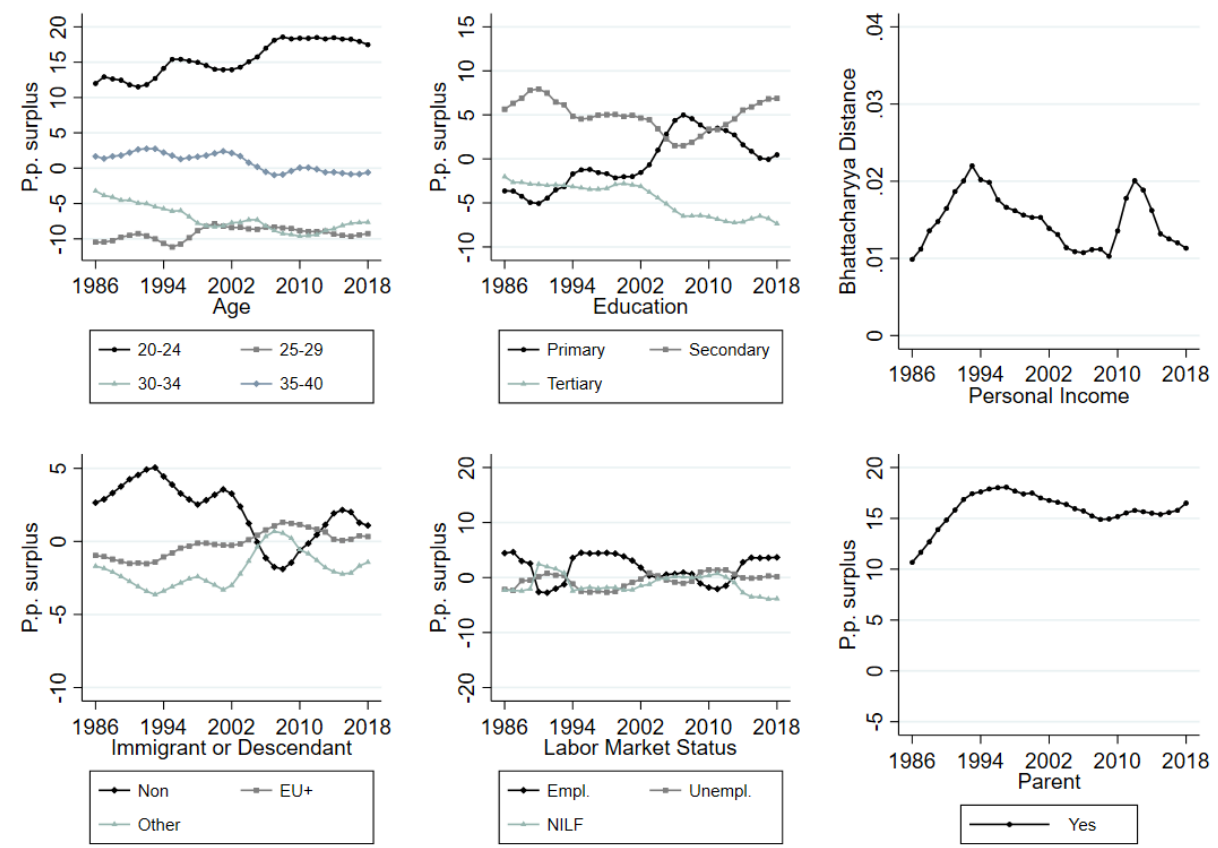

B: In relationship vs. single
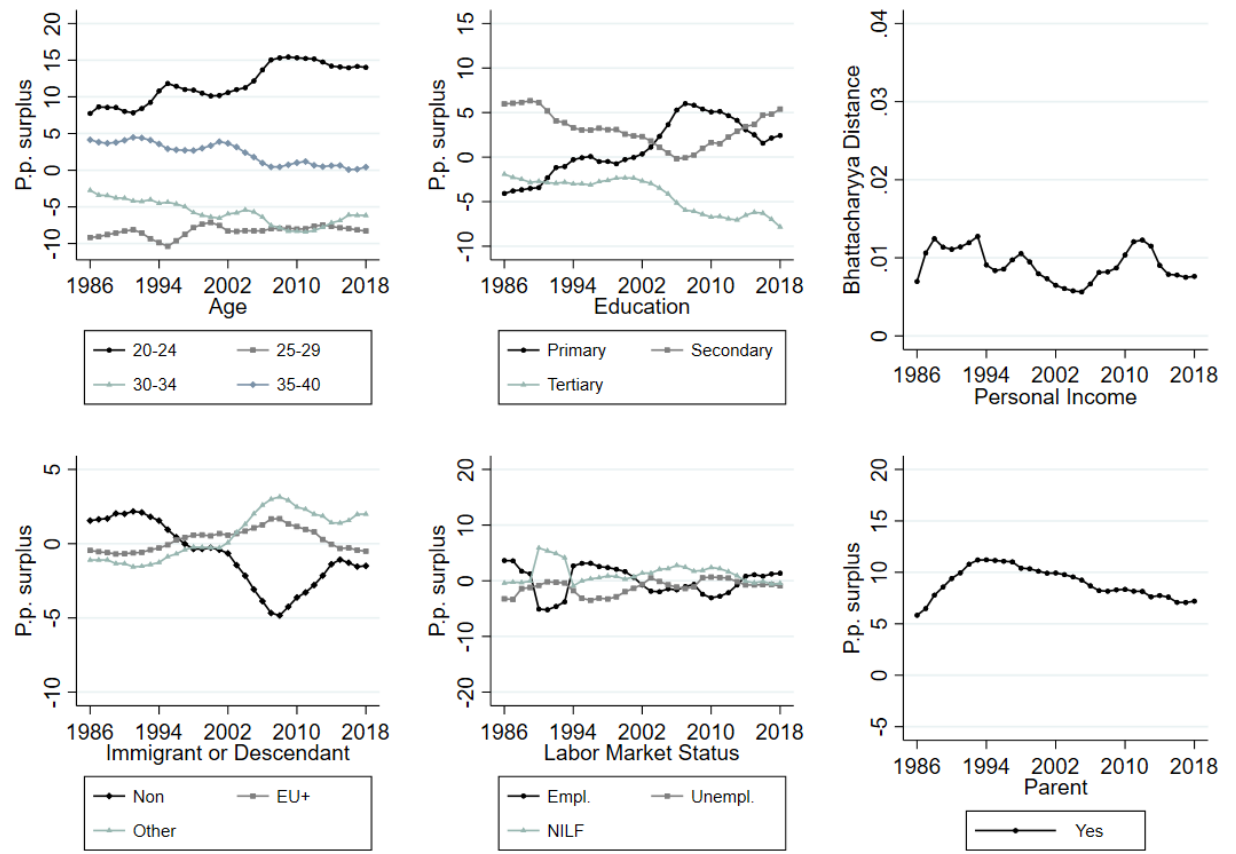

Note: Bhattacharyya distance is calculated with 250 bins. Source: Own calculations on data from Statistics Denmark. 
Figure A24 Share of relationships formed within the preceding five years by finding a partner from an existing relationship, 1986-2018

\section{A: Women}

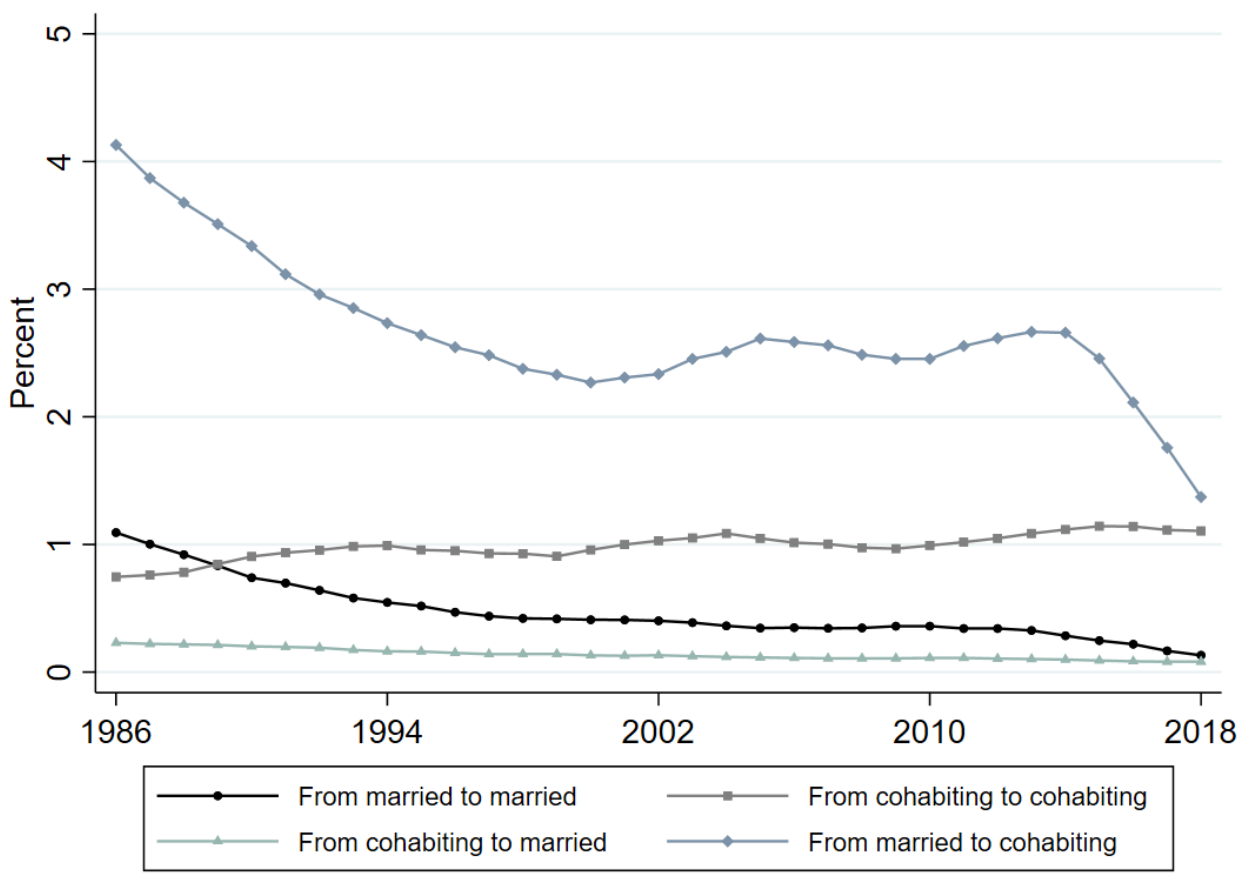

B: Men

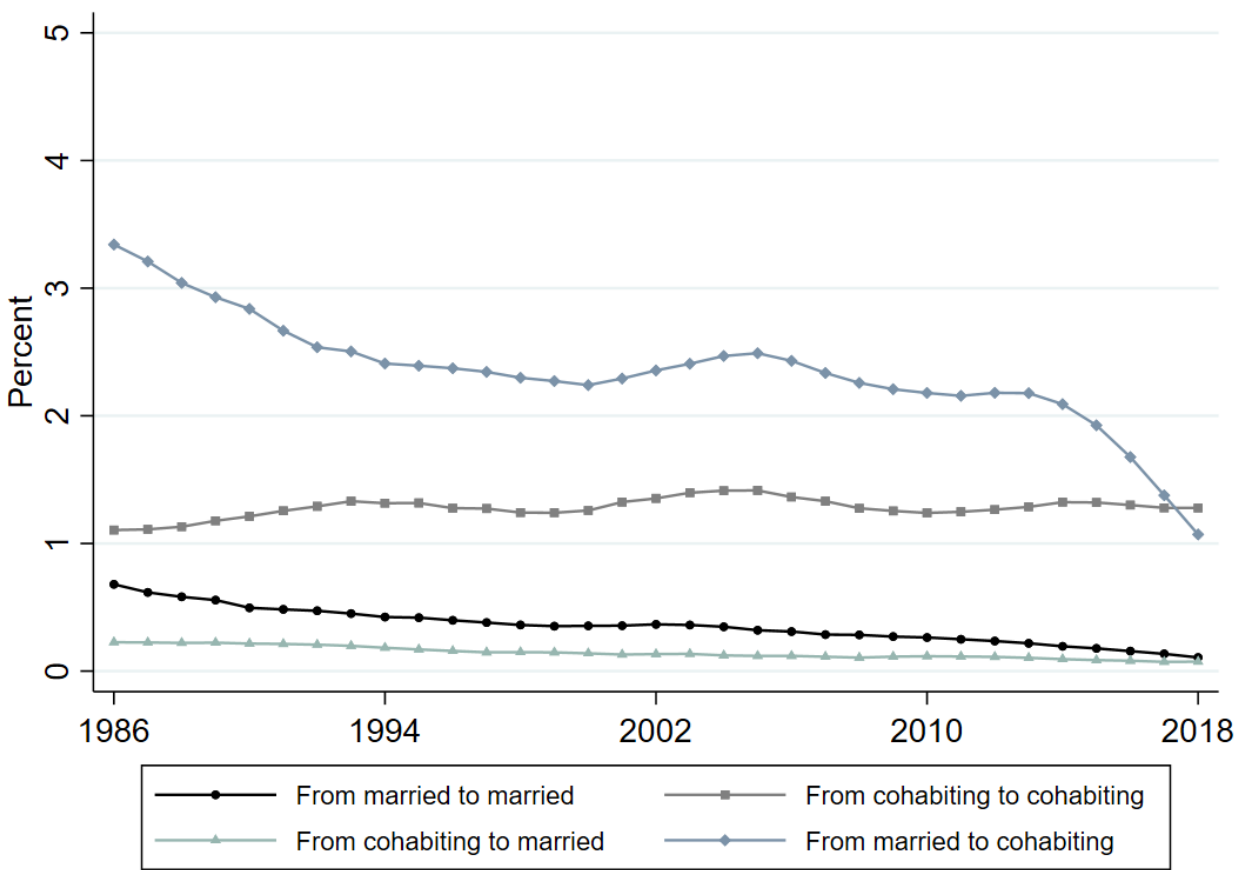

Source: Own calculations on data from Statistics Denmark. 